\title{
Die Cetoniden der Philippinischen Inseln
}

beschrieben

von

Dr. Otto Mohnike.

Hierzu Tafel VI-XI.

Die nachfolgende Bearbeitung der Cetoniden der Philippinen und theilweise auch der Sulu-Inseln schliesst sich in mehr als einer Beziehung an die Uebersicht an, welche ich in Troschel's Archiv für Naturgeschichte von den auf den Sunda-Inseln und Molukken vorkommenden Mitgliedern dieser Unterabtheilung der Lamellicornien gegeben habe, und kann gewissermassen als ihre Fortsetzung angesehen werden.

Wie ich in der Einleitung zu jener Abhandlung bemerkte, war allein der Mangel an zureichendem Material die Ursache, weshalb ich damals die Cetoniden der Philippinen unberührt lassen musste. Seitdem aber habe ich Gelegenheit gehabt dieselben, und zwar nicht allein fast alle bis jetzt bekannten und beschriebenen, sondern auch noch eine beträchtlich grössere Anzahl neuer Arten kennen zu lernen. Hierzu trug besonders der Umstand bei, dass Herr Georg Semper in Altona die Güte hatte, mir für den $Z$ weck ihrer Bearbeitung alle von seinem Bruder in jener östlichsten Provinz des Indisclen Insclmeeres gesammelten Melitophilen zuzusenden. 
Diese Sammlung, deren Reichhaltigkeit mich überraschte, enthält in 195 Exemplaren 66 Arten, woruster 41 oder vielleicht 42 neue.

Herr A. R. Wallace führt in seinem 1868 erschienenen Catologe der Malaiischen Cetoniden, worin auch die von den Philippinen aufgenommen sind, 32 als daselbst vorkommende an.

Ich halte diese Angabe aber für nicht ganz genau. Unter den darin erwähnten finden sich nämlich erstens zwei Arten, von denen es kaum mehr zweifelhaft ist, dass sie Bengalen als Vaterland besitzen. Es sind $\mathrm{He}$ terorrhina dives Westw., (Gnathocera Mac Leay Gor. ct Perch.; Mystroceros Diardi Burm.) und Heterorrhina confusa Westw. (Cetonia bimacula Wiedem.; Gnathocera bimaculata Gor. et Perch.). Zweitens hat W allace die Heterorrh. biguttata Westw., welche nichts als eine Farbenvarietät von Heterorrh. (Diceros) ornata Hope ist, als selbstständige Art angeführt. Drittens aber findet sich in seinem Cataloge nicht der schon 1862 von Gerstaecker beschriebene Phaedimus (Mycteristes) Jagori und sind von ihm, wie es mir scheint, mit Unrecht $C \varepsilon$ tonia querula Newman zu Cet. mandarinea Weber, Cet. (Protaetia) chlorotica und Cet. ambigua Burm. zu Cet. Manillarum Chevrol. gezogen worden. Auch Cet. Rogeri Burm. halte ich für eine selbstständige und nicht mit Cet. Guerini Eydoux und Souleyet, identische Art.

Nach dieser Correction des von W all ace gegebenen Verzeichnisses Philippinischer Cetoniden und mit Hinzuzählung der erst neuerdings von We st w o od Callynomus niveo-sparsa genannten, bis jetzt einzigen auf jenen Inseln entdeckten Cremastochiliden-Art, betrug die Gesammitsumme aller bekannten und beschriebenen Cetoniden von denselben 35 Arten, wozu jetzt aus der Semper'schen Sammlung 41 neue kommen. Ihre Zahl wird hierdurch also mehr als verdoppelt.

Unter diesen letzteren befindet sich nicht nur eine beträchtliche Anzahl auffallend schöner und für die beschreibende Entomologie merkwürdiger Arten, sondern es wird auch unsere Kenntniss von der geographischen 
Verbreitung der Cetoniden-Gattungen über die verschiedenen Regionen oder Provinzen des Indisehen Inselmeeres, durch diese Bereicherung sehr erweitert. In letzterer Bezichung ergeben sich einige interessante Thatsachen. Es zeigt sich nämlich, dass, wenn man den Indischen Archipel in fünf zoologische Bezirke theilt, von denen der erste Java, Sumatra , und Borneo mit den in der Nähe von ihnen gelegenen klcineren Inseln; der zweite Timor mit den Nachbar-Insein Flores u.s.w.; der dritte die Molukken mit Inbegriff von Neu-Guinea und den Aru-Inseln; der vierte Celebes; der fünfte aber die Philippinen und Sulu-Inseln umfasst, die letztgenannte Region, was die Cetoniden betrifft, wie überhaupt in entomologischer Beziehung, eine grössere Uebereinstimmung mit der am weitesten westlich von ihr entfernten erstgenannten Region, namentlich mit Java, besitzt, als mit den ihr viel näher gelegenen, die dritte und vierte Region bildenden Inseln, nämlich mit Celebes und den Molukken, besonders aber mit letzteren.

Von den drei bis jetzt bekannten Gattungen wirklicher Goliathiden des Indischen Archipels kommen zwei, Mycteristes und Prigenia, jede mit einer Art, auf Java, die dritte aber, Phaedimus, mit zwei, vielleicht mit drei Arten, auf Luzon vor. Von den beiden Arten der Gattung Plectrone findet sich auf jeder der genannten Inseln eine. Die Macronotiden-Gattungen Clerota und Chalcothea gehören der ersten Region ausschliesslich an und sind auf den Philippinen nicht vertreten, während von der Gattung Macronota daselbst 14, auf Celebes 5, in den Molukken 2, auf Timor keine, auf den SundaInseln dagegen 25 Arten vorkommen. Die östlichste und die westlichste Region des Indischen Archipels besitzen also beide die grösste Anzabl von Vertretern dieser interessanten Gattung. Ein ähnliches Verhältniss zeigt die Gattung Cetonia (Protaetia Burm.). Von dieser kommen nämlich auf den Philippinen 32 Arten, worunter ganz besonders grosse and schöne; anf den Sunda-Inseln 16; auf Timor und Flores 3 ; in den Molukken 1 nat auf Celebes 5 vor. Dagegen besitzen dic Philippinen 
nur 7, die Molukken 13, die Sunda-Inseln aber 26 Glyeyphana-Arten.

Eine grössere Uebereinstimmung zwischen der ersten Region, namentlich Java, und der fünften ergibt sich wieder in der Verbreitung der Gattung Lomaptera. Von dieser finden sich nämlich zwei Arten, L. striata und L. pulla auf Java, eine dritte aber, L. cupripes, ( $L$. agni Wallace), zugleich auf Borneo, Sincapur und Luzon. In der zweiten Region kommt 'nur eine, auf Celebes keine Lomaptera-Art vor, während die Molukken mit den AruInseln und Neu-Guinea 16 Arten dieser für die letztgenannte Region charakteristischen Gattung besitzen.

Diese wenigen Bemerkungen genügen für den $\mathrm{Be}-$ weis dessen, was ich oben bemerkte, dass nämlich die Philippinen, hinsichtlich der auf ihnen vorkommenden Cetoniden-Gattungen und der Anzahl ihrer Arten, eine. grössere Uebereinstimmung mit den Sunda-Inseln, namentlich Java, als mit der Timor-Gruppe, Celebes und den Molukken zeigen. Alle sich hierauf beziehenden Einzelnheiten finden sich in der zum Schlusse dieser Arbeit mitgetheilten Uebersichtstabèlle der Verbreitung der einzelnen Abtheilungen und Gattungen der Cetoniden über den ganzen Indischen Archipel. Ich füge nur noch hinzu, dass die erwähnte Uebereinstimmung zwischen den Philippinen und den Sunda-Inseln sich allein auf die Gattungen, nicht aber zugleich auch auf die Arten bezieht. In dieser Beziehung besteht eine bemerkenswerthe Verschiedenheit. Es kommen nämlich im Ganzen nur drei Arten auf den Philippinen und andern Indischen Inseln zugleich vor, und zwar Lomaptera cupripes Waterh. ( $L$. viridi-aenea Gory et Perch.; L. nigro-aenea Waterh.; $L$. pulla Wallace); Macronota regia Fabr. und Cetonia (Protaetia Burm.) mandarinea Weber. Diese Arten sind nicht nur über alle Regionen des Indischen Archipels, sondern auch über die nächstgelegenen Küstengegenden des HinterIndischen und Indo-Chinesischen Festlandes verbreitet.

Was die Classification betrifft, so finden sich in Nachstehendem keine Abweichungen von derjenigen, welche ich meiner oben erwähnten "Uebersicht der. Ce- 
toniden der Sunda-Inseln und Molukken" zum Grunde legte und worin ich im Grossen und Ganzen Lacordaire folgte. Allein habe ich mich genöthigt gesehen, zwei neue Gattungen genuiner Cetoniden den schon bestehenden hinzuzufügen. Es sind dieses die Genera Astraea und Euglypta.

$\mathrm{Zu}$ ersteren gehört die Cetonia francolina Dupont, von welcher schon Bu rmeis ter - Handb. d. Ent. Bd.III, S. 795 - bemerkte, dass sie mit der Cet. felina Gor. et Perch. von Celebes und der Cet. Rogeri Dup. von Luzon eine eigene, sich am meisten an Glycyphana anschliessende Gattung bilden dürfte. Eine genaue, vergleichende Untersuchung auch der Mundtheile dieser drei Arten hat mir aber gezeigt, dass sie keineswegs zusammengehören. Cet. felina ist eine wirkliche Glycyphana, da sie alle dieser Gattung, welche in Nachfolgung von Lacordaire gegenwärtig ziemlich allgemein, wie es mir aber scheint nicht ganz mit Recht, mit der Gattung Euryomia Burm. vereinigt wird, eigenthümlichen Merkmale besitzt. Cet. Rogeri dagegen ist, ebenso wie die ihr sehr nahe stehende, aber doch nicht mit ihr identische Cet. Guerini Eydoux et Souleyet, eine wirkliche Cetonia oder, wenn man lieber will, Protaetia. Cet. francolina aber bildet mit drei andern Arten, von welchen eine, die von mir Astraea tigrina genannte, von Blanchard, wie ich glauben möchte, als Macronota flavopunctata beschrieben ist, unzweifelhaft eine besondere, sich an Glycyphana zunächst anschliessende, in einigen Punkten aber auch an Macronota annähernde Gattung.

Das zweite von mir aufgestellte, Euglypta genannte Genus, umfasst, gleichwie Astraeă, vier Philippinische Arten. Eine von ihnen wurde von $\mathrm{W}$ all a ce als Cet. megaspilota beschrieben. Sehr mit Recht setzte Herr W., als Zeichen des Zweifels, ob diese Art auch wohl wirk. lich der Gattung Cetonia angehöre, ein Fragezeichen hinter den Gattungsnamen. Schon bei oberflächlicher Betrachtung der Euglypta megaspilota sowie der drei andern, dieser neuen Gattung von mir beigezählten Arten, noch mehr aber bei der Untersuchung ihrer innern Mund- 
theile, ergiebt sich dass sie nicht zu Cetonia gerechnet werden können.

Schliesslich erwähne ich noch, dass ich in dieser Arbeit, in Abweichung von meiner früheren über die Cetoniden der Sunda-Inseln und Molukken, statt des Burmeis ter'schen Gattungsnamens Protaetia, wie solches auch von Lacordaire und den meisten Entomologen nach ihm geschehen ist, den Namen Cetonia gewählt habe. Als Burmeister die Gattung Protaetia creirte, bemerkte er dass "der äussere Habitus dieser Gattung sie so allmählich mit der vorigen (Cetonia) verbinde, dass es kaum möglich sein würde, beide von einander zu unterscheiden, wenn sich nicht in der Form der galea, des Kopfes und des Flügeldeckenendes ziemlich sichere und konstante Unterscheidungsmerkmale darböten."

Je grösser aber die Anzahl der von mir untersuchten Cetoniden ist, welche nach Burmeister zu Protaetia gehören oder, so weit es neue sind, nach ihm dieser Gattung zugezählt werden müssten, um so mehr habe ich mich tiberzeugen können, dass der Unterschied zwischen den Gattungen Cetonia und Protaetia kein naturhistorischer, sondern wesentlich nur ein geographischer ist. Alle von Burmeister als charakteristisch für Protaetia angeführten Merkmale sind durchaus nicht stichhaltig und constant. Es lässt sich daher das Verhältniss zwischen dieser Gattung und Cetonia im Ganzen und Grossen so darstellen, dass die letztere mit wenigen Ausnahmen die der gemässigten Zone angehörenden, Protaetia dagegen fast ausschliesslich die zwischen den Wendekreisen vorkommenden Arten ein und derselben Gattung umfasst. Es besteht daher kein Grund die Gattung Protaetia als solche beizubehalten.

\section{Sectio I. Goliathidae.}

Genus I. Phádimus Westwood. Westwood. Arcan. entom. I. p. 5.

1. Phaedimus Cumingi Waterhouse. Phaedimus Curningi Waterh. Ann. nat. Hist. 1841. 
p. 221; Transactions entom. Society 1845 . p. 36. - Phaedim. Cumingi Westwood, Arcana entomologica 1843. I. p. 5. t. 1. f. $1 . \sigma^{\text {f. } 2}$ ㅇ․ - Phaedim. Cumingi Burmeister, Handbuch d. Entomol. B. III. S. 176. - Mycteristes Cumingi Lacordaire, Genera des Coléoptères Vol. III. p. 476. - Mycter. Cumingi Wallace, Trans. entom. Soc. 3. Ser. Vol. IV. 1868. p. 523. - Phaedim. Cumingi Gemminger et de Harold, Catalogus coleopterorum T'om. IV. p. 1274 .

Mas: Capitis cornu antice convexo postice excavato, basi tenui, apice dilatato, truncato; thorace valde convexo, medio inflato, cornu incurvo, compresso, bifido munito; elytris nitidis, flavo-virescentibus, planis, leviter ac irregulariter cicatricoso-striatis, postice attenuatis; capite, thorace, cornubus, scutello, sutura vittaque in utroque elytro prope marginem a humero ad gibbum posteriorem decurrente laete viridi-aureis, politis, nitidissimis; pygidio viridi-flavo, nitido; abdomine punctato, pubescenti, subnitido, virescenti; pectore viridi-aureo, lateribus lanuginoso, medio nitido; femoribus testaceis, splendentibus; tibiis sparsim punctatis, nitidis, testaceis, parte superiori virescentibus; tarsis viridi-aeneis, nitidissimis; tibiis omnibus scopa flava, usque ad medium adscendente, praeditis.

Femina: Capite viridi-aureo, parum nitente, dense grosseque punctato, marginibus reflexis; clypeo emarginato angulis reflexis; thorace laetc viridi-aureo, nitido, prope marginem dense, disco sparsim punctato; scutello nitidissimo, viridi-aureo; elytris nitidis, flavo-virescentibus dense cicatricoso-striatis, prope scutellum laevioribus; pygidio flavo-virescenti; hoc, capite, thorace elytrisque pilis flavis distanter obsitis; abdominis segmentis laete viridiaeneis, nitidis, superioribus parum ultimo penultimoque plus ac grossius punctatis, punctis pilos flavescentes gerentibus; pectoris lateribus multo minus quam in mare crinitis, medio laevissimo, viridi-aeneo; femoribus testaceis, splendentibus; tibiis anterioribus viridi-aeneis, crebre punctatis, externe tridentatis, mediis posterioribusque bidentatis, viridi-aeneis, apice testaceis; tarsis aeneis nitidis. 
Longitudo maris . . . . . . . . . Mm. 23

feminae . . . . . ., 21.

Habitat in insula Luzon. -

\section{Phaedimus Jagori Gerstaecker.}

Phaedimus Jagori Gerstaeck. Wiegmann's Archiv Jahrg. 28. Bd. I. 1862. S. 362 fg. - Phaed. Jagori Gemm. et de Harold, Cat. coleopt. Tom. IV. p. 1275.

Mas: "Phaed. cornu capitis antrorsum deplanato, basi parum attenuato, apice bifido: thorace parum convexo, antrorsum declivi, ubique subtiliter coriaceo, subopaco, viridi, vitta utrinque crocea subinterrupta: cornu thoracico capiti incumbente, subtus truncato: scutello subtiliter coriaceo, flavo, viridi-marginato: elytris ubique subtiliter coriaceis, seriatim punctulatis, flavescentiaureis, sutura, margine vittaque laterali viridibus: abdomine densissime piloso, segmento quinto scopa pilorum flavescentium vestito; coxis anticis ferrugineis, tibiis extus ultra medium usque tarsisque totis cum unguiculis viridi-metallicis: tibiarum posteriorum scopa fulva latissima ad basin fere usque adscendente." Gersta ecker.

Longitudo . . . . . . . . . Mm. 20,5.

Habitat in insula Luzon.

Das Männchen, dessen Beschreibung von Herrn Gerstaecker hier mitgetheilt worden ist, befindet sich in dem Museum zu Berlin, an welches es von Dr. F. $\mathrm{J}$ ag or geschickt wurde. Meines Wissens ist das Weibchen dieses Käfers bis jetzt unbekannt oder doch noch nicht beschrieben. Da es möglich wäre, dass ein mir vorliegendes Weibchen einer Phaedimus-Art, welches von Professor Semper gleichfalls auf Luzon gefangen wurde, zu $\mathrm{Ph}$. Jagori gehörte, so lasse ich hier die Beschreibung desselben folgen, theile zugleich auch eine Abbildung davon mit. Tafel VI. Figur 1.

Obgleich zwischen diesem Weibchen und dem von Phaedimus Cumingi, hinsichtlich der Grösse und Körperverhältnisse im Allgemeinen, eine grosse Uebereinstimmung 
besteht, so zeigen beide doch in verschiedenen Einzelnheiten eine zu grosse Abweichung von einander, um sie als einer Art angehörend und das erstere bloss als Varietät betrachten zu können. Der Kopf desselben ist kürzer und schmäler wie bei $\mathrm{Ph}$. Cumingi, der vordere Randausschnitt des Clypeus weniger tief, die Randspitzen sind kürzer und ragen weniger nach oben empor. Hauptsächlich zwischen den Augen ist der Kopfschild schmäler wie bei letztgenannter Art und zeigt sich an dieser Stelle eine kleine, glänzende, ovale Erhabenheit. Auch ist bei dieser neuen Art der Uebergang der Stirn in den Clypeus durch eine sehr deutliche, nach vorn convexe Linie angegeben welche sich bei $\mathrm{Ph}$. Cumingi nicht findet. Die schwielenartige Anschwellung in der Mitte des Clypeus ist bei ihr weniger erhaben wie bei letzterer. Hinsichtlich der Sculptur der Kopftheile stimmen beide Arten überein. Die Oberfläche des Kopfes ist bei der neuen metallisch grün, wegen der starken Punctur nur wenig glänzend, mit einem leichten röthlichen Anfluge. Der Thorax ist bei ihr etwas breiter, viel gewölbter und sind die Winkel seiner Seitenränder mehr nach vorn gelegen wie bei $\mathrm{Ph}$. Cumingi. Seine Umrandung ist feiner und weniger hervortretend wie bei letztgenannter Art. Er ist von dunkelkirschrother Farbe, in der Mitte sehr wenig, neben dem vorderen und den seitlichen Rändern stärker punctirt. Diese Puncte haben einen leichten, grünlich goldenen Metallschimmer. In demselben stehen, ebenso wie bei Ph. Cumingi, einzelne gelbe Härchen. Sein Glanz ist viel geringer wie bei dieser Art. Das Schildchen ist stark metallisch glänzend, roth mit grünlichem Anfluge. Die Flügeldecken sind weniger flach wie bei $\mathrm{Ph}$. $\mathrm{Cu}-$ mingi. Neben dem Schildchen żeigen sie an jeder Seite eine leichte Anscbwellung, wodurch dieses etwas tiefer liegend erscheint. Auch befindet sich, zwischen dieser Anschwellung und dem Scutellum eine vertiefte Linie, welche, sich nach hinten fortsetzend, auf jeder Flügeldecke neben der Naht bis zu deren Ende verläuft. Die Flügeldecken sind hinten geradelinigt ohne hervorstechende Nahtspitze. Ihre Sculptur ist wie bei $\mathrm{Ph}$. Cumingi und 
besteht aus sehr dicht neben einander stehenden Reihen von kleinen oberflächlichen, blatternarbigen Vertiefungen, welche allein auf den mehrerwähnten Anschwellungen zu beiden Seiten des Schildchens fehlen. Die Grundfarbe der Flügeldecken ist ledergelb, aber dunkler wie bei $\mathrm{Ph}$. Cumingi und anstatt wie bei dieser Art grün metallisch, röthlich schimmernd, besonders bei schräge auffallendem Lichte. Ihr innerer Rand, die Naht und die auf jeder von ihnen von der Schulter bis zu dem Endbuckel, unweit des äussern Randes verlaufende, beiden Geschlechtern der Gattung Phaedimus eigenthümliche Binde, sind von schwärzlich grüner Farbe mit stark rothem Anfluge. Das Pygidium ist gelblich grün, metallisch glänzend mit sehr feinen queren Nadelstrichen. Die Unterfläche zeigt grosse Uebereinstimmung mit $\mathrm{Ph}$. Cumingi. Der Bauch ist wie bei diesem grün, ziemlich lebhaft metallisch glänzend und, mit Ausnahme der beiden letzten Segmente, nur zerstreut und mässig punctirt. An dem vorletzten Segmente findet sich eine dünne Bürste von gelblichen Haaren. Die Brust ist in der Mitte glatt und glänzend, an den Seiten mit ziemlich langen aber nicht dichten gelblich grauen Haaren bedeckt. Der Mesosternalfortsatz ist wie bei $\mathrm{Ph}$. Cumingi, klein, wie seitlich zusammengedrückt und weder nach unten noch nach vorn ausstechend. Die Oberschenkel sind schaalroth, metallisch glänzend mit dunkelgrünen Gelenkenden, die Schienbeine dunkelgrün, metallisch glänzend und an ihrem untersten Stiele mit schaalrothem Anfluge. Schenkel und Schienen sind stark punktirt und die ersteren an ihrem hinteren Rande mit sperrigen Haaren besetzt. Die Vorderschienen haben oberhalb des Endzahnes zwei starke Randzähne, die mittleren und hinteren einen. Alle Tarsalglieder sind dunkelgrün metallisch glänzend. Die Länge von dem Rande des Clypeus bis zu dem Pygidium beträgt $21 \mathrm{Mm}$.

Schliesslich bemerke ich noch, dass bei einer genauen Vergleichung beider Geschlechter von Mycteristes rhinophyllus mit denen von Phaedimus Cumingii und dem eben beschriebenen Weibchen, ich denjenigen nicht beistimmen kann die, wie Lacor daire, Wallace und Andere, 
die Gattung Phaedimus mit Mycteristes vereinigt haben wollen. Die Verschiedenheit $\mathrm{zwischen}$ beiden ist jedenfalls eine grössere als ihre Uebereinstimmung und muss als generelle angesehen werden. Phaedimus hat, wie schon von Gerstaecker dargethan wurde, volle Berechtigung als eigene Gattung und nicht bloss als Untergattung von Mycteristes dazustehen. Die gezähnten Vorderschienen, die unverhältnissmässige Länge der Tarsalglieder der Vorderbcine, welche das doppelte von der des Hinterfusses beträgt, bei den Männchen, so wie die eigenthümliche Sculptur der Oberfläche und ihre starke Behaarung bei beiden Geschlechtern von Mycteristes, während bei den Männchen von Phaedimus die Vorderschienen unbewehrt, die Tarsi der Vorderbeine aber kürzer als - die der mittleren und hinteren sind und die Oberfläche bei beiden Geschlechtern haarlos und in einem hohen Grade glänzend ist, auch bei Phaedimus Cumingi sowohl, als bei $\mathrm{Ph}$. Jagori und dem von mir beschriebenen Weibchen ein ähnliches aber eigenthümliches und von dem von Mycteristes durchaus abweichendes Colorit zeigt, liefern vollgültige Gründe auf, um beide Gattungen von einander getrennt $\mathrm{zu}$ halten.

\section{Sectio II. Coryphoceridae.}

Genus I. Diceros Gory et Percheron.

Monogr. des Cét. p. 300.

\section{Diceros ornatus Hope.}

Diceros ornatus Hope, Proceedings entomol. Society. 1841. p. 33; Transact. entom. Soc. III. p. 280. - Heterorrhina ornata Westwood, Arcan. Entom. I. p. 140. t. 36. fig. 6-7. - Dicer. ornatus Burmeister, Handb. d. Entom. B. III. S. 219. - Heterorrh. ornata Wallace, Transact. entom. Soc. 3. Ser. Vol. IV. 1868, p. 525. - Heterorrh. ornata Gemminger et de Harold, Catal. coleopt. Tom. IV. p. 1283.

Mas: Capite nutante, bicornuto, nigro; clypei margine anteriori vix sinuato; cornubus trigonis, parum re- 
clinatis, non divergentibus, externe convexis, ante apicem dilatatis; antennis nigris; pronoto convexo, nitido, lateribus punctato, nigro plus minusve rubro-maculato; scutello, scapulis elytrisque nigris, laevigatis; his irregulariter substriato-punctatis, apice parum acuminatis, maculis duabus magnis, oblongis, flavis ornatis; pygidio transversim aci culato, rubro; pectore abdomineque, segmento hujus ultimo rubro solum excepto, nigris, lateribus sparsim punctatis; processu mesosternali longo, inter coxas anteriores protracto, reclinato; femoribus rubro-corallinis; tibiis inermibus tarsisque nigris.

Femina: Capite non bicornuto; fronte dentato; elypeo excavato, margine prominenti, antrorsum altiori, sinuato, parum reflexo; ceterum corporis totius forma coloreque mari simillima.

Longitudo maris cum cornubus . . . . Mm. 22. feminae .

Habitus in insula Bohol. - $\delta$ 우

In meiner "Uebersicht der Cetoniden der SundaInseln und Molukken" bemerkte ich auf Seite 12 mit Beziehung auf Diceros Peteli, bei welchem der Thorax lebhaft kirschroth gefärbt ist, dass die Grösse und Gestalt der schwarzen Flecken auf demselben durchaus nicht bei allen Individuen dieselben seien. In einigen, wiewohl seltneren Fällen sei der Thorax gänzlich ungefleckt, oder aber es befände sich auf ihm auf jeder Seite, in der Nähe des Randes, ein grösserèr oder kleinerer schwarzer Fleck, während der Discus roth bliebe. Am häufigsten werde die Mitte des Thorax von drei grösseren, mehr oder weniger runden Flecken eingenommen, die entweder isolirt ständen oder mit ihren Rändern aneinander stiessen und auf diese Weise eine zusammenhängende breitere oder schmälere Querbinde bildeten. Aehnlich verhält es sich mit den rothen Flecken auf dem schwarzen Thorax bei Diceros ornatus. Auch hinsichtlich ihrer besteht eine grosse individuelle Verschiedenheit. Bei einigen Stücken sind allein die Seitenränder an ihrem unteren Theile roth gefärbt, während sich bei anderen diese Randflecken in grösserer oder geringerer Breite nach der Mitte des 
Thorax hinerstrecken und mitunter eine nur eben unterbrochene Querbinde bilden. Aber gleich wie bei $D$. Peteli die schwarzen, sind bei D. ornatus die rothen Querflecken auf dem Thorax immer näher dem hinteren als dem vorderen Rande desselben gelegen. Die grösseren oder kleineren Flecken auf dem Thorax der Diceros-Arten können bei ihrer Veränderlichkeit nicht als charakteristische Kennzeichen der Species dienen. So ist Heterorrhina (Diceros) biguttata Westwood, - Westwood, Arc. Entom. I. p. 141. t. 36. f. 5 \&; Schaum, Annal. Soc. entom. de France 1849. p. 252; Wallace, Trans. ent. Soc. 3. Ser. IV. 1868. p. 526 - eine blosse Farbenvarietät von Diceros ornatus. - Ganz anders verhält es sich mit den rothen Flecken der Flügeldecken bei D. plagiatus und den gelben bei D. Peteli, D. ornatus u. a. m. Diese bleiben sich nämlich bei allen Individuen einer Art immer gleich und sind bei den kleinsten wie bei den grössten Exemplaren constant von derselben relativen Grösse und Gestalt.

Genus II. Coryphocera Burmeister.

Burm. Handb. d. Entom. Bd. III. S. 220.

1. Coryphocera Mac Leayi Kirby.

Cetonia Mac Leayi Kirby, Transact. entom. Soc. 1818. p. 408. tab. 21. f. 11. - Cet. pretiosa Eschscholz, Entomographieen. 1822. S. 23. - Coryphocera Mac Leayi Burmeister, Handb. d. Entom. B. III. S. 226. - Heterorrhina Mac Leayi Westwood, Arcan. Entom. I. p. 134. tab. 33. f. 4. - Heterrorh. Mac Leayi Wallace, Transact. Entom. Soc. 3 Ser. vol. IV. 1868. p. 527. - Heterorrh. Mac Leayi Gemminger et de Harold, Catal. coleopt. T. IV. p. 1283.

C. supra et subtus laete viridis, nitidissima; thorace aut disco atro-plagiato aut maculis duabus majoribus minoribusve nigris ornato; elytris planis, fasciis duabus latis transversis, anteriori scutello interrupta; sutura postice callosa, feminae parum, maris maxime acuminata; pygidio viridi; femoribus viridibus; tibiis rubris; tarsis nigris; capite, thorace, eiytrorum apice, pygidio, abdominis pe- 
ctorisque lateribus maris parum, feminae magis nigro punctatis aciculatisque.

Langitudo. . . . . . . . Mm. 20-25.

Habitat in insulis Luzon, Bohol, Panaon, Camiguin de Mindanao. $-\sigma$ o

Bei dieser bekannten und in den Sammlungen nicht seltenen Art zeigt sich der Geschlechtsunterschied bei dem Männchen ausser in seinen zahnlosen Schienen, der sehr beträchtlichen Zuspitzung des Nahtendes seiner Flügeldecken, dem längeren Fühlerfächer und seiner viel geringeren und schwächeren Punctur allenthalben, auch noch darin, dass bei ihm die an dem Vorderrande des Clypeus, durch den Ausschnitt desselben gebildeten Ecken viel schärfer, spitzer und hornartiger hervortreten wie bei dem Weibchen. Bei den C. Mac Leayi nahe stehenden Arten, C. sexmaculata Fabr. und C. imperatrix Mohn. von Java und Sumatra findet dieses Verhältniss nicht statt.

2. Coryphocera simillima n. sp. Mohnike. Taf. VI. Fig. 2 u. Fig. 2 a. $\delta$.

C. praecedenti statura multo minor, colore simillima, clypei forma valde distincta; supra et subtus laete viridis, nitidissima; capite dense nigro-punetato; thorace convexiori, maculis duabus nigris ornato; elytris apice integris, sutura non acuminatis, angulo scapulari, juxta scutellum, apicemque versus juxta suturam nigro-maculata; abdominis segmentis nigro marginatis; his, pygidio, abdomine, pectoris lateribus, femoribus tibiisque dense nigropunctatis; tarsis nigris, tibiis femoribusque viridibus.

Longitudo . . . . . . . . . Mm. 17.

Habitat in insula Mindanao. - $\sigma$.

Diese Art gleicht der vorigen in dem Maasse, dass man sie auf den ersten Blick für ein ausnahmsweise kleines Exemplar derselben halten kann. Und doch bestehen zwischen ihr und C. Mac-Leayi sehr wesentliche Unterschiede. Ein sehr wichtiger zeigt sich in der Form des Kopfschildes. Desselbe ist nämlich bei dieser neuenArt dem von C. laeta Fabr. ähnlich, fast nicht vertieft, mit einem dünnen, wenig hervorragenden Rande umgeben 
und vorne nicht ausgeschnitten, sondern kaum eingebuchtet. Daher fehlen dieser Art auch die beiden bei C. Mac-Leayi so besonders spitzigen und hervorstechenden Zähne zu Seiten des Ausschnittes am vorderen Clypealrande. Die Stirnleiste ist bei ihr nur eben angedeutet als eine glänzende, nach vorne zugespitzte Linie auf der dicht punctirten Fläche des Clypeus. Die Fühlhörner sind bei dem vorliegenden Männchen verhältnissmässig gross und von schwärzlich brauner Farbe. Der Thorax ist viel gewölbter wie bei C. Mac-Leayi, leicht umrandet, seitlich zerstreut punctirt. Auch die Flügeldecken sind weniger flach wie bei der letzteren und erheben sich von dem Seitenrande nach der Naht zu. Diese ist an ihrer hinteren Hälfte schwielig hervorragend, an ihrem Ende aber durchaus nicht zugespitzt. Die Endbuckel erstrecken sich weiter nach der Naht und treten stärker hervor wie bei C. Mac-Leayi. An ihrem unteren Ende sind die Flïgeldecken zerstreut punctirt. Dasselbe ist mit dem Pygidium, den Bauchringen und der Brust in dem Maasse der Fall, dass nur die Mitte des Sternums und der Fortsatz desselben vollkommen glatt und glänzend erscheinen. Alle Puncte aber sind schwarz eingestochen. Der Mesosternalfortsatz ist wagerecht, bis zwischen die Hüften des ersten Paares der Beine hervorragend, mit der Spitze etwas nach oben gebogen. Die Grundfarbe ist allenthalben ein sehr lebhaftes, glänzendes Grün, ähnlich wie bei Mac-Leayi. In der Mitte der glänzenden Stirn, oberhalb des Ursprunges ihrer nur eben angedeuteten Leiste, befindet sich ein kleiner, schwarzer Punct. Auf dem Thorax liegen zwei unregelmässig dreieckige, mit ihrer Spitze nach vorne gerichtete, durch einen breiten $Z_{w i-}$ schenraum getrennte schwarze Flecke; sein Schildchenausschnitt ist schwarz gerandet. Das Schildchen ist glänzend grün. Die Flügeldecken haben einen feinen schwarzen äusseren Rand und auf der Schulterhöhe wie dem Endbuckel einer jeden Seite einen länglichen schwarzen Fleck. $Z$ wei viel grössere, schief von innen und oben nach unten und aussen gerichtete liegen neben dem Schildchen, stossen unterhalb desselben aber nicht zusammen und 
bilden keine Querbinde. Etwas unterhalb ihrer Mitte befindet sich ein beiden Flügeldecken gemeinschaftlicher querer Fleck, der sich aber nicht soweit nach ihren Seitenrändern erstreckt, wie die hintere Querbinde bei C. Mac-Leayi. Die Enden dieses Fleckes, der hierdurch einige Aehnlichkeit mit einem Anker erhält, setzen sich nach unten bis in die Nähe der schon erwähnten Flecken auf den Hinterbuckeln fort, während seine Mitte sich zu beiden Seiten der Naht bis zu deren Ende verlängert. Die Bauchringe sind oben mit breitem schwarzen Rande versehen. Der starken, schwärzlichen Punctur allenthalben auf der Unterseite wurde schon erwähnt. Alle Oberschenkel und Schienen sind grün, stark punctirt und nadelrissig; die Tarsi schwarz. Die Vorderschienen zeigen die Andeutung eines äusseren Zahnes; die mittleren und hinteren sind gezähnt und am inneren Rande röthlich braun gewimpert.

3. Coryphocera paupera n. sp. Mohnike. Taf. VI. Fig. 3. $\delta$.

C. supra subtusque picea, nitidissima, laevigata; pronoti marginibus lateralibus, scapulis, scutello, fascia in utriusque elytri medio, pygidio, coxis posterioribus, femoribus tibiisque flavo-rufescentibus; tarsis nec non fomorum ac tibiorum articulis nigris; tibiis mediis posterioribusque interne flavo fimbriatis; processu mesosternali forti, protracto, apice parum reflexo.

Longitudo

Mm. 24,50.

Habitat in insula Mindanao. - $\delta$.

Diese Art zeichnet sich durch ihr eigenthümliches aber einfaches Colorit von den übrigen, meistens in so glänzendem Farbenschmucke prangenden Coryphoceriden aus. Der Clypeus ist beträehtlich vertieft und von breiten, hervorragenden Seitenrändern umgeben. Auch die Stirnschwiele ist kräftig entwickelt und hervortretend. Der vordere Rand des Clypeus steigt ungleich mehr wie bei den schon erwähnten Arten, sich nach oben verjün-. gend, hornartig empor und ist an seiner Spitze kaum eingebuchtet. Alle diese Theile, wie auch der ganze Kopf, sind schwarz und dicht punctirt, die Fühlhörner 
braun. Der Prothorax ist braunschwarz, ziemlich gewölbt, in der Mitte sehr glatt und glänzend, seitlich mässig punctirt. Sein umgeschlagener Theil ist von braungelblich rother Farbe. Diese Färbung breitet sich nach der Oberfläche des Thorax aus und bildet auf jeder Seite einen Randflecken der oben und in der Mitte ziemlich breit ist, sich aber nach der Schulter hin sebr verschmälert. In der Mitte dieses Fleckens, neben dem erhabenen Rande des Thorax, zeigt sich ein verwischter, schwärzlicher Fleck. Die Schultern und das Schildchen sind von derselben braungelb röthlichen Farbe, glatt und glänzend. Eine eben so gefärbte, mit der der andern Seite an der Naht zusammenstossende, sich aber nicht bis zum Seitenrande erstreckende Querbinde zeigt sich in der Mitte einer jeden Flügeldecke. Diesclben sind pechschwarz, flach und verschmälern sich nach hinten etwas. Ihre Naht ragt an der hinteren Hälfte schwielig hervor. Sie ist an ibrem Ende zugespitzt und neben ihr verläuft an jeder Seite eine punctirte Linie. Das Pygidium ist rothbraun, an seinem Rande mit einer Reihe gelblicher Haare besetzt. Die Unterfläche ist schwarz, glänzend und an den Seitentheilen mässig punctirt. An dem Ende eines jeden Bauchabschnittes findet sich ein verwischter bräunlicher Fleck. Der Mesosternalfortsatz ist mit seiner hervorragenden Spitze etwas nach oben gebogen. Alle Oberschenkel und Schienen sowie die Hüften der Hinterbeine sind gelblich braunroth, ihre Gelenkenden aber und die Tarsi glänzend schwarz. Die mittleren und hinteren Schienen tragen an ihrem inneren Rande einen röthlichen Haarsaum.

\section{Sectio III. Gymnetidae.}

Genus I. Clinteria Burmeister.

Burm. Handb. d. Entom. B. III. S. 290.

Clinteria formosa n. sp. Mohnike. Taf. VI. Fig. 4. ㅇ.

Cl. nigra, supra opaca, subtus nitidior; thorace punctis 
duobus minimis flaveşcentibus, elytro utroque macula laterali, magna, triangulari, aurantiaca ornatis.

Longitudo . . . . . . . . . . . . Mm. 18.

Habitat in insula Mindanao. - 9 .

Stirn sammetschwarz. Clypeus glänzender, sehr dicht und fein punctirt mit wenig vorstehendem vorne nur sehr wenig eingebuchtetem Rande, in der Mitte etwas erhaben. Fühlhörner schwarz. Thorax ziemlich gewölbt, tief sammetschwarz, mit Ausnahme seiner Mitte und seines hinteren Lappens zerstreut und fein punctirt. Letzterer ist kurz und hinten abgestumpft. Auf dem Discus des Thorax zwei kleine, nur eben sichtbare gelbliche Puncte. Das Schildchen ist sebr klein und, wie die Schultern, tief sammetschwarz. Die Flügeldecken verschmälern sich nach ihrem hinteren Ende zu beträchtlich, sind daselbst rechtlinigt und ohne vorstehende Nahtspitze. Sie sind flach, neben dem Schildchen etwas vertieft, während der untere Theil der Naht und die Hinterbuckel nicht unbeträchtlich hervorragen. Sie sind schwarz und sammetartig. In der Mitte jeder Flügeldecke befindet sich neben dem Rande ein grosser, dreieckiger orangefarbiger Fleck, der sich mit seiner Spitze bis über ibre Mitte hin erstreckt, ohne jedoch die Naht zu erreichen. Auf diesen gleichfalls sammetartigen, hellfarbigen Flecken gewahrt man am deutlichsten die Längsreihen der sehr feinen und dicht neben einander stehenden eingestochenen Puncte, welche die ganze Flügeldecke einnehmen. Das Pygidium sowie die Seiten des Bauches und der Brust sind mattschwarz, letztgenannte Theile in der Mitte dagegen glänzend und nicht dicht aber grob punctirt oder nur blatternarbig. An dem ersten Bauchsegmente zeigt sich ein punctiörmiger gelblicher Randfleck, ar dem zweiten nur die Andeutung eines solchen. Der Mesosternalfortsatz ragt als ziemlich langes, dreieckiges, vorne abgestumpftes Horn etwas nach unten hervor. Die Beine sind schwarz, glänzend, stark punktirt und nadelrissig. Die Vorderschienen haben unterhalb der Endspitze zwei Zähne, die mittleren und hinteren nur einen. Letztere tragen 
an ihrem inneren Rande zugleich einen dünnen, schwärzlichen Haarsaum.

Genus II. Agestrat a Eschscholtz.

Eschsch. Zoolog. Atlas I. S. 13.

1. Agestrata Luzonica Eschscholtz.

Agestrata Luzonica Eschscholtz, Zoologischer Atlas I. S. 13. Taf. 4. Fig. 8. - Agestr. splendens Gory et Percheron, Monographie des Cétoines, p. 306. pl. 59. f. 3. Agestr. luzonica Burmeister, Handb. d. Ent. B. III. S. 309. - Agestr. luzonica Lacordaire, Gen. d. coleopt. Vol. III. p. 502. - Agestr. luzonica Wallace, Trans. entom. Soc. 3. Ser. Vol. IV. 1868. p. 534. - Agestr. luzonica Gemminger et de Harold, Catal. coleopt. Tom. IV. p. 1294.

A. supra et subtus laete viridi-aurea, nitidissima; antennarum flabello fusco; pygidio rubro inaurato.

Longitudo . . . . . . . . . . Mm. 40.

Habitat in insula Luzon. - $\delta q$.

Diese auffallend schöne Art unterscheidet sich von A. orichalcea Linné; A. de Haanii Dupont und A. Parrii Wallace durch ihre geringe Breite, die sie mit der von mir beschriebenen A. augusta von Celebes theilt. $\mathrm{Zu}$ gleich ist ihre Farbe oben wie unten viel lichter, weniger grün und mehr metallisch golden glänzend als bei einer der genannten Arten. Charakteristisch bei ihr ist die schön roth metallische Färbung des Pygidiums. Auch sind bei ihr weder die Schenkel und Schienen, die Hinterhüften, seitlichen Bruststücke, Schultern und Enden der Bauchringe braungelblich, noch die unteren Gelenkenden der Schenkel und Schienen schwarz gefärbt, wie bei jenen Arten. Die Tarsi sind bei ihr glänzend broncefarben, nicht viel dunkler als die Schienen. Die ganze Unterfläche ist bei ihr von derselben hellen, goldglänzenden Metallfarbe and ebenso glatt und schimmernd wie die obere.

2. Agestrata Semperi n. sp. Mohnike. Taf. VI. Fig. 5. $\sigma^{\top}$.

A. praecedenti similis sed multo maior; supra et subtus viridi-aurea aliquid rufescens, nitidissima; tarsis 
aeneis; antennis aeneis, flabello marum longissimo; elytris apice prope suturam parum sinuatis, hac acuminata.

Maris longitudo Mm. 53,0. latitudo inter scapulas . . . . $~ 23,5$. " longitudo flabelli antennarum . . " $, 10,5$.

Feminae longitudo . . . . . . . . $\quad 57,5$. " latitudo inter scapulas . . . " $, 24,0$. " longitudo flabelli antennarum . $~ 5,0$.

Habitat in insula Mindanao. - $\delta$ \%

Diese von mir nach ihrem Entdecker im östlichen Theile der Insel Magindanao, Herrn Professor Semper, genannte Art, übertrifft noch $A$. de Haanii an Länge und Breite des Körpers, ist daher von allen bekannten Agestrata-Arten die grösste. Sie hat mit A. Iuzonica die mit der Oberseite durchaus übereinstimmende Färbung ihrer Unterseite und der Beine, mit Ausnahme der dunkleren Tarsalglieder, gemein. Auch das Colorit ist bei beiden sehr ähnlich, nur bei dieser neuen Art etwas mehr rötblich schimmernd, während es bei jener in das goldgelbliche spielt. Auch ist ihre Oberfläche etwas weniger glatt und glänzend. Das Pygidium ist bei ihr grün und nicht rothmetallisch wie bei jener. Bei dem Männchen ist dasselbe schmal und kegelförmig, wird auch von dem hinteren Rande der Flügeldecken überragt; bei dem Weibchen dagegen ist es breit, länger als bei A. orichalcea und A. de Haanii, mehr nach unten gesenkt und stimmt in dieser Beziehung mehr mit dem des Weibchens von A. luzonica überein. Auf den Flügeldecken lassen sich unter der Loupe schwache Andeutungen von Punctreihen erkennen, während ihre Seitentheile eine gröbere Sculptur zeigen wie die vollkommen glatten von A. luzonica. Auch ist der dreieckige, durch die Naht in zwei Hälften getheilte Raum zwischen beiden Hinterbuckeln bei dieser neuen Art verhältnissmässig viel grösser als bei der letztgenannten. Die Naht dehiscirt an ihrem untersten Theile ein wenig. Neben dem Nahtende sind die Flügeldecken zugespitzt und zugleich etwas eingebuchtet. Die Spitze sowohl wie die Einbuchtung sind bei den Männchen beträchtlicher als bei dem Weibchen. Das Schildchen ist 
bei dieser Art verhältnissmässig länger als bei A. luzonica. Auffallend ist die Länge des Fühlhörnerkolbens bei dem Männchen. Sie beträgt, wie schon bemerkt wurde, 10,5 Mm., während derselbe bei dem Weibchen noch nicht ganz halb so lang ist. Das erste Fühlerglied hat den hellen goldigen Metallglanz des Kopfes, während der übrige Theil des Stranges und der Fächer dunkler erzfarben sind. Der Kopfschild ist durehaus glatt und ohne alle Punctur. Seine Seitenränder sind breiter, aber nicht so hoch und scharf wie bei A. luzonica. Der Mesosternalfortsatz ist länger als bei A. orichalcea, A. de Haani und A. augusta, auch vorne nicht, wie bei diesen Arten, zugespitzt sondern abgerundet, ähnlich wie bei A. luzonica.

Genus III. Lomaptera Gory et Percheron. Monogr. des Cét. p. 43.

1. Lomaptera cupripes Waterhouse.

Lomaptera cupripes Waterh. Proceed. entom. Soc. 1841. p. 27 ; Transact. entom. Soc. IV. 1845 . p. $58 .-$ Lomapt. ebena Dupont. Burmeister, Handb. d. Entom. Bd. III. S. 315 fgd. - Lomapt. nigro-aenea Waterh. Proceed. entom. Soc. 1841. p. 27; Transact. ent. Soc. IV. 1845. p. 38. - Lomapt. viridi-aenea Gory et Percheron Mon. d. Cét. p. 309. pl. 60. fig. 5. - Lomapt. Schaumii Eydoux et Souleyet, Voyage autour du monde de la Bonite. Zool. Tom. I. p. 302. Atl. pl. 2. f. 13. - Lomapt. nitens Blanchard, Liste des Cet. du Muséum (1842) p. 17. - Lomapt. pulla Blanchard, Catalogue de la collection entomologique du Muséum. Livrais. I. (1850) p. 39. partim. - Lomapt. pulla Wallace, Transact. ent. Soc. 3. Ser. IV. 1868. p. 356. partim. - Lomapt. pulla Gemminger et de Harold, Catal. coleopt. T. 14. p. 1296. partim. - Cetonia nigrita Fröhlich, Naturforscher. Bd. 26. S. $110 ;$ Bd. 29. Taf. 3. fig. 5. forsitan.

L. magnitudine et colore valde variabilis; supra aut nigra aut fuliginosa aut aenea, nitidissima; subtus aut nigra magis minusve purpurescens, aut cuprea vel aenea; thorace plano, lateribus punctato, disco laevissimo, lobo posteriori longo, scutellum paene tegente; hoc acuto, 
minimo; elytris planis, aut glaberrimis aut basi magis minusve obsolete striato-punctatis, postice lateribus transversim aciculatis, apice inter gibbos posteriores subtilissime et densissime striolatis, sutura parum acuminata; pygidio densissime subtiliter striolato; abdomine pectoreque medio laevibus, lateribus punctatis variolosisque; processu mesosterni longo, parum curvato, apice reflexo; femoribus tibiisque nigris saepius rufescentibus, tarsis nigris; tibiis anterioribus externe tridentatis, mediis et posterioribus unidentatis, his interne distanter nigro fimbriatis.

Longitudo . . . . . . . . Mm. 23-34.

Habitat in insulis Mindanao, Babuyanes, Bohol et Luzon. - бㅇ.

Ich habe unter den Synonymen dieser weitverbreiteten Art Cetonia pulla von Billberg-Schönherr, Synonym. Insect. Bd. I. 3. App. p. 46 - sowie auch Cet. anthracina von Wiedemann - Zool. Magaz. Bd. II. 1. S. 83 - weggelassen, weil ich mich bei genauer Vergleichung der von mir in meiner "Uebersicht der Cetoniden der Sunda-Inseln und Molukken" auf Seite 13 als Lomapt. pulla erwähnten Art aus dem östlichen Java, von welcher ich jetzt noch cine grosse Zahl von Exemplaren vor mir habe, mit einer Reihe von Exemplaren der von mir als L. cupripes beschriebenen von den Philippinen und Sulu-Inseln, überzeugen musste, dass beide Arten wesentlich von einander verschieden sind. Dagegen aber stimmen die Beschreibungen der Cet. pulla von Billberg und die der Cet. anthracina von Wiedemann ungleich mehr mit jener javanischen Art als mit der von den Philippinen überein. Es scheint mir daher richtig, den Namen pulla auf die von Billberg und mir pulla, von Wiedemann aber antbracina genannte Lomapteren-Art zu beschränken, für die vorliegende von den Philippinen aber einen andern zu wählen. Ich habe der Benennung „cupripes", worunter Waterhouse im Jahre 1841 zuerst die hellfarbigere Varietät dieser Art bekannt machte, vor den anderen oben angeführten den Vorzug gegeben, weil sie sich auf eine Eigenthümlichkeit, die sich bei den meisten 
Individuen dieser Art wiederfindet und daher beinahe charakteristisch für sie ist, nämlich die mehr oder weniger rothen oder kupferfarbigen Schenkel und Schienen, bezieht. - Wie schon oben bemerkt wurde, variirt die Lomapt. cupripes in einem hohen Grade mit Beziehung auf Körpergrösse, Farbe und Sculptur der Oberfläche. Ich habe Exemplare von 23 bis zu $34 \mathrm{Mm}$. Länge vor mir, solche die tief schwarz sind, dunkelbraune, grünlich schwarze, und ein hell bronzefarben metallisch glänzendes Weibchen, bei welchem der Grund, der obere Theil des äusseren Randes und die Spitze der Flügeldecken tief kupferroth sind, ganz wie Waterhouse seine cupripes beschreibt. Bei allen aber sind das Verbältniss der Länge zu der Breite des Körpers sowie die auffallende Flachheit des Prothorax und der Flügeldecken dieselben. Letztere verschmälern sich nur äusserst wenig und sind an ihrer Spitze fast eben so breit wie an ihrem Grunde. Die Hinterbuckeln erheben sich durchaus nicht über die Fläche der Flügeldecken, fallen aber schroff nach dem Hinterrande derselben und der Naht zu ab. Der Kopf ist stets von der Grundfarbe des Thorax und der Flügeldecken; der Einschnitt des Clypeus halb so lang als letzterer und mässig boch umrandet. Die schwielige von der Stirn nach dem Ende des Clypealausschnittes verlaufende mittlere Erhebung ist glatt und glänzend, die grubige Vertiefung zu jeder Seite derselben bei einigen Individuen mehr, bei anderen weniger punctirt. Der Thorax ist in der Mitte sehr glatt und glänzend, seitlich neben dem fcinen, glatten, hervorragenden Rande mehr oder weniger dicht punctirt. Oben ist dieser punctirte Theil am breitesten. Der hintere Lappen ist lang, an seiner Endspitze gerundet und bedeckt das schmale, spitzige Schildchen fast gänzlich. Die Flügeldecken sind bei einigen Individuen mit Ausnahme ihres hinteren Seitenrandes und ihrer Spitze ohne alle Sculptur und durchaus glatt. Bei anderen zeigen sich auf ihrem Grunde bald stärkere, bald schwächere schon mit dem blossen Auge zu erkennende Andeutungen von Punctreihen. Bei- einem grossen, schwarzen Weibchen von Mindanao. erstrecken sich die- 
selben bis über die Mitte der Flügeldecken hinaus. Bei demselben Individuum verläuft auch eine punctirte Linie an jeder Seite neben der Naht bis zu deren Ende. Bei anderen Stlicken findet sich nur eine Andeutung hiervon. Der hintere Theil des Seitenrandes der Flügeldecken ist bei allen quer nadelrissig, bei einigen aber in viel stärkerem Masse als bei andern. Durchaus eigenthümlich ist die Sculptur an der Spitze der Flügeldecken, besonders zwischen den Hinterbuckeln. Dadurch nämlich dass in dieser Gegend eine Menge sehr feiner, von aussen nach innen bogenförmig gekrürnmt verlaufender, längerer Nadelstriche sehr dicht concentrisch neben einander liegen, erhält diese Gegend, ebenso wie das Pygidium, an dessen oberen Theile dasselbe stattfindet während sein unterer Theil rechtlinigt transversal gestrichelt ist, einen eigenthümlichen seidenartigen Glanz. Ich habe diese Art der Sculptur bei keiner der vielen Lomapteren-Arten des indischen Archipels in meiner Sammlung wiedergefunden. Schon Burmeister erwähnt derselben in der Beschreibung seiner L. ebena Dupont. Die Unterseite ist bei den heller gefärbten Individuen meistens von der Earbe der Flügeldecken, bei den dunkleren schwärzlich; bei einem dunkelfarbenen erscheint sie allentbalben tiefkirschroth. Die Bauchabschnitte und Brust sind in der Mitte glatt und glänzend; die ersteren an den Seiten bei den Männchen wenig, bei den Weibchen viel stärker punctirt, während die Seitentheile der Brust bei diesen sebr stark, bei den Männchen aber viel zerstreuter und weniger tief blatternarbig sind. Der Mesosternalfortsatz ist lang, zuerst etwas nach unten, mit der Spitze aber nach oben gebogen. Schenkel und Schienen sind in der Regel mehr oder weniger kupferig roth und nur ausnahmsweise rein schwarz. Selbst in den Fällen, wo sie scheinbar schwarz sind, zeigen sie bei auffallendem Sonnenlichte meistens einen röthlichen Schimmer. Die Schenkel sind nadelrissig, die Schienen punctirt, bei den Männchen weniger stark wie bei den Weibchen. Die Vorderschienen haben oberhalb des Endzahnes noch zwei andere, die mittleren und hinteren am untersten Drittheile einen Zahn. Beide 
letzteren haben innen einen wenig starken und dichten, schwärzlichen Haarsaum. - Zum Schlusse bemerke ich noch, dass die von mir als L. pulla, in meiner „Uebersicht der Cetoniden der Sunda-Inseln und Molucken " erwähnte Art von der eben beschriebenen hauptsächlich darin abweicht, dass sie weniger schlank und verhältnissmässig viel kürzer und breiter, oben aber viel gewölbter ist und dass bei ihr die Spitzen der Flügeldecken, namentlich die Hinterbuckel derselben anders gestaltet sind. Ihre Sculptur ist auch allenthalben viel seh wächer. Ausserdem zeigt sie eine viel geringere Grössenverschiedenheit der einzelnen Stücke, und keine Veränderlichkeit der Farbe. Ich bemerkte schon mit Beziehung hierauf a. a. O., wie es mir aufgefallen sei unter Hunderten von Individuen dieser Art auch nicht eines gefunden zu haben, welches in seiner Farbe nur Spuren eines Ueberganges in Grün gezeigt hätte. Bei allen Exemplaren welche ich hiervon besitze, ist die Farbe das nämliche glänzende, tiefdunkle Blauschwarz.

\section{Sectio IV. Macronotidac.}

Genus I. Plectrone Wallace.

Transact. entom. Soc. 3. Ser. IV. 1868, p. 546.

1. Plectrone nigrocoerulea $\mathrm{W}$ aterhouse.

Macronota nigrocoerulea Waterhouse, Proceed. entom. Soc. 1841. p. 27; Transact. entom. Soc. IV. 1845. p. 40. - Chalcothea Barrotiana Dupont. Burmeister, Handb. d. Entom. Bd. III. S. 319. - Plectrone nigrocoerulea Wallace, Transact. entom. Soc. 3. Ser. IV. 1868. p. 546. - Plectr. nigrocoerulea Gemminger et de Harold, catal. coleopt. Tom. IV. p. 1297.

Plectr. aut coerulescens nigra aut viridis aenea, nitidissima; tarsis nigris; elytris foveola media non striolata impressis; processu mesosterni brevi, lato, obtuso; maris tibiis anticis mediisque inermibus, posterioribus intus calcaratis, foeminae anterioribus extus tridentatis, mediis et posterioribus inermibus. 
Magnitudo . . . . . . . Mm. 25-29.

Habitat in insulis Luzon, Panaon, Mindanao. - $\delta$ r

Von dieser Art liegen mir dunkelblau schwarze und andere, theils hellere theils dunklere metallisch grüne Stücke vor. Alle sind sehr glänzend und unterscheiden sich hierdurch sowie durch ihre geringere Grösse und die nicht gestrichelten Vertiefungen in der Mitte ihrer Flügeldecken von Plectr. tristis von Java, bei welcher diese Eindrücke immer nadelrissig sind. Auch ist die letztere, obschon von ihr dieselben Farbenvarietäten vorkommen wie von Pl. nigrocaerulea, doch stets viel weniger glänzend.

Genus II. Macronota Hoffmannsegg. Wiedemann Zoologisches Magazin, Bd. I. 1. S. 15.

\section{Macronota regia Fabricius.}

Cetonia regia Fabricius, System. Eleuther. tom. II. p. 159. - Cet. zebra Billberg in Schönh. Synon. Insect. Bd. I. 3. App. p. 54. - Macronota zebra Schaum, Ann. Soc. entom. de Fr. 1844. p. 369. - Macron. regia Gory et Percheron, Mon. d. Cét. p. 316. pl. 62. fig. 3. - Macron. depressa Gor. et Perch. 1. c. p. 315. pl. 62. fig. 2. Macron. regia Burmeister, Handb. d. Entom. Bd. III. S. 224. - Macron. fraterna Westwood, Transact. entom. Soc. 2. Ser. III. p. 71. pl. VII. fig. 5. - Macron. venerea Thomson, Arch. Entom. Vol. I. p. 284. - Macron. venerea Lacordaire, Genera des Celéopt. Atlas. pl. 39. fig. 1. - Macron. Apelles Thomson, Mus. scient. Vol. I. p. 36. - Macron. Forsteni von Vollenboven, Tydschrift voor Entom. 1858. I. p. 24. - Macron. regia Wallace, Transact. entom. Soc. 3. Ser. IV. 1868. p. 552. - Macron. regia Gemminger et de Harold, Catal. coleopt. t. IV. p. 1299. - Macron. regia Mohnike, Uebers. d. Cet. der Sunda-Inseln und Mollukken. S. 46.

M. nigra; antennis pedibusque rubris; capite inter oculos lineis duabas, thorace vittis tribus, utroque elytro vittis tribus maculaque, pygidio gutta magna flavis ornatis; scapulis et scutello flavis; pectoris abdominisque lateribus flavofasciatis. 
Magnitudo . . . . . . . . . . . . Mm. 16.

Habitat in insulis Luzon et Mindanao. - $\delta q$.

Die mir vorliegenden Exemplare dieser weit verbreiteten Art von den genannten Inseln zeigen eine grosse Uebereinstimmung mit jenen der Molukken, und weichen so wie diese, sehr von denen von Java und Sumatra ab, bei welchen die Flügeldecken roth, alle filzigen Zeichnungen aber viel feiner sind. Der Körper ist schwarz; mit Ausnahme der sehr glatten Mitte des Bauches und der Brust sowie der hervorragendsten Stellen der Flügeldecken, nur wenig glänzend und allenthalben dicht punctirt. In den Punkten erheben sich kurze Härchen. Die Fühlhörner sind roth; der vordere Rand des Clypeus ist mässig ausgebuchtet; von dem vorderen Rande des Thorax verlaufen auf dem Kopfe bis zu den Seitenecken des Clypeus zwei gleich breite gelbe, vorne zugespitzte filzige Streifen. Auf dem Thorax zeigen sich drei ähnliche Streifen, der mittlere von seinem Vorderrande bis zur Spitze seines hinteren Lappens, die beiden anderen in geringer Entfernung von seinen Seitenrändern von vorne nach hinten verlaufend. Das Schildchen und die Schultern sind gleichfalls gelbfilzig. Unterhalb der Spitze des ersteren nimmt auf jeder Flügeldecke ein anderer gelbfilziger Streifen seinen Anfang, verläuft neben der Naht bis zu ihrem Ende um dort mit einer Krümmung nach aussen sich neben dem untern Ende der Flügeldecke bis zu ihrem äussern unteren Winkel hin zu begeben. Zwei andere, kürzere, nur die Hälfte jeder Flügeldecke einnehmende gelbfilzige Längsstreifen umfassen auf jeder Seite den Schulterbuckel. Zwischen den Enden dieser Streifen und dem von dem umgebogenen horizontalen Theile des die Naht begleitenden, befindet sich auf jeder Seite ein grosser, eben so gefärbter Randfleck. Ein grosser, runder Fleck zeigt sich in der Mitte des Pygidiums. Gleichfalls gelbfilzig sind der umgeschlagene Theil des Thorax, der vordere und hintere Rand der Mesosternalplatte, ein Fleck auf der Hinterhüfte und drei oder vier Querbinden an den Seiten der Bauchabschnitte. Auch alle hier angeführten gelbgefärbten Streifen und Flecken 
sind punctirt, nadelrissig und mit Härchen besetzt. Die Schenkel, Schienen und Tarsi sind roth, die Vorderhüften und Schenkel an dem unteren, die vier hinteren Schienen an dem innern Rande schwach gewimpert. Vorderschienen mit drei feinen Randzähnen.

2. Macronota philippinensis Waterhouse.

Macronota philippinensis Waterhouse, Proceed. entom. Soc. 1841. p. 27 ; Transact. entom. Soc. IV. 1845. p. 39. Macron. auroguttata Burmeister, Handb. d. Entom. Bd. III. S. 323. - Macron. philippinensis Wallace, Transact. entom. Soc. 3. Ser. IV. 1868. p. 555. - Macron. philippinensis Gemminger et de Harold, Catal. coleopt. t. IV. p. 1298.

M. nigra; antennis pedibusque rubris; capite flavobilineato; thorace marginibus vittaque mediana flavis ornato; scapulis et scutello flavis; elytris, pygidio, abdominis pectorisque lateribus flavo-maculatis.

Longitudo . . . . . . . . Mm. 16-18.

Habitat in insulis Luzon, Bohol, Panaon. - $\delta 9$.

Der Kopf ist vorne breiter, der Einschnitt des Clypeus tiefer und seine Ecken sind spitzer wie bei M. regia. Gleich wie bei letzterer verlaufen von der Stirne nach vorne zwei gelbe filzige mit ibren Enden etwas divergirende Streifen. Sie, sowie die erhabene Mitte des Clypeus zwischen ihnen, ist dicht punctirt und mit sehr kurzen Härchen bestanden. Der Halsschild ist schwarz wie der Kopf, glänzend aber ebenfalls dicht punctirt und behaart. Ausgenommen hinten wird derselbe neben dem erhabenen, feinen und glänzenden Rande von einem gebogenen gelben Filzstreifen eingefasst, dessen seitliche Theile aber nicht ganz bis zu den Schulterecken hinabreichen. In einigen Fällen ist dieser Streifen an den Kopfecken unterbrochen und besteht alsdann aus einem vorderen und zwei seitlichen Theilen.

Von seiner Mitte entspringt eine breitere gelbe Längsbinde welche sich bis in den Anfang des hinteren Lappens fortsetzt, das Ende desselben aber nicht erreicht und stets von dem Schildchen durch einen schwarzen Zwischen- 
raum getrennt bleibt. Mitunter findet sich an Stelle dieser, oben mit dem Randstreifen zusammenhängenden mittleren Längsbinde in der Mitte des Thorax, ein grösserer oder kleinerer gelber Flecken, Die Schultern und das Schildchen sind gelbfilzig. An jeder Scite der Basis des letzteren liegt ein dreieckiger, mit der Spitze gegen den Schulterbuckel gexichteter Querfleck. Ausserdem befindet sich auf jeder Flügeldecke in der Mitte, dicht neben der Naht, ein bald viereckiger, bald nach aussen abgerundeter Flecken, welcher mit dem der andern Seite eine Querbinde bildet. Ober- und unterhalb desselben liegen auf jeder Seite zwei längliche, quere Randflecken. Der untere Theil der Naht wird, eben wie bei M. regia, auf jeder Seite von einem breiteren oder schmäleren sich unten nach aussen umbiegenden Streifen eingefasst. Alle diese Streifen und Flecken sind filzig, matt, punctirt und nadelrissig. Neben ihnen sind die Flügeldecken glänzend schwarz, aber punctirt und mit sehr kurzen Härchen besetzt. Die Afterklappe steht ziemlich wagerecht nach hinten aus, ist mattschwarz, kurz aber dicht behaart, nadelrissig und in der Mitte mit einem grossen, runden Flecke geschmückt. Die Unterfläche ist ziemlich glänzend, in der Mitte glatt, an den Seiten punctirt und mit Haaren besetzt. Der nach unten gebogene Theil des Thorax, der vordere und hintere Rand der Mesosternalplatte, ein Flecken auf der Hinterhüfte und drei bis vier Querbinden auf den Seitentheilen der Bauchsegmente sind gleichfalls gelbfilzig. Die Fühlhörner und Beine sind roth; die vorderen Hüften tragen an dem unteren, die mittleren und hinteren an dem hinteren, die mittleren und hinteren Schienen an den innern Rande lange röthliche Wimpern.

3. Macronota vidua Wallace. Taf. VI. Fig. 6. ㅇ.

Macronota vidua Wallace, Transact. entom. Soc. 3. Ser. IV. 1868 p. 550. - Macron. vidua Gemminger et de Harold, Catal. coleopt. t. IV. p. 1299.

M. nigra, nitens, supra et subtus densissime punctatis, punctis setigeris; clypeo parum sinuato, angulis rotundatis; 
fronte inter oculos albo bilineato; thorace linea alba mediana, juxta margines laterales aut una aut duabus lineolis albis tomentosis ornato; scapulis et scutello albis, tomentosis; elytro utroque maculis aut quatiuor, aut quinque aut sex, pygidio gutta mediana, pectoris abdominisque lateribus fasciis transversis albis tomentosis distinctis; antennis et pedibus nigris.

Magnitudo.

Mm. 16.

Habitat in insula Mindanao. $\delta$ ㅇ․

Diese Art hat, wie schon Wallace, der sie zum ersten Male beschrieb, richtig bemerkte, viele Aehnlichkeit mit Macron. luctuosa van Vollenh., von Ceram und Amboina, weicht aber doch von ihr, so wie von den beiden folgenden Arten, denen sie auf den ersten Blick ebenfalls sehr gleicht, wesentlich ab. Sie ist mit Ausnahme der $\mathrm{zu}$ beschreibenden weissen, filzigen Flecken allenthalben von schwarzer Farbe und, ausgenommen die Fühlhörner, das Sternum und die Tarsalglieder, dicht punctirt oder nadelrissig und mit kurzen Härchen bestanden, dessen ungeachtet aber ziemlich glänzend. Der vordere Randeinschnitt des Clypeus ist unbedeutend, seine Ecken sind abgerundet. Von der Stirn erstrecken sich zwischen den Augen nach vorne zwei weisse, unten divergirende Linien, ähnlich wie die gelben bei M. regia und M. philippinensis. Sie sind aber meistens viel kürzer und schwächer wie die gelben bei letztgenannten Arten, fehlen auch nicht selten ganz. Auf dem Thorax befindet sich ein weisser mittlerer Längsstreifen. Neben seinem Rande zeigen sich auf jeder Seite entweder eine längere, mehr oder weniger verwischte weisse Linie, oder zwei kürzere Strichelchen, wie auf der Abbildung, als Andeutung des gebogenen Randstreifens von M. philippinensis. Die Schultern und das Schildchen sind weiss. Auf jeder Flügeldecke befinden sich vier bis sechs weisse Flecke. Einer oberhalb ihrer Mitte neben der Naht; ein zweiter, gleichfalls neben letzterer, unweit ibres Endes; ein dritter neben dem Rande oberhalb des Seitenausschnittes und ein vierter zwischen diesem und der Spitze des Schildchens. Ein fünfter befindet sich gleichfalls mehr in der Nähe des Randes, un- 
gefähr in der Mitte zwischen beiden Nahtflecken. Mitunter, wiewohl nur selten, findet sich noch ein sechsier, kleinerer in dem untern, äusseren Winkel jeder Flügeldecke. Ausser dem letzteren fehlt der neben der Spitze des Schildchens am häufigsten. In der Mitte der Afterklappe zeigt sich ein runder Tropfen. Unten sind die Seiten des ersten, zweiten und vierten Bauchringes, der vordere und hintere Theil der Metasternalplatte, die Vorderhüfte, die Pleura und der umgeschlagene Theil des Thorax weiss gefleckt. Die Beine sind schwächer behaart wie bei M. regia und philippinensis, die Schienen der beiden binteren Paare innen viel weniger lang gesäumt.

4. Macronota propinqua n. sp. Mohnike. Taf. VII. Fig. 1. ․

M. praecedenti similis sed major, nigra, nitida, supra et subtus, excepto sterno, creberrime punctata et aciculata, punctis setiferis; clypeo profunde sinuato, angulis rotundatis; thorace medio lateribusque albo-maculato; scapulis albis; scutello basi albo; elytro utroque maculis quattuor albis, quarum duo suturales, duo marginales, pygidio macula mediana rotunda, abdominis pectorisque lateribus fasciis et maculis albis ornatis.

Magnitudo . . . . . . . Mm. 19-20.

Habitat in insula Mindanao. - $\delta$.

Diese Art unterscheidet sich bei aller scheinbaren Uebereinstimmung von M. vidua constant durch ihre Grösse, die ungefähr $4 \mathrm{Mm}$. mehr wie die von jener beträgt; durch ihren weniger viereckigen, seitlich mehr gebogenen und vorne tief ausgebuchteten Clypeus, sowie auch durch grössere Abflachung des obern Theiles ihrer Flügeldecken. Während nämlich bei M. vidua die erhabene zwischen der Naht und dem Kande jedes Deckschildes verlaufende Längsleiste mit zwei Schenkeln entspringt, welche in seiner Mitte sich vereinigen, oberhalb ihrer Vereinigung aber eine dreieckige, spitzige Vertiefung einschliessen, ist dieses bei M. propinqua nicht der Fall, und findet sich von dieser vertieften Stelle bei ihr, oben auf der Schulter, nur eben eine Andeutung. Die Stirn ist bei allen mir vorliegenden Exemplaren ohne 
weisse Linien zwischen den Augen, übrigens, gleich wie alle andern Kopftheile, eben so stark punctirt als bei M. vidua. Der Thorax ist gleichgestaltet mit dem der letztgenannten Art. $\mathrm{Er}$ hat auf seinem Discus einen runden, und zu jeder Seite desselben neben dem Rande einen länglichen weissen Filzfleck. Diese Randflecke fehlen häufig und auch der mittlere ist in einigen Fällen nur angedeutet. Die Schultern und das Schildchen, seine Spitze ausgenommen, sind weiss. Auf jeder Flügeldecke befinden sich zwei weisse Randflecken und ein in der Mitte zwischen beiden gelegener dreieckiger Nahtfleck, der mit dem der andern Seite eine kaum durch die Naht getrennte Querbinde bildet. Ein zweiter Nahtfleck liegt weiter nach unten oberhalb der Spitze der Flügeldecke. Auch er stösst mit dem der andern Seite fast zusammen und bildet mit ihm ein mit der Basis nach unten, mit der Spitze nach oben gerichtetes Dreieck. In der Mitte des Pygidiums befindet sich ein runder weisser Fleck. Unten ist die Zeichnung ganz so wie bei M. vidua, wie ausserdem auch die Sculptur aller Körpertheile, die Behaarung, die Gestalt und Behaarung der Beine sowie die Form des Mesosternalfortsatzes bei beiden Arten dieselben sind.

5. Macronota Mindanoensis n. sp. Mohnike Taf. VII. Fig. 2. $\subsetneq$.

M. nigra, nitidissima; clypeo, thorace, elytrorum basi margineque parum ac distanter grosse punctatis, punctis non setigeris; thorace, scutello, scapulis, elytris, pygidio, abdominis pectorisque lateribus albo maculatis; tarsis mediis ac posterioribus incrassatis, articulis penicillatis; processu mesosterni brevi apice parum dilatato.

Habitat in insula Mindanao.

Longitudo . . . . . . Mm. 19-21. - סㅇ.

Diese Art unterscheidet sich von den beiden vorigen, mit denen sie in der Farbe sowie in der Vertheilung der weissen Flecken Uebereinstimmung besitzt, hauptsächlich dadurch, dass sie oben wie unten sehr glatt und glänzend, nicht wie jene allenthalben dicht und fein punctirt ist, sondern nur an einzelnen Stellen zerstreute grössere und 
tiefere, mehr grubige Punkte, an dem Körper aber nirgends einige Behaarung zeigt. Der Clypeus ist vorne nicht so breit und etwas weniger tief eingebuchtet, seine Mitte weniger erhaben und glänzender wie bei der vorigen Art, die Punctur auf demselben viel zerstreuter. Die Seiten des Thorax sind abgerundeter und weniger achteckig wie bei M. vidua und M. propinqua, sein hinterer Theil ist weniger tief eingedrückt, der Lappen etwas kürzer. Seine ganze Oberfläche ist mit grössern, grubigen, in ihrem Grunde ebenfalls glänzenden, ziemlich entfernt von einander stehenden Puncten besetzt. In seiner Mitte befindet sich ein kleiner, viereckiger, wie aus zwei Hälften bestehender weisser filziger Fleck, der bei einem der mir vorliegenden Exemplare durch einen kleinen Punct angedeutet wird. Die Schulterblätter und die Basis des Schildchens sind weiss filzig. Die Flügeldecken sind neben dem letzteren flach und nur sehr sparsam punctirt; ihre erbabene Längsleiste ist weniger scharf wie bei den beiden vorigen Arten. In der Vertiefung zwischen ibr und der Naht zeigen sie einige, aber auch glänzende Nadelrisse. Auf jeder von ihnen befindet sich neben der Naht, ungefähr in ihrer Mitte, ein weisser Fleck, sowie ein zweiter mehr nach ihrem Ende zu. Unmittelbar über der Spitze jeder Flügeldecke zeigt sich eine weisse Querlinie. Ausserdem befinden sich auf jeder, neben ihrem Rande zwei Querflecken, von denen der obere der längere ist. In der Mitte des Pygidiums liegt ein runder weisser Fleck. An der Unterseite, die allenthalben sehr glatt und glänzend, auch an den Seiten nur wenig punctirt oder nadelrissig ist, zeigen sich weisse Flecken an dem umgeschlagenen Theile des Thorax, dem vorderen und hinteren Rande der Metasternalplatte, dem Vorderrande der Hinterhüfte so wie auf den Seitentheilen des ersten, zweiten und vierten Bauchringes. Der Mesosternalfortsatz ist kurz, an seiner Spitze etwas seitlich erweitert. Die Vorderschienen haben bei dem Weibchen drei starke Randzähne; bei dem Männchen nur eine Andeutung des oberen; die mittleren und hinteren sind bei beiden Geschlechtern mit einem schwärzlichen Haarsaume versehen. 
Auffallend dick und an den.Gelenken mit Haarpinseln besetzt sind bei den Weibchen die mittleren und hinteren Tarsi.

6. Macronota abdominalis n. sp. Mohnike Taf. VII. Fig. 3.

M. nigra; supra sericea, opaca; subtus nitidior; scapulis et scutello albo-marginatis; elytro utroque juxta suturae medium maculis duabus exiguis, linealisque duabus quarum una juxta scutellum, altera prope marginem situ, albis ornato; abdominis segmentis albo-marginatis; processu mesosterni brevi, apice non dilatato.

Longitudo . . . . . . . Mm. 25-26.

Habitat in insula Mindanao. $-q$.

Eine sich durch ihre Grösse sowie durch ihren robusten Körperbau und ihren sehr entwickelten, sowohl nach unten als nach den Seiten stark hervortretenden Unterleib auszeichnende Art. Der Clypeus ist seitlich wicht umrandet; vorne tief ausgebuchtet, mit abgerundeten Spitzen; die Umgegend der Ausbuchtung glänzend, der übrige Theil aber so wie auch die. Stirn, matt, sammetartig schwarz, mässig dicht und nicht schr fein punctirt. Seine Mitte ist wenig gewölbt und hervorragend. Der Thorax ist achtseitig, fein umrandet, vor dem Schildchen wenig vertieft, an den Seiten zerstreut punctirt, schwarz, sammetartig. Die Fühlhörner sind braun. Die Schultern hinten weisslich gelb gerandet. Auch das Schildchen ist mit einem oben feineren, seitlich dickeren, perlmutterartig schillernden, gelblich weissen Rande umgeben. Auch der an das Schildchen stossende Theil der Flügeldecken ist ähnlich gerandet. Die letzteren sind an ihrer Basis sehr breit, haben einen tiefen Seitenausschnitt und verschmälern sich nach der Spitze zu beträchtlich. Sie sind flach, neben der Naht nur wenig eingedrückt; ihre mittlere Längsleiste tritt kaum hervor, an dem Nahtende zeigen sie eine klcine Zuspitzung. Tief schwarz und sammetartig, sind sie nur an ihrem Grunde, hauptsächlich in der Schultergegend punctirt, während die Naht zu jeder Seite ihrer ganzen Länge nach von einer feinen eingerissenen Linie begleitet wird, neben welcher sich in der 
Mitte und unten noch einige kürzere befinden. In der Mitte zeigt sich ein beiden Flügeldecken gemeinschaftlicher kleiner Fleck und neben demselben auf jeder Seite ein anderer, so dass eine kurze Querbinde gebildet wird. Unterhalb derselben, etwas höher als die Mitte zwischen ihr und der Nahtspitze, befindet sich auf jeder Seite ein länglicher, nach oben gerichteter Randfleck. Das grosse, gewölbte, hervorragende Pygidium ist mattschwarz, ungefleckt, quernadelrissig. Der Bauch ist in der Mitte glänzend, an den Seiten sammetartig, zerstreut punctirt. Die drei oberen Bauchringe sind seitlich bis zu ihrer Mitte, dēr vierte in seiner ganzen Länge mit einem hintern weissen Rande versehen. Auch die hintere Hüfte zeigt einen solchen Rand. Die Brust ist in der Mitte glänzend, an den Seiten matt, allenthalben zerstreut punctirt und in den Puncten mit röthlichen Härchen besetzt. Der Mesosternalfortsatz ist kurz, an der Spitze nicht erweitert und wie von unten nach oben hinaufgedrückt. Die Beine sind schwarz, mässig punctirt; die Vorderschenkel an ihrem unteren, die mittleren an ihrem hinteren Rande dicht röthlich behaart. Die mittleren Schienen haben in ihrer ganzen Länge, die hinteren nur an ihrem unteren Theile einen mässig dichten Haarsaum. Die Vorderschienen haben ausser der Endspitze zwei Randzähne, die mittleren und hinteren einen.

7. Macronota tricolor n. sp. Mobnike. Taf. VII. Fig. 4. ㅇ.

M. praecedenti statura haud dissimilis sed minor; capite, antennis, pygidio, pectore, pedibusque nigris ; scapulis et scutello nigris marginibus albo-flavescentibus ornatis; elytris ferrugineis, postice nigris, utroque juxta marginem fasciolis duabus, medio maculis duabus parvis, albo-flavescentibus distinetis; annulis abdominalibus plus minusve albo-marginatis.

Longitudo . . . . . . . Mm. 20-21.

Habitat in insula Mindanao. - $\delta q$.

Diese Art steht der vorigen sehr nahe, gleicht ihr auch in den Körperverhältnissen, ist aber etwas klciner, relativ weniger dick und anders gezeichnet. Die Gestalt 
des Kopfes und des Clypeus, der vordere Randausschnitt des letzteren sowie auch die Sculptur aller Kopftheile zeigen keinen Unterschied, eben so wenig auch der Thorax. Alle diese Theile sind mit Ausnahme des Kopfschildes sammetschwarz. Das Schildchen ist gleichfalls schwarz und auf dieselbe Weise wie bei Macron. abdominalis, aber etwas feiner gelblich weiss umrandet. Auch die Schultern haben hinten einen solchen Randfleck. Die Flügeldecken sind zwischen den Schultern sehr breit, haben einen tiefen seitlichen Randausschnitt und verschmälern sich nach ihrer Spitze hin beträchtlich. Ihre Farbe ist auf ihren beiden oberen Dritttheilen ein ziemlich helles Braun, auf ihrem untersten Drittheile aber Schwarz. Auch sie sind sammetartig. Die mittlere Längsleiste ragt auf ihnen noch weniger hervor wie bei der vorigen Art; dagegen aber sind bei dieser die Hinterbuckel entwickelter. Die Naht ist wenig geschwollen, ihre Spitze kurz, die Umgègend ihrer Mitte fast nicht vertieft. Neben ihr verlaufen einige feine, eingerissene, gekrümmte Linien von den Schultern zu dem Flügeldeckenende. Die Basis der letzteren ist sehr spärlich punctirt. In der Mitte einer jeden Flügeldecke zeigen sich dicht neben der Naht zwei gelblich weisse, kleine Flecken, die mit denen der andern Seite eine kurze Querbinde bilden. Unterhalb und oberhalb der letzteren befinden sich auf jeder. Flügeldecke zwei kleine längliche Randflecke, von denen die oberen, welche häufig fehlen, nach unten, die unteren aber nach oben gerichtet sind. Alle diese Flecken und Linien sind kleiner und weniger deutlich wie die bei M. abdominalis. Das Pygidium ist schwarz, ungefleckt und quer nadelrissig. Die Unterseite ist glänzend. Die Bauchringe sind allenthalben zerstreut punctirt und an ihren hinteren Rändern mit einer weissen Einfassung versehen, die aber nicht so vollständig ist wie bei der M. abdominalis und nicht sclten fehlt. Auch die Brust, mit Ausnahme der Mitte, ist allenthalben punctirt und in den Puncten mit gelblichen Ḧ̈rchen besetzt. Der Mesosternalfortsatz ist wie bei der vorigen Art und auch die Beine zeigen keine Abweichung von derselben, mit Ausnahme dass die mitt- 
leren und hinteren Schienen am inneren Rande gänzlich ungewimpert sind.

8. Macronota jucunda n. sp. Mohnike. Taf. VII. Fig. 5.

11. nigra, supra velutina subtus nitida; thorace lineolis quattuor punctoque mediano albidis; elytris basi medioque rubris, juxta marginem, suturum et apicem maculis alboflavescentibus ornatis; pygidio-albo vittato; scutello, scapulis, femoribus posterioribus necnon abdominis segmentis albo-marginatis.

Longitudo . . . . . . . . . . . Mm. 16.

Habitat in insula Mindanao. - $\$$.

Eine in ihrem Colorite der Macron. Malabariensis - Gory et Percheron Monogr. d. Cét. pl. 63 fig. 3 sehr nahe stehende, aber von dieser durch ihre Gestalt im allgemeinen, besonders aber durch den relativ viel breiteren Thorax und den ganz anders geformten Clypeus abweichende Art. Der letztere nämlich ist auffallend kurz, kaum länger als breit, seitlich mit einem feinen erhabenen Rande versehen, vorne aber kaum etwas eingebuchtet. Seine Mitte ist nur wenig erhaben, bloss zwischen den Augen zeigt sich die Spur einer Leiste. Von allem diesen findet bei M. malabariensis aber das Gegentheil statt. Der Kopfschild ist allenthalben dicht und fein punctirt, an seinem vorderen Theile glänzend, hinten mattschwarz. Die Fühlhörner sind schwarz. Der Thorax ist achteckig, verhältnissmässig schmal, kaum gewölbt und vor dem Schildehen sehr wenig vertieft. Er ist sammetartig, schwarz, allenthalben punctirt. Von dem Augenwinkel sowohl als von der am meisten nach aussen vorspringenden Stelle des seitlichen Randes erstrecken sich auf jeder Seite zwei gelbliche convergirende Linien nach dem Discus bin. In der Mitte, zwischen den beiden unteren von ihnen, befindet sich ein kleiner gelblicher Flecken. Die Schultern haben einen hintern gelblich weissen Rand und ebenso auch das Schildchen. Der helle Rand des letztern wird sowohl durch dasselbe wie durch den nächstliegenden Theil der Flügeldecken gebildet, gleichwie bei M. abdominalis und M. tricolor. 
Die Flïgeldecken sind oben nicht so breit, seitlich nicht so tief ausgeschnitten und verschmälern sich nach der Spitze zu nicht in dem Grade wie bei den beiden vorigen Arten und bei M. malabariensis. Sie sind flach, die mittlern Längsleisten ragen wenig hervor, so wie auch die an ihrem Ende mit einer ganz kleinen Spitze versehene Naht. Neben der letzteren, in ihrer ganzen Länge, verlaufen einige eingerissene Linien. Die Seiten der Flügeldecken sind mässig punctirt. An dem Grunde sind sie in ihrer ganzen Breite und beinahe in einem Dritttheil ihrer Länge hell rothbraun gefärbt. Diese Färbung setzt sich auch in der Mitte jeder Flügeldecke nach hinten fort. Ihre Seiten, von dem Ausschnitte an, ihre Spitzen und der nächste Raum neben der Naht, von der Spitze des Schildchens an, bleiben aber schwarz. Auf jeder Flügeldecke befinden sich neben dem Seitenrande cin oberer, länglicher, ein unterer mehr runder Flecker und an der Spitze, dicht oberhalb derselben, ein querer Streifen so wie ein kleinerer Fleck neben der Nahtmitte, alle von gelblich weisser Farbe. Unterhalb der beiden Flecke, in der Mitte der Flügeldecken, befindet sich ein beiden gemeinschaftlicher. Das Pygidium ist mattschwarz, sammetartig mit einer mittleren weissen Längsbinde. Die Bauchringe sind glänzend schwarz, an den Seiten stärker wie in ihrer Mitte punctirt und mit einem hinteren weissen Rande versehen der sich fast bis zur Mitte erstreckt. Auch die Seiten der Brust sind stark punetirt, mit einzelnen kurzen Härchen besetzt. Der Mesosternalfortsatz ist kurz und an seiner Spitze seitlich zusammengedrückt. Die Schenkel der schwarzen, glänzenden, wenig punctirten Beine sind gewimpert, während den Schienen diese Behaarung fehlt. Die Tarsi sind kurz und fein.

9. Macronota sponsa n. sp. Mohnike. Taf. VII. Fig. 6.

M. nigra, supra velutina, opaca; subtus nitida; capiti, thorace, scutello elytrisque lineolis albis, plus minusve obsoletis, ornatis; segmentis abdominis albo-marginatis.

Longitudo

Habitat in insula Mindanao. $-\sigma q$. 
Allenthalben schwarz, oben matt sammetartig, unten glänzend. Der Kopfschild umrandet, vorn wenig ausgebuchtet mit abgerundeten Ecken, in der Mitte, besonders auf der Stirn, erhaben, neben dieser Anschwellung bei einigen Exemplaren auf jeder Seite die Andeutung einer feinen, kurzen Linie, übrigens glänzend, dicht punctirt. Der Thorax achteckig, ror dem Schildchen tiefer eingedrückt wie bei M. jucunda, nicht sehr dicht punctirt. Neben der unteren Hälfte seines Seitenrandes eine feine, mit der der andern Seite etwas convergirende Linie. Zwei noch feinere und kürzere, gleichfalls unten convergirende Linien verlaufen von den Augenwinkeln nach dem Discus, und unterhalb der letzteren eine vierte in der Richtung von oben nach unten. Alle diese Linien fehlen häufig theilweise oder gänzlich, so dass bei einigen Individuen der Thorax ganz schwarz ist. Auch die Schultern sind hinten mit feinen weissen Linien eingefasst und das Schildchen wird auf jeder Seite von einem weissen Rande umgeben. Die Flügeldecken verschmälern sich von dem Grunde nach der Spitze zu nur wenig und sind neben dem Nahtende nur sehr wenig zugespitzt. Die mittlere Längsleiste verläuft auf jeder von ihnen, von der Spitze des Schildchens an bis zu dem Endbuckel durchaus geradlinigt. Sie ist auffallend hoch und oben scharfkantig. Zwischen jeder dieser Kanten und der Naht zeigen sich, die untere Hälfte dieses Raumes einnnehmend, feine, dicht neben einander gelegene, mit der Naht parallele, eingerissene Linien. Auf der Mitte der Naht liegt ein grösserer, dreieckiger, unten zugespitzter beiden Flügeldecken gemeinschaftlicher Fleck; unterhalb derselben, auf jeder von ihnen, neben der Nabt ein weisses Strichelchen, sowie eine weisse Querlinie oberhalb ihres Endes. Ausserdem befinden sich auf jeder Flügeldecke zwei weisse, nạch innen convergirende Randstreifen, welche mit denen der andern Seite den erwähnten grösseren Flecken in der Mitte der Naht einschliessen. Das Pygidium ist bei den meisten Individuen ungefleckt, bei einzelnen mit einem weissen Punkte an der Endspitze und mit feinen queren Nadelrissen versehen. Die Bauch- 
ringe sind zerstreut fein punctirt und hinten bis zu ihrer Mitte weiss gerandet. Auch die Hinterhüften haben diesen weissen Rand gleichwie auch die Parapleuren. Alle Seitentheile der Brust sind fein und zerstreut punctirt. Der kurze Mesosternalfortsatz ist vorn nicht ganz so zusammengedrückt wie bei der vorigen Art. Die vorderen und mittleren Schenkel sind an ihrem unteren und hinteren, die hinteren Schienen an ihrem inneren Rande gewimpert.

10. Macronota pilosa n. sp. Mohnike. Taf. VII. Fig 7.

M. supra viridis, submetallescens, pilis brevibus flavescentibus obsita; subtus aenea, niteus, squamulis ac pilis flavescentibus dense tecta; clypeo quadrato, antice non sinuato, angulis acutis; processu mesosternali apice aliquid incrassato; antennis tarsisque nitidis aeneis.

Longitudo . . . . . . . . . . . Mm. 17.

Habitat in insula Mindanao. $-\delta q$.

Oben grün, matt, mit leichtem Metallschimmer, der an den Rändern und abgeriebenen Stellen stärker hervortritt, allenthalben mit kurzen etwas zerstreut stehen den gelblichen, anliegenden Härchen bestanden. Unterseite und Beine, die Tarsen ausgenommen, erzfarben, glänzend, aber dicht mit kleinen gelblichen Schuppen und Härchen besetzt die selbst in der Nitte des Bauches und der Brust nicht fehlen, an diesen Stellen aber weniger gedrängt stehen. Auch die Schenkel und Schienen sind mit diesen Härchen und Schuppen bestanden. Sie alle erheben sich aus der, die ganze obere und untere Fläche bedeckenden feinen Punctur. Der Kopfschild ist viereckig, umrandet, in der Mitte erbaben, vorne ohne Einbuchtung, mit scharfen Ecken, dicht punctirt und mit Härchen besetzt. Der Thorax ist achtseitig, fein gerandet und vor dem Schildchen mässig vertieft. Die Flügeldecken sind herzförmig, seitlich wenig ausgeschnitten und fallen flach von ihrer Mitte nach dem Rande zu ab. Ihre mittlere Längsleiste so wie die Naht ragen sehr wenig hervor; das Ende der letzteren ist nicht zugespitzt. Der Mesosternalfortsatz ist kurz, an seiner Spitze etwas erweitert und abgerundet. Die Vorderschienen 
sind bei beiden Geschlechtern dreigezähnt, jedoch ist der obere Zahn bei dem Männchen kleiner wie bei den Weibchen. Fühlhörner und Tarsi sind glänzend broncefarben.

11. Macronota gratiosa n. sp. Mohnike. Taf. VII. Fig. 8.

M. fronte prominente, medio carinato, bilineato, squamulis minimis rufescentibus tecto; clypeo nigro, marginato, antice modice sinuato, angulis rotundato; thorace marginato, castaneo-rufescente, densissime punctato, punctis setulas minimas gerentibus, disco guttula flava ornato; elytris basi latis, apice multo angustioribus, costis et sutura modice prominentibus, hac non acuminata, castaneorufis, densissime punctis setiferis obsitis, juxta margines maculis quattuor totidemque juxta suturam flavis; pygidio nigro; transverse dense striolato, subnitido; abdominis segmentis nigris, nitidis, lateribus striolatis, punctatis, flavo marginatis; coxa posteriore flavo maculata; pectoris lateribus dense punctatis, aciculatis, partim pilosis, flavo tomentosis; processu mesosternali apice aliquid dilatato; pedibus nigris, nitidis, femoribus tibiisque mediis ac posterioribus flavo-fimbriatis.

Longitudo . . . . . . . . . . Mm. 16.

Habitat in insula Luzon. - ㅇ.

Thorax und Flügeldecken dunkel castanienbraun mit starkem röthlichen Anfluge, ziemlich glänzend obwohl sehr dicht und fein punctirt und in den Puncten mit sehr feinen und kurzen gelblichen Härchen besetzt. Alle übrigen Körpertheile schwarz und theiiweise stark glänzend. Der Clypeus fein umrandet, dicht punctirt, mit ziemlich tiefem vorderen Einschnitte, dicht punctirt, in den Puncten feine Härchen. Seine Mitte ist etwas gewölbt. Auf der Stirn befinden sich ein Längskiel sowie zu jeder Seite derselben eine kurze gelbliche Linie. Die Fühlhörner sind schwarz. Der Brustschild ist an den unteren Seitentheilen und hinten fein schwarz und glänzend umrandet. $\mathrm{Zu}$ Anfange seiner hinteren Vertiefung befindet sich ein kleiner gelblicher Filzfleck. 
Das Schildchen ist ungefleckt. Die Flügeldecken sind zwischen den Schultern sehr breit, werden aber von dem Ausschnitte an beträchtlich schmäler und lassen die Seiten des Unterleibes unbedeckt. Die Längsrippe einer jeden Flügeldecke entspringt mit zwei, eine Grube zwischen sich einschliessenden Schenkeln; sie so-wie die hinten nicht zugespitzte Naht ragen nur wenig hervor. Auf jeder von ihnen befinden sich vier gelbe etwas verwischte Filyflecke, ein oberer neben dem Rande unterhalb des Ausschnittes, ein zweiter Randfleck nicht weit unterhalb jenes, ein Nahtfleck in gleichem Abstand von beiden Randflecken und ein zweiter in der Mitte von diesem und der Nahtspitze. Das Pygidium ist gross und nach allen Richtungen stark hervortretend, schwarz, fein horizontal nadelrissig, von seidenartigem Glanze. Die Bauchringe sind sehr glatt und glänzend, in der Mitte sehr wenig, an den Seiten etwas häufiger punctirt, die vier oberen an den Seiten mit einem gelben Filzrand, der letzte in der Mitte mit einer gelben Haarbürste versehen. Auch die Hinterhüften sind gelbfilzig und die Schultern sowohl oben als unten mit solchem Filze überzogen. Die Seiten der Brust sind punctirt, nadelrissig, mit feinen röthlichen Härchen und theilweise auch mit gelhem Filze bedeckt. Der Mesosternalfortsatz ist kurz, an der Spitze aber etwas abgerundet und etwas seitlich erweitert. Alle Schenkel, sowie die mittleren und hinteren Schienen tragen gelbliche Haarsäume; die Torsalglieder sind schwarz.

12. Macronota guttulata Wallace- Tab. VII. Fig. 9. Macronota guttulata Wallace. Transact. entom. Societ. 3. Ser. IV. 1868. p. 551.

.M. nigra, clypeo elongato, profunde sinuato, angulis subacuto, punctato; fronte carinato; thorace marginibus rotundato, subconvexo, punctato-varioloso, aut nigro aut magis minusve punctulis albis asperso; scutello scapulisque nigris; elytris antice latioribus, apice valde attenuatis, medio carinatis, sutura parum prominente non acuminata, 
utroque guttulis albis $25-30$ ornato; pygidio nigro; abdominis segmentis punctato-variolosis aut nigris aut albomarginatis atomisque albis plus minusve aspersis; pectoris lateribus variolosis, processu mesosterni forti, promincnte, compresso ; pedibus nigris, tibiis maris inermibus, foeminae anterioribus dilatatis, externe tridentatis, mediis ac posticis unidentatis.

Longitudo maris . . . . . . . . . . Mm. 16. feminae . . . . . . . . , 19.

Habitat in insula Mindanao et Laniquin de Mindanao. $-\delta$ s.

Diese von Herrn Wall ac e zuerst beschriebene Art, von der ich eine Reihe von Exemplaren und beide Geschlechter vor mir habe, hat auf den ersten Blick eine grosse Uebereinstimmung mit der folgenden. Bei einer näheren Vergleichung aber zeigen sie hinreichende $A b$ weichungen von einander, um sie nicht als blosse Varietäten sondern als selbstständige, wiewohl sehr nahe stehende Arten halten zu müssen. M. guttulata ist, die näher zu beschreibende Punctur mit weiss abgerechnet, allenthalben schwarz, oben matt, unten etwas glänzend. Der Clypeus ist verhältnissmässig lang, leicht umrandet, vorne tief eingebuchtet mit ziemlich spitzen Ecken, punctirt und glänzend. Dic Mitte der Stirn zeigt eine hervorragende Leiste und neben derselben, aber nicht bei allen Individuen, zwei. kurze, aus dicbt neben einander stehenden feinen Puncten zusammengesetzte weisse Linien. Der Thorax ist leicht gewölbt, seitlich abgerundet, umrandet, in der Mitte und neben den Seitenrändern grob punctirt und blatternnarbig gegrubt. Diese Vertiefungen sind mit einer eigenthümlichen weissen Substanz ausgefüllt und werden durch sie verdeckt. Wo diese Substanz durch Abreiben oder Alter verloren gegangen ist, sieht man die erwähnten Vertiefungen am deutlichsten und erscheint der Thorax alsdann schwarz. Ein solches Exemplar, wie ich auch vor mir habe, dürfte das von $\mathrm{W}$ allace beschriebene gewesen sein, da er der weissen Puncte auf dem Thorax nicht gedenkt. Die Schultern sind schwarz mit einem hinteren feinen, weissen Rande. 
Das Schildchen ist dreieckig, ungefleckt. Die Flügeldecken sind zwischen den Schultern breit, werden aber nach der Spitze zu sehr viel schmäler. Sie haben eine mittlere Leiste und zwischen dieser und der wenig hervorragenden, hinten nicht zugespitzten Naht noch einige mit letzterer parallel verlaufende Längslinien. Auf jeder Flügeldecke befinden sich 25 bis 30 kleine punctförmige weisse Flecken die, gleichwie schon bei dem Thorax bemerkt wurde, in ebensovielen pockenartigen Grübchen sich befinden. Das Pygidium ist in der Regel einfach schwarz, ausnahmsweise aber an seinem oberen Rande mit zwei kleinen neben einander liegenden weissen Querlinien versehen. Die Bauchringe sind an den Seiten hinten schmal weiss gerändert. Auch die Hinterhüften und Pleuren zeigen ähnliche feine Ränder. Ausserdem ist die ganze Unterfläche, kaum die Mitte des Sternums ausgenommen, dicht pockennarbig gegrubt und erscheinen in diesen Grübchen, wenn das Thier gegen das Licht gehalten wird, dieselben weissen Atome wie auf der Oberfäche. Ausserdem zeigt die ganze untere Seite, bei schräge auffallendem Lichte einen sehr eigenthtimlichen, grün, blau und gelb schillernden Glanz. Hin und wieder zeigen sich auf ihr auch einzelne, zerstreut stehende kurze schwärzliche Härchen. Der letzte Bauchring ist mit einem solchen Saume eingefasst. Der Mesosternalfortsatz ragt nach unten und vorne hervor, ist seitlich zusammengedrückt und an seiner Spitze wie schief von unten nach oben abgeschnitten. Die Vorderschienen sind bei dem Weibchen vorne breit und mit zwei Randzähnen oberhalb des Endzahnes versehen. Die mittleren haben bei demselben einen Zahn in ihrer Mitte. Bei den Männchen dagegen sind alle Schienen ungezähnt. Hierdurch sowie durch ihre geringere Grösse und die tiefe Längsfurche in der Mitte ihres Unterleibes unterscheiden sich die Männchen von den Weibchen.

13. Macronota lugubris n. sp. Mohnike.

Taf. VIII. Fig. 1 б Fig. 2 \%.

M. nigra, praecedenti valde similis sed diversa; tho- 
racis lateribus medioque guttulis albis densius aspersis; seapulis ac scutello albis; elytris albo multo-guttatis, maris juxta suturam vittis albis duabus medianis ornatis; abdomine pectoreque varioloso-punctatis, lateribus latius albo fasciatis; processu mesosternali fortiore, prominente, compresso, apice oblique truncato; tibiis maris inermibus, feminae anterioribus tridentatis, mediis ac posterioribus unidentatis.

Longitudo maris . . . . . . . . Mm. 17. foeminae . . . . . . . . $\quad 20$.

Habitat in insulis Panaon, Leyte, Luzon. - $\sigma$.

Bei der grossen Aehnlichkeit dieser Art mit der vorhergehenden, ist es hinreichend hier allein die Puncte anzudeuten, worin sie von einander abweichen. Auch bei dieser Art, von welcher, eben wie von der vorigen, mir eine Reihe von Exemplaren vorliegt, ist das Männchen beträchtlich kleiner und schlanker, namentlich zwischen den Schultern nicht so breit wie das Weibchen. Im Allgemeinen ist diese Art, wiewohl von derselben Länge wie M. guttulata, doch weniger robust gebaut. Die Kopfbildung ist bei beiden dieselbe. Auch der Thorax zeigt keine andere Verschiedenheit, als dass die grubigen Vertiefungen an den Seiten und in der Mitte gröber sind und dichter neben einander stehen. Namentlich bei den Männchen stehen diese mit Weiss bedeckten Grübchen so dicht neben einander, dass durch sie zwei weisse, oberhalb des Schildchens in einander fliessende nach den Augenwinkeln zu divergirende Längsbinden gebildet werden. Bei den Weibchen ist diese Zeichnung undeutlicher. Schildchen und Schultern sind bei beiden Geschlechtern ganz weiss. Die Sculptur der Flügeldecken ist wie bei M. guttata; die weiss bedeckten Grübchen stehen aber bei den Männchen gedrängter wie bei den. Weibchen, bei welchen sie etwas grösser sind. Ausserdem findet sich bei ersteren in der Mitte jeder Flügeldecke, dicht neben der Naht eine weisse Längsbinde. Das Pygidium, die Bauchringe und die Brust zeigen eine ähnliche Sculptur wie bei der vorigen Art, aber bei auffallendem Lichte nicht das schöne, eigenthümliche Farben- 
spiel dieser letzteren. Dagegen aber sind die Seiten des Bauches und der Brust viel breiter weiss gefleckt. Der Mesosternalfortsatz und die Beine sind wie bei M. guttulata, alle Schienen des Männchens ungezähnt, seine hinteren am inneren Rande schwärzlich gesäumt.

\section{Macronota favopunctata Blanchard.}

Taeniodera favo-punctato Blanchard, Catal. d. l. coll. entom. da Mus. d'hist. nat. de Paris 1850. p. 41. - Macronota flavopunctata Wallace, Transact. entom. Soc. 3. Ser. IV. 1868. p. 555. - Macronota Alavopunctata Gemminger et de Harold, Catal. coleopt. t. IV. p. 1298.

"Supra nigra, subtus medio nigra, lateribus cinerea, thoracis vittis quinque maculisque duabus baseos, seapulis elytrorumque maculis octo aureis. Longitudo Mm. 14. Habitat in insulis Philippinis." Blanchard.

Ich kenne diese Art zwar nicht durch Anschauung, aweifle aber sehr ob es wirklich eine Macronota ist und werde weiter unten Gelegenheit haben auf sie zurückzukommen.

\section{Sectio V. Cetonidae genmini.}

Genus I. Glycyphana Burmeister.

Burm. Handb. d. Ent. Bd. III. S. 346.

1. Glycyphana rubromarginata $\mathrm{n}$. sp. Mohnike. Taf. VIII. Fig. 3.

Gl. nigra, supra opaca, thorace rubro-marginato, eJytro utrogue macula magna, marginali, transversa, flavo; pygidio maculis duabus trigonis rubris pictis; subtus nitido, functata, abdominis segmentis, coxis posterioribus, pleuris, scapulis albo-maculatis.

Longitudo.

Mm. 16.

Habitat in insulae Mindanao parte occidentali. - ․

Diese Art gleicht der Gl. (Cetonia) torquata Fabr. in dem Grade, dass ich eine Zeit lang gezweifelt habe $o b$ sie wohl als selbstständige Art aufgestellt werden llürfte. Bei genauester Vergleichung aber mit einer An- 
zahl von Stücken jener Art von Java und Sumatra, ergaben sich mir constante Verschiedenheiten zwischen beiden, die berechtigen sie als Species zu trennen, wie sehr verwandt und einander nahe stehend sie auch sein mögen. Der Kopfschild ist bei der rubromarginata kürzer, gewölbter, feiner punctirt und an seinem vorderen Rande, neben dem Einschnitte, dicker aufgewulstet. Der Thorax ist flacher, besonders vor dem Schildchen und zeigt, anstatt wie bei Gl. torquata in seinem ganzen Umfange mit einem gleichmässig breiten, nur hinter der Stirn und vor dem Schildchen etwas unterbrochenen rothen Rand umgeben zu sein, nur die Andeutung desselbeu in einem viel schmäleren, sich nur von den Augenwinkeln bis zu den Schultern hinerstreckenden, oben wie unten zugespitzten, bloss in der Mitte etwas breiteren Randstreifen. Auch die Flügeldecken sind bei ihr etwas flacher, zeigen übrigens an den Seiten und der Spitze dieselbe Punctur und neben der Naht dieselben eingerissenen gekrümmten Längslinien wie die von Gl. torquata. Der gelbe Randfleck ist ganz wie er bei letztgenannter Art häufig vorkommt. Dass dieser letzteren die beiden mehr neben der Naht, sowie etwas näher nach der Spitze zu gelegenen beiden kleineren gelben Filzflecke, welche in der Regel bei ibr gefunden werden, doch mitunter fehlen, bemerkte ich schon auf S. 63 meiner Uebers. d. Cetonid. d.'Sunda-Inseln und Molukken. Das Pygidiun ist bei beiden Arten mit zwei grossen rothen, nur einen schmalen Zwischenraum zwischen sich lassenden Randflecken verziert. Die Unterseite ist bei der Gl. rubromarginata weniger dicht punctirt und in den Puncten lange nicht in dem Maasse mit kurzen röthlichen Härchen besetzt, erscheint daher viel lebhafter schwarz und glänzender wie bei der andern. Die weissen Filzflecken auf den Bauchringen, den Hinterhüften und den Brustseiten sind bei beiden sehr ähnlich, nur bei der rubromarginata grösser und glänzender. Auch ist diese an der Unterseite der Schultern weiss gefleckt, jene aber nicht. Das Mesosternum bietet einen wesentlichen Unterschied zwischen beiden, da es bei der rubromarginata in seiner Mitte eine tiefe Längsrinne, bei 
der torquata aber nur eine Andeutung hiervon zeigt. Die Spitze des Mesosternalfortsatzes is t bei letzterer auch breiter wie bei ersterer. Die übrigens gleichgebildeten Beine sind bei dieser auch lange nicht so stark punctirt und mit hurzen Härchen besetzt wie solches bei der torquata der Fall ist.

2. Glycyphana aethiessida White. Taf. VIII. Fig. 4.

Glycyphana aethiessida White, Nomenclature of coleopt. insects of the British Museum P. I. 1841. p. 20. Euryomia aethiessida Wallace, Transact. entom. Soc. 3. Ser. IV. 1868. p. 568. Glycyph. aethiessida Gemminger et de Harold, Catal. coleopt. t. IV. p. 1309.

Gl. nigra, supra opaca; clypeo marginato, angulis rotundatis, medio elevato, densissime subtiliter punctato, antice nitido; antennis nigris; thorace subconvexo, angulis posterioribus rotundatis, ante scutellum parum sinuato, prope angulum anteriorem utrinque macula longitudinali marginali flavo ornato; scapulis flavis; scutello nigro; elytris subconvexis, sutura parum prominente, non acuto, utroque macula marginali transversali flavo distincto; pygidio albo bimaculato; subtus nitida, modice punctata, abdominis nec non pectoris medio lateribusque albo-maculatis.

Longitudo . . . . . . . . . . . Mm. 16.

Habitat in insula Luzon. - q. $^{\circ}$

Oben tief sammetschwarz. Der Clypeus glänzend, in der Mitte etwas erhaben, sehr fein und dicht punctirt, vorn ziemlich tief eingebuchtet mit abgerundeten, etwas aufgewulsteten Ecken. Die Stirn matt, Fühlhörner schwarz. Der Thorax breiter als lang, mässig convex, mit abgerundeten hinteren Ecken, vor dem Schildchen wenig ausgebuchtet. An seinem vorderen Rande befindet sich auf jeder Seite ein von dem Augenwinkel sich nach hinten erstreckender ovaler Filzfleck von goldgelber Farbe. Neben dem unteren Ende desselben an dem Seitenrande, liegen noch ein bis zwei kleine, goldgelbe Puncte. Das Schildchen ist von mittlerer Grösse, dreicckig und unten zugespitzt. Die Schulterstücke sind oben mit gelbem, unten mit weissem Filze bedeckt. Die Flügeldecken sind 
mässig gewölbt, hinten abgerundet, daselbst etwas verschmälert, mit wenig hervorragenden Mittelrippen und an ihrem Ende nicht zugespitzter Naht. Zwischen letzterer und den Rippen zeigen sich ähnliche, cingerissene, gekrümmte Längslinien wie bei Gl. rubromarginata, Gl. torquata und den meisten anderen Glycyphanen, aber weniger deutlich. Oberhalb des ersten Bauchringes erstreckt sich von dem Rande bis zu der Mitte jeder Flügeldecke ein länglicher, vor seinem Ende etwas eingeschnürter Querfleck von goldgelber Farbe. Herr Wallace beschreibt denselben als ${ }^{\text {a }}$ transverse band across the middle of four fulvous spots the middle ones small." Ungeachtet dieser Verschiedenheit aber halte ich diese Cetonide für die von Wallace aethiessida genannte, da sie in allen übrigen Puncten mit seiner Beschreibung der letzteren genau übereinstimmt und es bekannt ist wie sehr die Zahl und Gestalt der hellfarbigen Flecken auf den Flügeldecken der Glycyphana-Arten individuellen Abweichungen unterworfen sind. Hierüber habe ich mich in meiner Uebersicht der Cetoniden der Sunda-Inseln und Molukken mit Beziehung auf Gl. torquata näher, ausgesprochen. Das Pygidium, zeigt in jeder oberen Ecke einen kleinen dreieckigen weissen Fleck. Die Unterseite ist glänzend und, die Mitte ausgenommen, allenthalben mässig dicht punctirt. Die Mitte zeigt sechs weisse Filzflecke von denen je zwei auf dem letzten und dem ersten Bauchringe sowie vor den Hinterhüften auf dem Metasternum gelegen sind. Ausserdem sind die drei obersten Bauchringe seitlich, der untere Theil der Hinterhüften, die Mesosternalplatten und die Schultern unten weiss gefleckt. Die Spitze des Mesosternalfortsatzes ist seitlich erweitert, Schenkel, Schienen und Tarsi sind schwarz und glänzend, die ersteren mässig punctirt und nadelrissig.

3. Glycyphana pulcherrima n. sp. Mohnike.

Taf. VIII. Fig. 5.

G1. nigra, subtus nitida, supra opaca; elytro utroque macula marginali permagna triangulari flavo-aurantiaco ornato, coxis posterioribus flavo maculatis. 
Longitudo Mm. 14-15.

Habitat in insula Mindanao. - $\sigma$ ㅇ.

Diese auffallend schöne Art weicht von den beiden vorigen schon durch ihre Gestalt $a b$, da sie verhältnissmässig kürzer, breiter und robuster ist. Sie ist oben tief sammetartig schwarz, unten glänzender. Der Clypeus "ist ziemlich lang und schmal, sehr deutlich umrandet, vorne tief eingebuchtet mit abgerundeten Ecken, in der Mitte erhaben, fein und dicht punctirt, glänzend. Die Fühlhörner sind schwarz. Der Thorax ist breiter als lang, ziemlich gewölbt, durchaus ungefleckt, mit feinem, schwarzem, glänzendem Rande versehen, vor dem Schildchen kaum ausgebuchtet, mit abgerundeten Hinterecken und erscheint bei seinem dichten Sammetüberzuge kaum punktirt. Das Schildchen ist dreiseitig und von mittlerer Grösse. Die Schultern sind dicht punctirt und etwas glänzend; die Flügeldecken hinten nur sehr wenig verschmälert, hinter den Schultern tief ausgebuchtet und in ihrer Mitte gewölbter, während die nicht zugespitzte Naht, die Rippen und die eingerissenen Längslinien zwischen letzteren und der Naht, sowie auch die Punctur, auf ihnen viel weniger deutlich hervortreten wie bei Gl. torquata und Gl. rubromarginata. Auf jeder von ihnen befindet sich, mehr wie ibre Hälfte einnehmend, ein grosser, mehr oder weniger regelmässig dreieckiger, mit seiner Spitze fast die Naht erreichender filziger Randfleck von schöner gelblicher Orangefarbe. Die Gestalt dieser Flecken ist bei allen Individuen nicht dieselbe, bei einigen sind sie grösser, bei andern kleiner. Bei einem der mir vorliegenden Exemplare befinden sich ausnahmsweise unter den grossen Flecken noch zwei andere kleinere, mehr halbmondförmige wie auf der Abbildung. Bei eben demselben zeigen sich auch noch oberhalb der grossen Flecken auf jeder Seite zwei kleine gelbe Randpuncte. Die seitlich hervorragenden Spitzen der Hinterhüften sind bei allen gelb gefärbt. Das Pygidium ist ungefleckt, sammetartig, fein punctirt. Die Unterseite ist mässig glänzend; die Bauchringe sind selbst in der Mitte punctirt und in den Puncten mit sehr kurzen, röthlichen 
Härchen besetzt. An dem Vorderrande des vorletzten zeigen sich bei einigen Stiicken in der Mitte zwei feine weisse Querflecke. Auch die Brust, kaum das Sternum ausgenommen, ist dicht punctirt, nadelrissig und in den Vertiefungen mit Härchen besetzt. Dasselbe ist auch mit allen Schenkeln und Schienen der Fall. Die vorderen und mittleren Schenkel, so wie die mittleren und hinteren Schienen haben einen röthlichen Haarsaum. Die Tarsi sind kurz und ziemlich kräftig. Die vorderen Schienen haben zwei Randzähne, die mittleren und hinteren einen vor der Endspitze. Der Mesosternalfortsatz ist kurz, seine Spitze stumpf und seitlich erweitert.

4. Glycyphiana rubroscutellaris n. sp. Mohnike. Taf. VIII. Fig. 6.

Gl. nigra, supra opaca; clypeo nitido, emarginato, punctato; thorace late rubro-marginato, antice albo-bipunctato; scutello rubro; scapulis albo-marginatis; elytro singulo guttula inter humerum et scutellum, medio maculis duabus multo majoribus fasciam transversam formantibus, prope apicem punctis duobus, flavis ornato; sutura acuta; pygidio albo bimaculato; subtus nitida; abdominis medio et lateribus, coxis posterioribus, mesosterni margine antico et postico nec non humeri inferiori parte albo maculatis; processu mesosterni antice valde dilatato.

Longitudo . . . . . . . . Mm. 13-14.

Habitat in insulis Bohol et Mindanan. - $\delta$ ㅇ.

Auch diese Art ist verhältnissmässig kurz, breit und steht in dieser Beziehung wie in einigen anderen der vorigen nahe, ist oben aber etwas flacher. Auch bei ihr ist der Clypeus lang, schmal, mit deutlichem, wie wohl sehr feinem erhabenem Rande umgeben, glänzend, punctirt und vorne beträchtlich eingebuchtet. Die Ecken sind abgerundet, aber aufgewulsteter wie bei der vorigen Art. Bei dem einen der mir vorliegenden beiden Stücke, einem Männchen, welches aber, wie ich glaube, eine Farbenvarietät darstellt, befinden sich auf der Stirn vier neben einander liegende kleine weisse Puncte. Der Halsschild ist breiter als lang, sammetschwarz, wenig sichtbar punctirt, 
mit einem breiten, lebhaft rothen Seitenrande umgeben der vor dem Schildchen geöffnet ist und mit seinen vorderen, zugespitzten Enden nicht ganz die Kopfwinkel erreicht. Vorn befinden sich auf ihm bei dem Weibchen zwei, bei dem Männchen aber vier gelbe Puncte, von denen die in unterer Reihe stehenden kleiner und weiter von einander entfernt sind. Das Schildchen ist lebhaft roth, schmal, unten etwas abgestumpft. Die Schultern sind oben schwarz, punctirt, unten weissfilzig. Die Flügeldecken verschmälern sich nach hinten sehr wenig und sind ziemlich flach. Die Naht und Längsrippen sind kaum sichtbar, erstere ist beträchtlich zugespitzt. Die Punctur an der Basis, der Seite und der Spitze der Flügeldecken ist nur unfer der Loupe erkennbar. Auf jeder von ihnen befindet sich bei dem abgebildeten Weibchen, dessen Zeichnung ich für die typische halte, auf der Basis, zwischen der Schulter und der Nahtspitze ein gelber filziger Punct. Bei dem Männchen vertritt die Stelle desselben ein grösserer gelber halbmondförmiger Querfleck. Etwas unterbalb der Mitte liegt neben dem Seitenrande ein ovaler gelber Querfleck und von demselben durch einen kurzen Zwischenraum getrennt ein zweiter unweit der Naht. Bei dem Männchen sind diese beiden Flecken theilweise verschmolzen. Alle vier bilden eine Querbinde über beide Flügeldecken. Genau unterhalb eines jeden von ihnen, unweit der Spitze, befindet sich ein kleiner, gelber Punct. Bei dem Männchen sind die beiden mittleren viel grösser als die äusseren und ist auch der Raum zwischen der mittleren Binde und den beiden Flecken auf der Basis der Flügeldecken noch mit einzelnen gelben Atomen bestreut. Béi letzterem ist auch die Farbe derselben sowie des Thorax nicht das tiefe Sammetschwarz wie bei dem Weibchen, sondern geht mehr in das braunrothe über, und das Roth am Rande des Thorax und des Schildchens ist ein viel tieferes, weniger lebhaftes. Das Pygidium ist tief schwarz, fein punctirt und zeigt $t_{H}$ an jeder Seite einen grossen, von oben nach unten reichenden weissen Randfleck. Die Bauchringe sind dicht punctirt und in den Puncten mit ganz 
kurzen, schuppenartigen weisslichen Härchen besetzt. Auf ihnen befinden sich auf jeder Seite, neben dem Flügeldeckenrande drei und neben der Mitte zwei weisse Flecken. Diese sind bei dem Weibchen grösser und fliessen mehr in einanderals bei dem Männchen. Auch die Brust zeigt, ausgenommen in ihrer Mitte, dieselbe Punctur und Behaarung wie der Unterleib. Die Hinterhüften, der vordere und hintere Rand der Mesosternalplatte und der untere Theil der Schultern sind weiss gefleckt. Auch die Schenkel und Schienen sind mit Puncten und Härchen besetzt. Die vorderen und mittleren Schenkel sowie die mittleren und hinteren Schienen haben einen röthlichen Haarsaum. Die Tarsi sind ziemlich kurz und kräftig. Die Spitze des Mesosternalfortsatzes ist, wie bei Gl. pulcherrima, seitlich erweitert.

\section{Glycyphana cuculus Burmeister.}

Glycyphana cuculus Burmeister, Handb. d. Entom. Bd. III. S. 352. - Glycyph. cuculus Schaum, Ann. Soc. entom. d. Fr. 1849. p. 263. - Euryomia cuculus Wallace, Transact. entom. Soc. 3. Ser. IV. 1868. p. 575. - Glycyph. modesta Gemminger et de Harold, Catal. coleopt. t. IV. p. 1310.

Gl. supra viridis, opaca, capite antennisque nigris; clypeo nitido, subtiliter punctato, emarginato, angulis rotundatis; thorace partim luteo-marginato, medio bipunctato; scapulis luteo-tomentosis; scutello subacuto; elytro singulo juxta suturam punctis quattuor, juxta marginem fasciolis duabus luteis ornato; pygidio virescente, basi bimaculato; subtus laete viridis, medio nitidissima, lateribus densissime luteo-tomentosis; pedibus viridibus.

Longitudo . . . . . . . . . Mm. 11..

Habitat in insulis Luzon, Mindanao, Bohol, Babuyanes, Camotes. $d$ ?

Bei genauer Vergleichung einer Anzahl von Stücken dieser Art von den genannten Inseln mit einer noch beträchtlicheren von Glycyphana (Cetonia) modesta Fabr. aus den westlicheren Gebiten der Indischen Inselwelt, 
habe ich mich überzeugen müssen, dass sie von dieser wesentlich verschieden und nicht, wie $\mathrm{Burmeister}$ und Wallace vermuthen, Gemminger und von Harold aber für gewiss halten, blosse Varietät derselben ist. Sie weicht von dieser vielleicht noch mehr ab wie von der ihr näher stehenden, von mir in meiner Uebersicht der Cetoniden der Sunda-Inseln und Molukken auf Seite 69 als neue Art aufgestellten Gl. pygmaea. Aber auch zwischen dieser und ihr zeigt sich eine constante Verschiedenheit, so dass sie als $\mathrm{zwischen}$ beiden in der Mitte stehend betrachtet werden muss. Alle mir vorliegenden 9 Stücke von Gl. cuculus sind von derselben Grösse, während unter einer gleichen Anzahl von Gl. modesta von Java und Sumatra die kleinste 10, die grösste $13 \mathrm{Mm}$. lang ist. In dieser Beziehung stimmt sie mehr mit Gl. pygmaea überein, welche, wie sie, $11 \mathrm{Mm}$. lang ist und keine bemerkenswerthe individuelle Grössenverschiedenheit zeigt. Der Clypeus ist bei ihr länger wie bei der modesta und pygmaea, sein vorderer Randeinschnitt etwas tiefer, seine Mitte etwas erhabener. Die Punctur ist bei allen dreien dieselbe. Bei Gl. cuculus und pygmaea ist die Stirn sammetartig schwarz, bei Gl. modesta dagegen stets grün wie der Thorax. Dieser ist bei der letzteren stets ohne weisse Randeinfassung, welche den beiden andern niemals fehlt und namentlich bei Gl. cuculus vorn am breitesten ist. Bei modesta und cuculus befinden sich a uf dem Brustschilde zwei weisse Puncte, die bei ersterer bald grösser, bald kleiner, aber stets vorhanden sind, der pygmaea aber immer fehlen. Die Schultern sind bei Gl. cuculus gänzlich, bei Gl. modesta nur an ihrer vorderen Hälfte mit gelblichem Filze bedeckt. Bei der pygmaea erstreckt si ch dieser Ueberzug weiter nach hinten, lässt aber einen kleinen Theil der Schultern immer unbedeckt. Hinsichtlich der Zeichnung auf den Flügeldecken stimmt Gl. cuculus mehr mit der modesta wie mit der pygmaea überein. Bei letzterer besteht dieselbe, zwei kleine Puncte hinter ihrer Mitte neben der Naht ausgenommen, in feinen, halbmondförmigen Strichelchen an ihrer Spitze und dem untern Theile ihrer Seitenränder. Bei Gl. cuculus be- 
finden sich auf jeder Flügeldecke neben der Naht vier runde weisse Puncte, der oberste neben der Spitze des Schildchens, der unterste neben dem Nahtende; ausserdem am unteren Seitenrande zwei kurze weisse Querbinden und oberhalb dieser, neben dem Ausschnitte der Flügeldecke, noch ein Randpunct. Bei der modesta ist die Zeichnung im allgemeinen dieselbe, die Puncte sind aber nicht bei allen Individuen von gleicher Grösse. Auch zeigen sie statt der ununterbrochenen Querbinden am unteren Seitenrande stets nur einige mehr oder weniger dicht aneinander gereihte Puncte. Die Zeichnung des Pygidiums ist bei Gl. cuculus ähnlich wie bei Gl. pygmaea und besteht in einem kleinen, halbmondförmigen, gelblich grauen Filzflecken oben in jeder Ecke des Grundes. Bei Gl. modesta dagegen lassen zwei grosse, sich über die Afterdecke von oben nach unten ausbreitende Seitenflecken nur einen schmalen mittleren Streifen unbedeckt. Dieser letztere ist nur sehr wenig punctirt, und kaum mit einzelnen Härchen besetzt, wäbrend die Punctur und schuppige Behaarung auf dem entsprechenden Theile bei Gl. cuculus viel stärker, am stärksten aber bei Gl. pygmaea ist. Die Seitentheile des Bauches und der Brust sind bei den beiden letzteren Arten mit einem, sich von dem Pygidium nach dem Thorax erstreckenden, sehr breiten und ununterbrochenen, gelblichen Filzuiberzuge bedeckt. Dieser letztere aber bedeckt bei Gl. modesta die Bauchsegmente und Brusttheile nur unvollkommen. Die von dem Filzüberzuge frei bleibende glänzende, aber mit kleinen schuppentragenden Puncten bedeckte Mitte des Bauches und der Brust, ist bei der pygmaea hell grünlich braun, bei Gl. cuculus lebhaft grün, bei der modesta dunkler grün. Von derselben Farbe sind auch die Beine der letzteren, die der pygmaea aber hellbraun, die ron cuculus dagegen schwarz. Bei den beiden letzten ist auch die Punctur und Beschuppung: der Schenkel und Schienen am stärksten. In der Faŕbe der Oberseite stimmt Gl. cuculus mehr mit der modesta, als mit der pygmaea überein, bei welcher letzteren das Grün viel heller und lebhafter ist. Auch hinsichtlich 
der Körperform im Allgemeinen zeigt sich eine grössere Uebereinstimmung zwischen Gl. cuculus und Gl. modesta als zwischen jener und der im Ganzen schmäleren und mehr gewölbten Gl. pygmaea.

\section{Glycyphana vernalis $\mathrm{W}$ allace.}

Euryomia vernalis Wallace, Transact. entom. Soc. 3. Ser. IV. 1868. p. 572. - Glycyphana vernalis Gem. minger et de Harold, Catal. coleopt. t. IV. p. 1311.

„Supra laete viridis, opaca; elytris singulis maculis quatuor vel quinque marginalibus ochreis; subtus nigra, nitida, convexa, lateribus crusta rufo-ochrea vestitis.

Above, fine green, opaque; clypeus black, shining, finely punctured, deeply notched in front; thorax immaculate, with scattered punctures on the sides; elytra truncate at the apex, finely punctate-striate, the outer edges blackish, ornamented with from three to five small marginal spots on each side; pygidium pale ochre, with a large black spot; beneath shining black, the sides of the thorax, sternum, and abdomen broadly crusted with pale reddish-ochre; median line of the sternum elevated and terminating in a dilated proces: the hind thighs with an ocbreous stripe on the inner edge.

Length 8 Lines.

Hab. Philippine Island (Coll. Parry).

This species is allied to E. moluccarum." Wallace.

Ich kenne diese Art nicht und begnüge mich daher, das von Herrn Wallace über sie mitgetheilte hier wiederzugeben.

7. Glycyphana robusta n. sp. Mohnike. Taf. VIII. Fig. 7.

Gl. supra viridis, opaca; clypeo émarginato, angulis obtusis, nigro, subnitente, dense punctato; fronte viridi; antennis nigris; thorace convexo, ante scutellum vix sinuato, punctis duobus albis medianis, quattuor marginalibus distincto; scapulis antice albo-maculatis; scutello apice albo-punctato; elytris convexis, medio maculis albis sex, margine maculis decem ornatis; pygidio, plaga mediana trigona excepta, griseo-tomentoso; subtus nigra, nitida; abdominis pectorisque lateribus tomento albo-rufescente 
obtectis; processu mesosierni antice obtuso, rotundato; pedibus nigris, nitidis, femoribus posterioribus margine postico albo-tomentosis, tibiis mediis posterioribusque flavo-fimbriatis.

\section{Longitudo}

Mm. $18-20$.

Habitat in insulis Samar, Leyte, Mindanao o $\sigma^{\top}$.

Diese Art steht der Gl. malayensis Guer. nahe, untorscheidet sich von dieser schon auf den ersten Blick nicht allein durch ihre viel gewölbtere Oberfläche, sondern auch durch die Zeichnung. In letzterer Beziehung gleicht sie der von mir beschriebenen, aber noch viel flacher gebauten Gl. flavopunctato von der Westkiiste Borneo's. Sie ist oben, mit Ausnahme des Clypeus, matt sammtartig, ihre Farbe ist ein gesättigtes Grün, welches, wie bei den meisten andern grösseren grüngefärbten Glycyphanen, an den Seitenrändern der Flügeldecken in eine schwärzliche Tinte übergeht. Der Clypeus ist sehr niedrig umrandet, schwarz, fein punetirt, in der Mitte etwas erhaben. Sein vorderer Randausschnitt ist ziemlich tief, die Ecken sind abgerundet aber nicht aufgeschwollen. Die Fühlbörner sind schwarz, die Stirn ist matt grün. Der Thorax ist nicht unbeträchtlich gewölbt, breiter als lang, mit etwas hervortretenden Hinter- und Seitenecken. In seiner Mitte befinden sich zwei weisse Punkte, während in jedem vorderen Winkel, unmittelbar hinter dem Auge und neben der Mitte des feinen, wenig erhabenen Seitenrandes, gleichfalls ein weisser Punkt steht. Die Schultern sind vorn mit weissem Filze gerandet. Das Schildchen trägt, gleich wie bei Gl. flavopunctato, an seiner Spitze einen weissen Punkt. Die Flügeldecken verschmälern sich nach hinten nur sehr wenig; sie sind gewölbter wie bei den meisten andern Arten, die Naht erhebt sich kaum etwas über die übrige Fläche und ist kaum sichtbar zugespitzt. Die auf den Flügeldecken der Glycyphana-Arten so gewöhnlichen, von der Schulter nach unten gekrümmt neben einander laufenden Punktreihen, sind bei dieser mit dem blossen Auge kaum sichtbar. Auf jeder Flügeldecke befinden sich drei kleine, punktförmige weisse Flecken, von denen der obere zwi- 
schen der Schulter und dem Schildchen liegt; ausserdem vier grössere, länglichere an dem Aussenrande und endlich ein kleiner Querfleck auf dem unteren Rande neben der Naht. Bei einem der mir vorliegenden Exemplare befinden sich zwischen "diesen grösseren Flecken noch einzelne zerstreute weisse Atome. Das Pygidium ist fast ganz mit grauweissem Filze überzogen, so dass nur in der Mitte eine dreieckige, schwärzlich grüngefärbte Stelle offen bleibt. Der Bauch ist schwarz, glänzend, aufgeschwollen und nach unten hervorragend. Die einzelnen Segmente sind mit weisslichem, etwas in das Rothe spie. lendem Filze bedeckt und zwar in der Weise, dass sie neben der Mitte in ihrer ganzen Breite, weiter seitlich aber nur an ihren hintern Rändern damit überzogen sind. Zugleich sind die Bauchringe punktirt und in den Punkten mit sehr kurzen gelblichen Härchen besetzt. Auch die Mesosternalplatten sind mit solchem Filze überzogen, grubig punktirt und behaart. Der Mesosternalfortsatz ist vorn breit aber abgerundet. Auch der umgeschlagene Theil des Thorax ist filzig. Die Beine sind schwarz, vordere und mittlere Schenkel, so wie mittlere und hintere Schienen mit gelblichem Haarsaum versehen, der besonders an den Vorderschenkeln sehr dicht und lang ist. Die Hinterschenkel haben am Hinterrande einen gelblichen Filzstreifen. Die Vorderschienen sind zweigezähnt, die Füsse kurz und kräftig.

Genus II. Astraea n. gen. Mohnike.

B ar meister bemerkte - Hdb. d. Ent. Bd.III. S. 795 - bei Erwähnung der Cetonia francolina Dup., dass diese so wie die beiden folgenden, nämlich C. felina Gor. et Perch. und C. Rogeri Dup., nicht mit Sicherheit in eine der von ihm aufgestellten Gattungen unterzubringen wären und dass, wie er glaube, alle drei eine eigenc, sich an Glycyphana anschliessende Gattung bilden dürften. Diese Bemerkung ist mit Beziehung auf.C. francolina sehr richtig, weniger aber mit Beziehung auf die beiden anderen Arten, zwischen denen und der francolina keine besondere generelle Uebereinkunft besteht und von welchen 
die eine, C. felina, alle wesentlichen Kennzeichen der Gattung Glycyphana, die andere aber, C. Rogeri, die der Gattung Protaetia trägt, weshalb sie auch diesen Gattungen zugezählt werden. C. francolina dagegen so wie einige andere, derselben äusserst nahe stehende, mir vorliegende Arten, können nicht ohne Zwang einer der bis jetzt aufgestellten. Gattungen eingereiht werden. Ich fasse sie daher als besondere Gattung hier unter dem Namen Astraea zusammen.

Diese Gattung erinnert in ihren allgemeinen Körperverhältnissen zugleich an Macronota und an Glycyphana, wozu besonders der kleine, schon an seiner Basis auffallend schmale, sich nach vorn noch mehr verschmälernde Thorax beiträgt. Derselbe ist an dem Grunde viel schmäler als der Rumpf zwischen den Schultern, schliesst sich demselben sehr fest und genau an, ist flach, an den Hinterecken ziemlich abgerundet und vor dem Schildchen sehr wenig ausgebuchtet. Auch die Flügeldecken sind flach und verschmälern sich gegen die Spitze hin nur sehr wenig. Die Naht ragt hervor und ebenso die mittlere Längsrippe, beide sind aber bei frischen und wohlerhaltenen Exemplaren viel weniger sichtbar wie bei abgeriebenen, wo dieselben mehr oder weniger glänzen. Bei den letzteren kann man auch wahrnehmen, dass der Grund der Flügeldecken, zwischen der Schulter und dem Schildchen, etwas aufgeschwollen, in der Mitte dieser Anschwellung aber vertieft ist und dass die Längsrippe von dem äussern Theile dieser etwas erhabenen Stelle ihren Anfang nimmt. Diese Bildung erinnert in etwas an den Ursprung der Längsrippe aus zwei in einander übergehenden, mehr oder weniger breiten und in einander verschmolzenen, fast immer aber eine kleinere oder grössere, mehr oder weniger vertiefte dreieckige Stelle zwischen sich lassenden Schenkeln auf den Flügeldecken der meisten Macronota-Arten. Ich wiederhole aber, dass dieses Verhältniss bei abgeriebenen Stücken viel sichtbarer als bei frischen, noch vollkommen mit ihrem Sammtüberzuge bedeckten Exemplaren ist. Hinten endigt die Naht in eine feine Spitze. Der Mesosternalfortsatz ist kurz, mit einer 
stumpfen, seitlich nicht erweiterten Spitze versehen. Die Beine sind gewöhnlich; die Vorderschienen unterhalb des Endzahnes bei dem Männchen mit einem, bei dem Weibchen mit zwei Randzähnen versehen, von denen der obere sehr klein und mitunter nur eben angedeutet ist. Auffallend und eigenthümlich sind bei dieser Gattung die sehr langen, häufig bogenförmig gekrimmten inneren Sporen der Hinterschienen. Der Kopf ist nicht sehr gross; der Clypeus seitlich nicht mit einem erhabenen Rande umgeben, wohl aber etwas aufgebogen, vorn stark ausgebuchtet, mit abgerundeten Ecken, in der Mitte beträchtlich erhaben, vor und an den Seiten dieser Erhabenheit vertieft und allenthalben dicht punktirt.

1. Astraea francolina Burmeister Taf. VIII. Fig. 8.

Cetonia francolina Burmeister, Handb. d. Ent. Bd. III. S. 794. - Cet. francolina Wallace, Transact. ent. soc. 3. Ser. Vol.IV. 1868. p. 588. - Glycyphana francolina Gemminger et de Harold, Catal. coleopt. Tom. IV. p. 1310.

A. nigra, supra opaca; clypeo emarginato, nitidiore, densissime punctato; fronte albo-bilineato; thorace antice lineolis quattuor, medio una abbreviatis, basi guttulis duabus albis; scapulis albis; scutello albo-rittato: elytró utroque maculis octo, maioribus quattuor suturalibus minoribus vero quattuor marginalibus, albis; pygidio albo quinque-maculato; subtus nitida; abdomine medio tribus, latere utroque quattuor maculis albis; pectoris lateribus magis minusve albo-maculatis, grosse punctatis, punctis setiferis.

Longitudo

Mm. 14.

Habitat in insulis Samar $\sigma$ \%

Der Clypeus ist glänzender wie bei den andern Arten dieser Gattung, sebr dicht punktirt, vorn tief eingebuchtet, in der Mitte wulstig erhaben, seitlich etwas vertieft. Auf der Stirn zwischen den Augen befinden sich zwei kurze, linienförmige, weisse Flecken. Der Thorax ist wie die ganze obere Fläche sammetartig schwarz; die Punkte auf demselben sind nur unter der Loupe sichtbar. Auf ihm liegen, von den Ecken seines Vorderrandes entspringend, zwei 
kleine, weisse, nach hinten divergirende Längsstriche und ein anderes so geformtes Längsstrichelchen neben der Mitte jedes Seitenrandes; ausserdem eine mittlere, oben wie unten abgekürzte Längsbinde und endlich oberhalb des Schildchens zwei weisse Punkte; die Schultern sind oben ganz mit weissem Filze bedeckt und in der Mitte des Schildchens zeigt sich eine weisse Längsbinde. Auf jeder Flügeldecke acht quere weisse Flecken, vier neben der Naht und ebenso viele neben dem Aussenrande. Die ersteren sind die grösseren. Der oberste von ihnen hat eine schiefe Richtung von aussen und oben nach unten und innen. Die Nahtflecken sind grösser als die am Rande gelegenen. Die hinten mässig zugespitzte Naht und die mittleren Längsrippen erheben sich nur wenig über die Fläche der Flïgeldecken. Auch einige eingerissene, gekrümmte Längslinien und Punktreihen neben der Naht sind mit blossem Auge kaum sichtbar. Das Pygidium bildet ein gleichseitiges, unten abgerundetes Dreieck, ist schwarz, grubig, mit fünf weissen Flecken verziert, von denen die drei grösseren in seinen drei Winkeln, die beiden kleineren aber in der Mitte der Basis liegen. Die Bauchsegmente sind glänzend schwarz, zerstreut grob punktirt, mit drei Flecken in der Mittellinie und vier länglichen Randflecken auf jeder Seite. Auch die Hinterhüften sind weissgefleckt. Die Brustseiten sind grubig, mit Härchen besetzt und neben dem Sternum sowohl als oben, mit weissen Flecken. Auch der umgeschlagene Theil des Vorderrïckens und das Mesosternum an der absteigenden Fläche vor dem Fortsatze, sind weiss. Die Beine sind kräftig, glänzend schwarz, nadelrissig, mit kurzen Härchen besetzt, an den Schenkeln mit weissen Randlinien und ebensolchen Kniepunkten versehen. Vorderschenkel und Hüften länger haarig, mittlere und hintere Schienen mit gelblichem Haarsaume versehen. Die Füsse sind ziemlich lang und kräftig. Bei dem vorliegenden Exemplare, welches ich für ein Männchen halte, ist der äussere Sporn am Tibialende auffallend lang und gebogen wie in der Abbildung. 


\section{Astraea margaritacea n. sp. Mohnike.} Taf. VIII. Fig. 9.

A. nigra; supra opaca, subtus nitida; thorace prope caput punctis minimis lineolisque quattuor, disco punctulis duobus, iuxla scutellum guttis duabus maioribus coeruleo-margaritaceis ornato; scapulis et scutello margaritaceo-maculatis; elytro utroque octo, pygidio tribus, abdomine medio tribus, latere utroque quattuor maculis coeruleo-margaritaceis pictis; coxis posterioribus, mesosterni lateribus, prothoracis parte inferiori margaritaceo-maculatis; processu mesosterni brevi, antice obtuso, non dilatato; femoribus robustis, tibiis apice calcaribus longis munitis.

Longitudo . . . . . . . . . . Mm. 13.

Habitat in insula Mindanao $\sigma$.

Diese Art ist keine blosse Varietät der vorigen und unterscheidet sich von ihr durch den kürzeren, breiteren, seitlich weniger aufgebogenen, nach der Stirn zu sich aber höher erhebenden, weniger glänzenden Clypeus; den kürzeren und robusteren Körperbau im Allgemeinen und die namentlich in den Schenkeln dickeren und kräftigeren Beine. Auch die Zeichnung ist eine andere. Auf dem Thorax befinden sich nämlich in den vorderen Winkeln zwei ganz kleine, kaum sichtbare Punkte; hinter diesen, in einem Halbbogen, vier kurze, aber gleich lange, den Discus nicht erreichende Längslinien; auf dem letzteren wieder zwei Punkte und unterhalb dieser, vor dem Schildchen, zwei grössere runde Flecken. Sie, wie überhaupt alle Flecken, sind bei dieser Art von einem weisslichen, wie Perlmutter schillernden Blau. Die Schultern zeigen an ihrem hinteren Rande und das Schildchen an seiner Spitze solche Flecken. Jede Flügeldecke trägt acht derselben, vier grössere, runde neben der Naht und ebenso viele kleinere längliche neben ihrem äusseren Rande. Die Naht und Längsrippe treten bei dieser Art stärker hervor wie bei der vorigen; im Uebrigen ist die Sculptur der Flügeldecken bei beiden dieselbe. Das Pygidium hat in jeder Ecke einen kleinen Flecken. Der Bauch ist eben wie bei der francolina sculptirt und, die Farbe ab- 
gerechnet, in der Mitte wie an den Seiten gezeichnet. Dasselbe ist mit den Brusttheilen der Fall, nur sind dieselben weniger dicht gegrub̀t und behaart. Der Mesosternalfortsatz ist kurz, vorn breit und stumpf, aber nicht seitlich erweitert, dic Mitte des Sternums bis zu der Spitze des Fortsatzes dicht punktirt und mit kurzen Härchen besetzt. Die Beine, namentlich die Schenkel, sind kräftiger und stärker entwickelt wie bei der vorigen; die letztern mit weissen Randstreifen und Kniepunkten und in dem vorderen und mittleren Paare mit gelblichem Haarsaum. Die Sporen an den Hinterschienen sind sehr lang, die inneren zugleich vorne krumm gebogen.

3. Astraea biguttulata n. sp. Mohnike Taf. IX. Fig. 1.

A. supra nigra, opaca; subtus nigra, nitida; clypeo breviori, latiori, planiori, antice minus emarginato, subnitido, punctato; thorace convexiore, postice latiori, disco albo-bipunctato; scapulis albo marginatis; scutello apice albo-guttato; elytro singulo iuxta suturam quattuor tribusque prope marginem maculis albis ornato; pygidio nigro, immaculato; abdomine medio punctis parvis quattuor, latere utroque maculis duabus albis; coxis posterioribus albomaculatis; pectore medio albo quattuor-punctulato; processu mesosterni brevi, lato.

Longitudo . . . . . . . . . Mm. 15.

Habitat in insula Luzon. $\delta$ \%

Sie ist von den mir vorliegenden Arten dieser Gattung die am meisten schlank gebaute und zugleich diejenige, bei welcher der Thorax hinten am breitesten ist, deshalb bei ihr das für diese Gattung charakteristische Verhältniss der beträchtlichen Schmalheit dieses Theiles zu der Breite des Rumpfes zwischen den Schultern, am wenigsten auffällig erscheint. Der Clypeus ist etwas glänzend, verhältnissmässig kurz, breit, in der Mitte wenig erhaben und vorn nur mässig ausgebuchtet. Er ist allenthalben fein und dicht punktirt. Der Thorax ist, wie schon bemerkt, verhältnissmässig breit, beträchtlich von vorne naeb hinten gewölbt, mit einem feinen, glänzenden, erhabenen Rande umgeben und zeigt auf seinem Discus zwei neben einander ste- 
hende weisse Punkte. Die ganze obere Fläche ist matt, sammetartig, schwarz. Die Schultern sind mit einer weissen hinteren Randeinfassung versehen und das Schildchen zeigt auf seiner Spitze einen ziemlich grossen weissen Fleck. Auf den von der Naht nach dem Rande hin etwas gewölbten Flügeldecken, treten die hinten zugespitzte Naht und die mittlere Rippe, zwischen ihnen aber eingerissene Längslinien deutlich herror. Das Pygidium ist gänzlich ungefleckt. Die ganze Unterseite ist glänzend schwarz; die Seiten der Bauchringe und der Brust sind zerstreut punktirt; die letztere aber ist nicht, wie bei den beiden vorigen Arten, mit Härchen besetzt. Auf dem Bauche befinden sich in der Mittellinie vier weisse Punkte, nämlich zwei auf dem Vorderrande des letzten und zwei auf dem Vorderrande des ersten Segmentes, dic letzteren zwischen den Hüft- und Schenkelgelenken der Hinterbeine; ausserdem auf jeder Seite, auf dem zweiten und dritten Segmente, ein äusserer, weisser Randfleck. Auch die Hinterhüften sind oben weissgefleckt. Auf dem Mittel- und Vorder-Brustbeine befinden sich ebenfalls vier weisse Punkte, zwei zwischen den mittleren Hüftgelenken, neben dem Mesosternalfortsatze und zwei zwischen denselben Gelenken der Vorderbeine. Die Entfernung der beiden Punkte einer jeden Reihe von einander ist bei allen dieselbe. Dex Mesosternalfortsatz ist kurz und vorn breit, aber nicht seitlich erweitert. Auch der umgebogene Theil des Thorax ist weiss gefleckt. Die vorderen und mittleren Schenkel zeigen nur die Andeutung eines Haarsaumes, welcher den mittleren und hinteren Schienen gänzlich feblt. Die Vorderschienen haben einen feinen scharfen Zahn nahe dem Endzahne, die mittleren und hinteren einen stumpfen Zahn an ihrem unteren Dritttheile. Die Sporen an den Hinterbeinen sind bei dieser Art viel weniger lang und nicht gekrümmt wie bei den beiden vorigen.

4. Astraea tigrina a. sp. Mohnike Taf. IX. Fig. 2.

A. supra nigra, opaca; clypeo subnitido, punctato, medio subelevato, antice emarginato; fronte flavo-bivit- 
tato; thorace rittis quinque guttulisque basalibus duabus flavis picto; scapulis flavis; scutello flavo vittato; elytro utroque maculis flavis maioribus octo duplici serie ornato; pygidio flavo quinque-maculato; abdomine lateribus late albo-marginatis; coxis posterioribus, pectorisque lateribus magis minusve albo-maculatis; femoribus flavo-marginatis; tibiis posticis calcaribus longis magis minusve curvatis munitis.

Longitudo

Mm. 14.

Habitat in insulis Luzon et Samar. $\delta$ 우.

Diese Art ist es, auf welche ich mich bezog als ich oben, bei Erwähnung der von Blan $\mathrm{c}$ hard beschriebenen Macronota flavopunctata einen Zweifel aussprach, ob dieselbe wohl wirklich eine Macronota sei und nicht einer andern Gattung angehöre. Seine Beschreibung davon stimmt mit der von mir tigrina genannten Art hinsichtlich der Grösse und Zeichnung in sehr auffallender Weise überein. Wenn ich dessenungeachtct für die vorliegende Art, anstatt sie mit Blan cbard flavopunctata zu nennen, einen anderen Namen wähle, so geschieht solches allein für den Fall, dass ich mich irren möchte, obgleich ich nicht glaube dass solches stattindet. Diese Art hat im Körperbau die meiste Uebereinstimmung mit A. francolina, ist oben matt, unten aber glänzend schwarz. Der Kopfschild ist vorn ziemlich tief ausgebuchtet, wenig glänzend, punktirt, aber in der Mitte weniger erhaben und mit weniger in die Höhe gebogenen Rändern wie bei letztgenannter. Die Ftihlhörner sind schwarz. Von der Stirn verlaufen nach unten zwei goldgelbe Längsbinden. Der Halsschild ist hinten viel schmäler und zugleich von vorn nach hinten weniger convex als bei A. bipunctata. A uf ihm zeigen sich fünf goldgelbe Längsbinden, von denen die mittleren beiden, nach hinten divergirenden, sich bis über den Discus hin verbreitenden, als Fortsetzung der Längsbinden auf dem Kopfe erscheinen. Neben denselben liegen, den unteren Theil des Seitenrandes bedeckend, eine dritte und vierte, so wie endlich in der Mitte zwischen den ersterwähnten eine, sich von dem Discus bis in dieNähe des Hinterrandes erstrek- 
kende kürzere fünfte Längsbinde. An jeder Seite der letzteren, vor, dem Schildchen, liegt ein gelber Fleck. Die Schultern sind ganz gelb und auch das Schildchen hat einen mittleren, von seiner Basis bis zur Spitze reichenden Längsfleck. Auf jeder Flügeldecke befinden sich acht grössere Flecken, vier neben der Naht und ebenso viele neben dem Rande. Der obere jeder Reihe ist länglich und schief von aussen nach innen gerichtet. Die hinten zugespitzte Naht, die Längsrippe, die Sculptur der Flügeldecken verhalten sich wie bei den vorgenannten Arten. Das Pygidium hat, wie A. francolina weisse, ähnliche gelbe Flecken an der Basis und im untern Winkel. Der Bauch ist in der Mitte glänzend schwarz, an den Seiten aber sehr breit mit weisslich gelbem Filze iiberzogen. In dieser Bedeckung zeigen sich an jeder Seite drei längliche, schwarze, unbedeckte Stellen. Die Punktur ist wie bei den andern Arten. Auch die Hinterbüften, das Mesosternum, die Pleura, die untere Seite der Schultern und der umgeschlagene Theil des Thorax sind weisslich gefleckt. Der Mesosternalfortsatz ist kurz und vorn breit, bis zu der Spitze fein punktirt. Die Vorderschenkel sind stark gewimpert; die mittleren und hinteren sind unten und hinten weiss gerandet, haben auch weisse Kniepunkte; die mittleren und hinteren Schienen sind mit einem kurzen, anliegenden Haarsaume versehen. Die Hinterschienen haben bei den meisten der vorliegenden Stücke lange, meistens mehr oder weniger gekrümmte innere Sporen. Eine Varietät dieser Art bilden cinige, anstatt schwarz, schmutzig dunkelgrün gefärbte, mit wenig lebhaften, mehr grünlichen Flecken versehene Exemplare.

\section{Genus III. Euglypta n. gen. Mohnike.}

$\mathrm{W}$ allace hat in seinem Cataloge der Malaiischen Cetoniden eine Cetonia megaspilota beschrieben, dem Gattungsnamen aber ein Fragezeichen beigefügt, als Ausdruck seines $Z_{w}$ eifels, ob diese Art wohl wirklich eine Cetonia sensu strictiori sei. Diese Art so wie drei andere, ihr mehr oder weniger nahestehende, noch unbeschriebene liegen mir vor. Die Bildung derselben ist 
jedenfalls zu eigenthümlich ụnd bietet $z u$ viele, charakteristische Abweichungen von den besonderen Kennzeichen der Gattung Cetonia dar, mit welcher das von Burmeister aufgestellte Genus Protaetia jetzt in der Regel, und zwar mit Recht, wieder vereinigt wird, als dass sie derselben zugezäblt werden dürfte. Ich fasse deshalb diese Arten hier als neue Gattung unter dem Namen Euglypta zusammen, deren hauptsächlichste Merkmale die folgenden sind. Der Clypeus ist auffallend lang und schmal, nimmt auich meistens, nach vorn zu, noch mehr an Breite ab. Er ist vorn tief ausgeschnitten, mit mässig stumpfen Ecken, seitlich entweder glatt oder mit etwas aufgebogenem Rande. Von der Stirn nach vorn verläuft eine ziemlich hohe, anfangs schmälere, später breiter werdende Leiste mit zwei Schenkeln zu den beiden Lappen neben dem Ausschnitte des Clypeusrandes. Neben derselben ist die Fläche des Kopfschildes mehr oder weniger vertieft. Der letztere ist allenthalben grob aber nicht dicht punktirt. Der Thorax ist breiter als lang, hinten und seitlich abgerundet, vor dem Schildchen wenig ausgebuchtet, vorn beträchtlich verschmälert, von hinten nach vorn bedeutend gewölbt. Er ist grob punktirt und wird meistens durch eine sehr schmale, entweder hell gefärbte oder bloss polirte Linie in zwei Hälften getheilt. Das Schildchen ist nicht sehr gross, länger als breit und unten abgestumpft. Die Schultern ragen seitlich stark hervor und ist der Rumpf hier beträchtlich breiter wie der Halsschild zwischen seinen hinteren Winkeln, nimmt aber nach der Spitze der Flügeldecken zu, sehr beträchtlich an Breite ab. Diese Erscheinung ist besonders bei der einen Art sehr auffällig. Die Flügeldecken sind flach, zwischen der nach hinten sich mehr erhebenden und angeschwolleneren, an ihrem Ende mehr oder weniger zugespitzten Naht und der mittleren Längsrippe, vertieft. Die letztere erhebt sich, von dem Seitenabschnitte an, als schwielige Randkante, da neben ihr sich die Flügeldecke in einem scharfen Winkel nach unten umbiegt. Sie begrenzt also die Fläche derselben. Das Pygidium bildet ein gleichseitiges, unten ab- 
gestumpftes Dreieck. Der Bauch ist nach unten und seitlich kräftig entwickelt, bei den Männchen in der Mitte abgeplatteter wie bei den Weibchen. Auch die Brusttheile, besonders das Mesosternum, treten nach unten kräftig hervor. Der Fortsatz des letzteren ist stark und ragt bei dem Weibchen mit stumpfer Spitze nach unten und vorn hervor. Er ist ähnlich gestaltet wie bei Clinteria. Die Beine sind nicht lang aber in allen Theilen kräftig. Die Vorderschienen sind bei beiden Geschlechtern am Aussenrande dreigezähnt.

1. Euglypta megaspilota Wallace. Taf. IX. Fig. 3.

Cetonia megaspilota Wallace, Transact. entom. Soc. 5. Ser. Vol. IV. 1868. p. 587. - Cet. megaspilota Gemminger et de Harold, Catal. Coleopt. Tom. IV., p. 1327.

E. nigra, supra opaca; clypeo longo, angustato, parum nitido, profunde emarginato; thorace convexo, punctato, medio linea, lateribus maculis duabus coerulescentibus opalines ornato; scapulis apiceque scutelli coerulescentibus; elytro utroque maculis septem, pygidio gutta mediana; abdomine pectoreque maculis lateralibus pictis.

Longitudo . . . . . . . . Mm. 16-24.

Habitat in insulis Luzon et Mindanao. $\delta$ ㅇ.

Eine schöne, auffallend kräftig gebaute Art, welehe, was die Grösse betrifft, eine nicht unbeträchliche individuelle Verschiedenheit zeigt. Sie ist schwarz, oben matt, unten in der Mitte glänzend; allenthalben mit grossen, schön hellblauen, iridisirenden Flecken bedeckt. Das Schildchen ist lang, nach vorn schmäler werdend, vorn tief ausgebuchtet, ohne aufgebogene Ränder, wenig dicht und ziemlich grob punktirt. Von der Stirn nach vorn verläuft eine starke Längsschwiele, an deren Seiten sich Vertiefungen befinden. Die Fühlhörner sind schwarz. Der Thorax ist von hinten nach vorn stark gewölbt, mit feinem, erhabenen Seitenrande versehen, an den hinteren Ecken abgerundet, vor dem Schildchen sehr wenig ausgebuchtet. In seiner Mitte verläuft, von seinem Vorderrande bis nicht ganz zu der Basis des Schildchens, eine sehr schmale, hellblaue Längslinie und neben 
derselben, auf jeder Seite ein grüner, dreieckiger flügelförmiger Flecken. An der Stelle der mittleren Linie, wie auf der Abbildung, befinden sich bei einigen Individuen kürzere oder längere, längliche Mittelflecken und auch dic beiden Seitenflecken sind bald grösser bald kleiner. Die Schultern sind ganz und das Schildchen ist entweder in der Mitte oder an seiner unteren Hälfte mit dem hellblauen Ueberzuge bedeckt. Alle genannten Theile sind weitläuftig grob punktirt. Die Flügeldecken sind zwischen der Naht und den stark hervortretenden, schwieligen Längsrippen vertieft und mit eingerissenen, kettenförmigen Längslinien bedeckt, ausserhalb der Rippen dicht und grob punktirt. Die Naht ist hinten stark zugespitzt. Auf jeder Flügeldecke liegen sieben grosse, blaue, schillernde Flecken; einer zwischen Schulter und Schildchen, drei am äusseren Rande und ebenso viele neben der Naht. Die letzteren sind die grösseren. Das P ygidium ist quer nadelrissig und hat einen grünen, etwas ovalen Mittelfleck. Die Mitte des Bauches ist glänzend schwarz; die Seiten der Segmente sind mit dem blauen, schillernden Ueberzuge bedeckt; an ihrem oberen Rande zeigen sie neben einander liegende grobe Punkte. Auch die Hinterhüften haben hinten solche Flecke. Die Brust ist mit Ausnahme des Mesosternums nadelrissig; der Fortsatz desselben stark nach unten und vorn vorragend, an der Spitze abgestumpft. Auch die Unterseite der Schulter, die Pleura und der Hintertheil der Mesosternalplatte sind mehr oder weniger blaugefleckt. Die kräftigen Schenkel und Schienbeine sind punktirt und nadelrissig, die ersteren an den beiden vordersten, die zweiten an den beiden hinteren Paaren gelblich gewimpert.

\section{Euglypta attenuata n. sp. Mohnike Taf. IX. Fig. 4.}

E. inter scapulas latior, elytrorum apice valde attinuata; nigra, supra opaca, subtus nitida; pronoto maculis quattuor, duabus medianis maioribus marginalibus duabus minoribus, albis margaritaceis ornato; scapulis et coxis posticis albo-marginatis; elytro utroque sex, pygidio dua- 
bus, abdomine decem, pectore octo maculis albis margaritaceis pictis.

\section{Longitudo . . . . . . . . . . Mm. 18.}

Habitat in insula Luzon. $\sigma$ q

Eine sehr merkwürdige, sich besonders bei dem Männchen durch die sehr beträchtliche Abnahme des Körpers von den Schultern nach der Spitze der Flügeldecken zu, auszeichnende Art. Sie ist, wie die vorige, schwarz, aber matt, unten glänzend und gleichfalls mit hellfarbigen Flecken bedeckt. Der Clypeus ist verhältnissmässig nicht ganz so lang und schmal wie bei der megaspilota, sehr viel glänzender, feiner punktirt und seine mittlere, schwielige Längserhebung anders gestaltet. Neben derselben zeigen sich keine längliche vertiefte Stellen; die Seitenränder und die Ecken neben dem vorderen Randausschnitte sind mehr aufgebogen. Die Stirn ist matt schwarz; die Fühlhörner sind wie bei der vorigen schwarz. Der Thorax ist beträchtlich schmäler als der Rumpf zwischen den Schultern, an den hintern Ecken und den Seiten abgerundet, vor dem Schildchen kaum ausgcbuchtet, mit einem sehr feinen, glänzenden, wenig erhabenen Seitenrande versehen. $\mathrm{Er}$ ist in seiner ganzen Ausbreitung fein aber zerstreut punktirt. Seine Wölbung von hinten nach vorn ist nicht ganz so beträchtlich wie bei der vorigen. Ueber seine Mitte läuft bei dem Männchen des mir vorliegenden Paares, eine sehr feine, polirte Längslinie von dem Kopfe bis zur Basis des Schildchens. Neben derselben, auf jeder Seite, in der Mitte des Discus, liegt ein runder, weisser, perlmutterartig schillernder Fleck und etwas höher, neben dem Rande, ein zweiter, kleinerer, mehr länglicher. Die Schultern sind glänzend und baben einen hintern weissen Rand. Das Schildchen ist bei dem Männchen oben glänzend und durch eine glänzende Längslinie in zwei mattschwarze Hälften getheilt, bei dem Weibchen ganz mattschwarz. Die Flügeldecken verschmälern sich, wie schon bemerkt, von den Schultern nach der Spitze zu, sehr beträchtlich, bei dem Männchen noch mehr wie bei dem Weibchen, sind aber zwischen der Naht und der Mittelrippe nicht 
ganz so vertieft wie bei der vorigen und in der Vertiefung mit einfachen, eingerissenen Längsstrichen, nicht mit Kettenlinien versehen. Die Naht ist hinten etwas weniger zugespitzt. Auf jeder Flügeldecke befinden sich sechs grosse, weisse, schillernde Flecken; ein schief von aussen nach innen gerichteter neben dem Schildchen, zwei neben der Naht, ein querer oberhalb der Spitze und zwei runde neben dem Rande. Auf dem Pygidium befindet sich in jeder Ecke des Grundes ein weisser Fleck. Die Unterseite und die Beine sind sehr glänzend schwarz, weniger punktirt und nadelrissig wie bei der vorigen. Auf den beiden vorderen Bauchringen liegen auf jeder Seite je zwei weisse Flecken, einer neben ihrer Mitte, einer neben ihrem Ende und zwei andere, mehr in der Form eines Querstreifens, neben der Mitte des letzten Bauchringes. Auf der Brust zeigen sich auf jeder Seite der Mesosternalplatte drei weisse Flecken und ein vierter auf der Pleura. Der Mesosternalfortsatz des Weibchens ist, wie bei der vorigen Art, sehr kräftig entwickelt, nach vorn wie nach unten hervortretend. Bei dem Männchen ist er schwächer, kürzer und mit seiner Spitze mehr horizontal gelegen. Die Beine zeigen keine Abweichung von denen der vorigen.

3. E. biplagiata n. sp. Mohnike Taf. IX. Fig. 5.

E. nigra, supra opaca; clypeo antice emarginato, angulis crassioribus, rotundatis, medio elevato, punctato; antennis nigris; thorace marginato, undique scrobiculato, flavo-aurantiaco biplagiato; scapulis flavis; scutello apice flavo-maculato; elytris punctato-striatis, sutura parum prominente, subacuminata, utroque maculis flavo-aurantiacis octo, una iusta scutelli basin, quattuor iuxta suturam, tribus prope marginem, picto; pygidio lateribus flavis; subtus nitida; abdominis pectorisque lateribus punctatis, fomento flavo-aurantiaco dense obtectis; processu mesosterni parum prominente, apice obtuso, incrassato; pedibus nigris, nitidis, striolatis, punctatis.

Longitudo . . . . . . . . . Mm. 20.

Habitat in insula Isabela Archipelagi Sulu. $\delta$. 
Diese Art und die folgende bilden den Uebergang der Gattung Euglypta zu Cetonia und treten deshalb die als charakteristisch für erstere bezeichneten Eigenthümlichkeiten bei ihnen nicht mehr so deutlich hervor, wie bei den beiden vorigen Arten. Der Clypeus ist verhältnissmässig breiter, nicht umrandet, vorn tief ausgebuchtet, mit stumpfen, etwas angeschwollenen Ecken, in der Mitte mässig erhaben, allenthalben ziemlich grob punktirt. Der Thorax ist nicht ganz so schmal wie bei der vorigen, aber doch beträchtlich schmäler wie der Rumpf zwischen den Schultern, hinten bogig geschweift, vor dem Schildchen kaum ausgebuchtet, mit feinem, wenig erhabenem Seitenrande, in seiner ganzen Ansbreitung narbig punktirt. In seiner Mitte zeigt sich die Andeutung einer sehr schmalen, glänzenden Längslinie und auf jeder Seite derselben ein grosser ovaler, gelblich orangefarbener Längsfleck. Zwischen ihnen, in der Mittellinie, unmittelbar vor dem Schildchen, befindet sich noch ein gelber Fleck. Die Schultern und die untere Hälfte des Scutellum sind mit gelbem Filze überzogen. Die Flügeldecken verschmälern sich nach hinten nicht in dem Masse wie bei den beiden vorigen Arten, fallen auch nicht ganz so schroff nach den Seiten ab, wegen ihrer weniger scharf hervorragenden Mittelrippe. Sie sind allenthalben mit sehr deutlichen, dicht neben einander liegenden Längsreihen eingestochener Punkte bedeckt. Die Naht ragt nicht sehr hervor und ist nur wenig zugespitzt. Auf jeder Flügeldecke befinden sich acht orangegelbe Flecke; ein schief von aussen und oben nach unten und innen gerichteter neben der Basis des Schildchens; ein zweiter runder unterhalb desselben, etwas von der Naht entfernt, und drei andere neben letzterer. Der unterste von ihnen ist ein querer und liegt auf dem Rande der Flügeldeckenspitze. Auf dem dreieckigen, dicht punktirten Pygidium lassen zwei grosse, seitliche, gelbe Filzflecke nur einen schmalen mittleren Streifen und die Spitze unbedeckt. Die Mitte des Bauches und der Brust ist sehr glänzend ' und glatt, die Seiten dieser Theile aber sind sehr deutlich grob. punktirt und dicht mit gelblichem Filze be- 
deckt. Auch die Hinterhüfte hat einen solchen Ueberzug. Der Mesosternalfortsatz ist nicht ganz so kräftig und stark wie bei den vorigen Arten, ragt weniger nach unten und vorn hervor und hat eine stumpfe, etwas angeschwollene Spitze. Die Schenkel und Schienen sind kräftig, glänzend schwarz, grob punktirt. Die Vorderschienen haben oberhalb des Endzahnes zwei Randzähne, von denen der oberste aber sehr schwach ist.

\section{Euglypta multoguttata n. sp. Mohnike.}

E. nigra, supra opaca; clypeo emarginato, medio parum elevato, punctato; thorace angulis rotundato, subconvexo, ante scutellum vix sinuato, grosse punctato, guttis tribus albo-flavescentibus ornato; scutello apice albo guttato; elytris dense punctato-striatis, sutura vix prominente non acuminata, in utroque guttae novem albo-flavescentes; pygidio toto tomento fulvo-rufescento obtecto; subtus nitida; abdominis pectorisque latera punctata, aciculata, tomento flavo-rufescente dense inducta; pedibus robustioribus, nitidis; femoribus tibiisque punctatis; tibiis anterioribus tridentatis.

Longitudo . . . . . . . . . . . Mm. 16.

Habitat in insula Mindanao. $\delta$.

Diese Art ist kleiner als die vorige, steht ihr aber, was Gestalt und Körperbau betrifft, sehr nahe. Der Clypeus ist ziemlich breit, niedrig umrandet, in der Mitte nur wenig erhaben, vorn tief eingeschnitten mit stumpfen Ecken, dicht aber eben nicht fein punktirt. Die Fühlhörner sind schwarz. Der Thorax ist hinten gebogen, vor dem Schildehen nicht ausgebuchtet, an den Seiten niedrig umrandet, mit hinteren abgerundeten Ecken. Er ist allenthalben dicht und grob punktirt. In seiner Mitte zeigt sich die Spur einer geglätteten Längslinie und zu jeder Seite derselben ein kleiner, ovaler, schmutzig gelblich weisser Fleck. Ein dritter, kleinerer, runder Fleck liegt vor dem Schildchen. Die Schultern sind bei dem einzigen mir vorliegenden Exemplar ungefleckt, vielleicht aber abgerieben. Die Spitze des Schildchens trägt einen 
ovalen Flecken. Die Flügeldecken verschmälern sich, gleich wie bei der vorigen Art, nach ihrer Spitze zu weniger wie bei der megaspilota und attenuata, fallen auch nicht in dem Masse schroff nach den Seiten zu ab, wie bei den letztgenannten Arten. Die mittlere Rippe und die hinten kaum zugespitzte Naht ragen wenig hervor. Gleich wie bei der vorigen Art sind sie mit sehr deutlich sichtbaren Punktreihen dicht bedeckt. Auf jeder Fliigeldecke liegen neun weisslich gelbe Flecke, einer neben der Basis des Schildchens, vier andere unterhalb desselben neben der Naht, von denen der letzte neben der Nahtspitze gelegene ein grosser ist; und vier an dem äusseren Rande. Das Pygidium ist gänzlich mit schmutzig röthlichgelbem Filze ïberzogen. Dic Seiten des Bauches und der Brust baben eine ähnliche breite Decke und sind, wie bei der vorigen Art, dicht punktirt, während ihre Mitte glänzend schwarz ist. Die Beine sind kräftig; Schenkel und Schienen punktirt, die letzteren an den Vorderbeinen erweitert und an dem Rande mit drei Zähnen besetzt, von denen der mittlere der hervorragendste. Der Mesosternalfortsatz ist wie bei der vorigen Art, ragt wenig nach vorne und unten hervor und hat eine stumpfe, etwas angeschwollene Spitze.

Genus IV. Cetonia Fabricius.

Fabr. System. Entomolog. p. 52.

1. Cetonia mandarinea Weber.

Cetonia mandarinea Weber, Observ. entom. p. 68. Cet. atomaria Fabr. Syst. Eleuth. Tom. II. p. 153. - Cet. atomaria Gory et Percheron. Monogr. d. Cét. p. 204. pl. 57. fig. 3. - Protaetia mandarinea Burmeister, Handb. d. Entom. Bd. III. S. 481. - Cet. fictilis Newman, Entom. Magaz. V. p. 169. - Cet. mandarinea Wallace, Transact. entom. Soc. 3. Ser. IV. 1868. p. 584. - Cet. mandarinea Gemminger et de Harold, Catal. Coleopt. Tom. IV. p. 1327. - Prot. mandarinea Mohnike, Uebers. d. Ceton. S. 78 .

C. supra fusco-viridis opaca, subtus fusco-aenea nitida; 
pronoti limbo postico elytrorumque carinis aliquid rufescentibus; capite, pronoto, scapulis, scutello, elytris, pygidio, abdominis pectorisque lateribus, femoribus ac tibiis griseosquamosis et variegatis.

Longitudo . . . . . . . . . Mm. 15-16.

Habitat in insula Luzon. $\delta$ \%

Ich finde $z$ wischen den mir vorliegenden vier Exemplaren dieser Art von Luzon und den zahlreichen, von mir auf Amboina, Celebes, Borneo, Java und Sumatra, wo dieselbe stellenweise ausserordentlich gemein ist, ge sammelten Stücken selbst nicht eine zureichende Verschiedenheit, um die ersteren als topische Varietät dieser weitverbreiteten Art ansehen zu können. Der Clypeus ist klein, viereckig, erhaben umrandet, vorn mässig eingebuchtet, mit breiten Ecken, grob punktirt, broncefarbig mit grünem Anfluge, etwas glänzend; die Stirn mit kurzer, leistenförmiger mittlerer Anschwellung, punktirt, in den Punkten mit gelblich grauen, kurzen Härchen besetzt. Der Thorax ist bräunlich grün, matt, mit feinem glänzenden Rande, vorn und an den Seiten, bis über die Mitte, mehr oder weniger dicht mit Punkten übersät, in denen sich kleine, gelblichgraue Schuppen befinden. Frei von denselben ist ein mittlerer Streifen und der Raum vor dem Schildchen. Auch auf den Schultern und dem Schildchen, neben den Seitenrändern des letzteren, befinden sich solche Punkte und Schuppen. Die Flügeldecken haben die Farbe des Brustschildes. Wie auf diesem nicht selten der Hintertheil, so zeigen auf jenen die Naht und die Längsrippen meistens einen mehr oder weniger röthlichen Anflug. Die Flügeldecken nehmen nach der Spitze zu nur wenig an Breite ab; die Naht erhebt sich, nach hinten zu, ziemlich beträchtlich und ist stark zugespitzt. Auch die Flügeldecken sind allenthalben, in der Mitte mehr zerstreut, in der Nähe des Randes dichter punktirt und geschuppt. Unmittelbar hinter dem Seitenausschnitte, oberhalb des zweiten und dritten Bauchsegmentes und neben der Spitze, findet eine dichtere Anhäufung der Schuppen statt, wodurch auf jeder Flügeldecke zwei breite, gekrümmte, seitliche, halbe Querbinden und 
eine dritte hintere, den Raum zwischen dem Hinterbuckel nnd der Naht ausfüllende, gebildet wird. Das Pygidium ist allenthalben, am meisten aber seitlich, punktirt und beschuppt. Die Unterseite ist bronzefarben, glänzend. Die Bauchringe sind, in ihrer ganzen Ausbreitung, an dem oberen Rande mit Härchen tragenden Schuppen besetzt. Ausserdem befinden sich auf jedem ron ihnen, neben der Mitte, zwei grössere, dichte, gelblichgraue Filzflecke. Das Sternum ist durchaus glatt und glänzend. Dagegen aber sind der umgeschlagene Theil des Thorax, die Schultern, die Mesosternalplatte, die Pleura und Parapleura so wie die Hinterhüften dicht grob punktirt und in den Vertiefungen mit längeren Schuppen besetzt. Der Mesosternalfortsatz ist kurz, stumpf, seitlich nicht unbeträchtlich erweitert. Die Beine sind kurz aber kräftig; Schenkel und Schienen sind dicht punktirt und gelbgrau geschuppt. Die ersteren haben gelblichgraue Kniepunkte und sind, so wie auch die mittleren und hinteren Schienen, dicht gewimpert. Bei den letzteren zeigt sich auch auf dem äusseren Rande, unmittelbar hinter dem mittleren Zahne, ein kleiner, dichter, gelblichgraver Haarfleck. - Diese Art variirt hinsichtlich der stärkeren oder geringeren Beschuppung, namentlich an der Unterseite, beträchtlich. So sind z. B. die erwähnten mittleren Flecken der Bauchringe bei einigen Stücken nur eben angedeutet.

\section{Cetonia arrogans Wallace.}

Cetonia arrogans Wallace, Transact. entom. Soc. 3. Ser. IV. 1868. p. 584. - Cet. arrogans Gemminger et de Harold, Catal. coleopt. Tom. IV. p. 1321.

${ }_{n}$ C. mandarineae similis, sed thorace maculis parvis rotundatis fulvis; elytris ad suturam minus spinosis; subtus rufo-maculata et pilis rufis vestita.

Very near $C$. mandarinea, yet looking very distinct; also near $C$. intricata, Saund. Above, deep brown; clypens quadrate, punctate, rather wider than in $C$. mandarinea; thorax with about sixteen small roundish fulvous spots; elytra with numerous small spots grouped in two irregular curved bands, the apex slightly spined at the suture; 
beneath coppery or coppery black, the sides more or less marked with rufous and much clothed with rufous hairs; the sternal process moderately dilated. - Length 7 lines.

Hab. Phillippine Islands. " Wallace.

Ich kenne diese Art nicht, glaube aber, dass sie der folgenden, obwohl speciell von ihr verschieden, doch sehr mahestehend ist.

3. Cetonia mutoguttulata n. sp. Mohnike. Taf. IX. Fig. 6.

C. supra brunnea opaca; clypeo quadrato, non emarginato, medio modice elevato, dense punctato; antennis brunneis; thorace decem guttulis flavis ornato; elytris longioribus apice parum attenuatis, singulo guttulis aut maculis decem vel undecim flavis signatis; pygidio flavobipunctato; subtus brunneo-rufescens; abdomine pectoreque magis minusve flavo-maculatis; pedibus rufescentibus, genubus flavo-punctatis.

Longitudo . . . . . . . . . . . Mm. 16.

Habitat in insula Luzon. \&.

Diese Art zeichnet sich durch einen schlanken langgestreckten Körperbau aus und erinnert hierdurch an die Gestalt der meisten Glycyphana-Arten. Sie ist oben lebhaft braun und, mit Ausnahme der Kopfläche, matt, unten gleichfalls braun, aber dunkler, mit einem starken röthlichen Anfluge, welcher letztere an den Beinen noch stärker hervortritt, so dass dieselben beinahe kirschroth erscheinen. Der Clypeus ist viereckig, umrandet, vorn nicht eingebuchtet, mässig glänzend, dicht punktirt, in der Mitte erhaben. Die Flügeldecken sind braun. Der Thorax ist vor dem Schildchen ein wenig ausgebuchtet und zeigt nur eine geringe Abrundung seiner hinteren Ecken. Auf ihm befinden sich acht oder zehn gelbe, runde Flecken. Im letzteren Falle zeigen sich auf jeder Seite einer in dem Augenwinkel dicht an dem vorderen Rande, und unterhalb desselben vier andere, von denen einer in der Nähe des Seitenrandes, die ütrigen aber mehr nach der Mitte zu gelegen sind. Die letztere selbst ist durchaus frei von Flecken. Das Schildchen ist ziemlich gross, unten ab- 
gestumpft und ungefleckt. Die Schultern haben hinten einen gelben Rand. Die Flügeldecken sind lang, hinten wenig verschmälert, mit mässig hervorragender, nicht zugespitzter Naht, abgerundeten Hinterecken und kurzen, nur ihr hinteres Dritttheil einnehmenden Längsrippen. Auf jeder von ihnen zeigen sich eilf kleine, theils runde, theils länglichere Flecken. Ein sehr kleiner liegt unter der Spitze des Schildchens, dicht neben der Naht ; ftinf liegen neben dem seitlichen und unteren Rande und fünf andere zwischen dem Seitenrande und der Naht. Das Pygidium ist fein und quer nadelrissig; hat auf jeder Seite einen gelben Fleck. Die Bauchringe sind seitlich zerstreut punktirt und in den Punkten mit feinen, gelblichen Härchen besetzt. Auf den vier letzten von ihnen zeigen sich auf jeder Seite zwei gelbliche Punkte, von denen der eine oben an seinem Flügeldeckenrande, der andere neben seiner Mitte steht. Auch die Seiten der Brust sind zerstreut grob punktirt, in den Vertiefungen mit Härchen besetzt und zeigen auf jeder Seite, in der Mitte vor dem Hüftgelenke, im hinteren oberen Winkel der Mesosternalplatte, auf der Pleura so wie auf dem umgeschlagenen Theile des Thorax gelbliche Flecken. Der Mesosternalfortsatz ist kurz, nach vorn wie nach den Seiten etwas erweitert aber abgerundet. Die Beine sind ziemlich lang aber kräftig, Schenkel und Schienen sind kirschbraun, etwas metallisch glänzend, sehr zerstreut punktirt und nadelrissig, in den Vertiefungen mit feinen und kurzen, anliegenden, röthlichen Härchen besetzt. Die Schenkel haben gelblichweisse Kniepunkte und die hinteren ausserdem noch an ihrer Unterseite, neben dem Kniegelenke, einen hinteren Randflecken. Die mittleren und hinteren Schienen sind gelblich gewimpert, die vorderen haben drei äussere Randzähne.

4. Cetonia coeruleo-signata n. sp. Mohnike. Taf. IX. Fig. 7.

C. nigra, supra opaca, subtus subnitida; clypeo marginato, antice non sinuato, angulis rotundatis, opaco, dense subtiliter punctato, medio elevato; thorace subconvexo, 
prope margines laterales punctato, disco coeruleo-bipunctato; scutello triangulari; elytris convexis, apice parum attenuatis, rotundatis, lateribus punctatis, sutura prominente, postice valde acuminata, carina mediana humili; in utroque elytro maculae coerulescentes quinque, una inter scutellum atque humerum, duo maiores marginales, totidemque, quarum una duplicata, suturales. Pygidium, abdomen, pectus, pedes nigra immaculata; processus mesosterni brevis apice dilatato.

Longitudo . . . . . . . . . . Mm. 20.

Habitat in insula Mindanao. $\sigma$.

Diese Art hat in der Gestalt viele Aehnlichkeit mit C. viridis, ist aber nicht ganz so breit und oben gewölbter. Sie ist tiefschwarz, oben sammetartig matt, unten glänzender. Der Clypeus ist viereckig, erhaben gerandet, mit etwas abgerundeten vorderen Ecken, vorn nicht eingebuchtet, mit sich weit nach unten erstreckender aber nicht sehr hoher mittlerer Schwiele, dicht punktirt und nicht glänzend. Die Fühlhörner sind schwarz. Der Thorax ist ziemlich kurz, hinten nur wenig schmäler als der Rumpf zwischen den Schultern, ziemlich gewölbt, neben den feinen, etwas erhabenen Seitenrändern bis fast zur Mitte hin weitläuftig punktirt. Wo die Punktur beider Seiten aufhört, befinden sich, neben einanderstehend, zwei punktähnliche Flecken von hellblauer, etwas in das Graue failender Farbe. Die Schultern und das grosse, dreieckige, unten ziemlich stumpfe Schildchen sind ungefleckt. Die Flügeldecken verschmälern sich nach hinten nur wenig; ihre Spitzen sind abgerundet, sie selbst ziemlich gewölbt, mit nicht stark hervortretender Längsrippe. Die Nabt ragt stärker hervor und ist hinten beträchtlich zugespitzt. Auf jeder Flügeldecke befinden sich fünf hellblaugraue Flecken. Ein kleinerer, runder zwischen der Schulter und der Mitte des Schildchens; unter diesem zwei längliche, etwas von oben nach unten gerichtete seitliche Randflecke, von denen der oberste aus zwei neben einander stehenden Punkten zusammengestellt ist. Die Seiten der Flügeldecken sind ziemlich grob und weitläuftig punktirt. Das Pygidium ist ungefleckt und fein 
quer nadelrissig. Bauch und Brust sind gleichfalls ungefleckt, seitlich bis zur Mitte hin punktirt und nadelrissig, mässig glänzend. Der Mesosternalfortsatz ist kurz, vorn abgerundet und seitlich erweitert. Die Beine sind wenig lang, kräftig, wenig glänzend und einfach schwarz. Die Vorderschienen sind dreigezähnt, die mittleren und hinteren innen sehwärzlich gewimpert.

\section{Cetonia irrorata Wallace.}

Cetonia irrorata Wallace, Transact. entom. Soc. 5. Ser. Vol. IV. 1868. p. 588. - C. irrorata Gemminger et de Harold Catal. coleopt. Tom. IV. p. 1326.

"Nigra nitida, subconvexa, grosse punctata, lateribus albo irroratis; elytris sinuatis apice truncatis; subtus corpore et femoribus pilis albis vestitis.

Black, shining, sub-convex; clypeus short, with two upturned teeth in front, wide apart; thorax convex, coarsely punctate, the sides broadly irrorated with white; scutellum subtriangular, smooth, with a few punctures at the basal angles; elytra rugosely punctate, and with faint elevated ridges, dotted and irrorated with white more densely towards the margins, the apex truncate; pygidium irrorated with white at the sides; beneath, a white spot at the lower angles of each abdominal segment; the thighs, thorax and body clothed with white hairs; anterior tibiae with two strong teeth below the apex; the sternal process abruptly dilated at the end. Length 7 Lines. Habit. Philippine Islands (Coll. Parry).

This insect appears to have some of the charakters of the African genus Diplognatha, and it will probably form a new genus between it and true Cetonia. (It is the Aenopoptochilu's, White, MS.) I refrain, however, from forming new genera, without a more complete knowledge of the whole family." Wallace.

Ich kenne diese Art eben so wenig als die nachfolgende.

\section{Cetonia procera White.}

Protaetia procera White, Proceedings zool. Soc. London 1856. p. 17. tab. XLI, fig. 6. - Cetonia procera 
Wallace, Transact. entom. Soc. 3. Ser. Vol. IV. 1868. p. 580. - C. procera Gemminger et de Harold, Catal. coleopt. Tom. IV. p. 1328.

"Supra viridi-subsericea, poroso-punctata, albido paululum submaculata in elytris praesertim, elytris apice spinoso-productis; subtus laete metallico-viridis, abdomine plagis 16 albo-pilosis in quattuor ordinibus dispositis.

In size between $\mathrm{P}$. ferruginea and $\mathrm{P}$. regalis; above, including upperside of legs, it is of a fine dull, dark velvety green, which, when rubbed, displays beneath a metallic base, as in many of the Cetonidae, such as Goliathus torquatus; the edges of the nasus are metallic. The head and thorax above are thickly and distinctly poroso-punctate; there is an indication of a gellowishwhite dot near each front angle of the thorax (which dot may vary in size in other specimens); the elytra have four dots passing into short transverse streaks on each side, and a small spot near the suture, about the middle, and a short white streak midway between the middle and the spine; three dots between that and the spine, which is longer and much more distinct than on the sides of elytra, transversely pitted in many shallow short waves; general surface punctured, the punctures chiefly in striae. Head small, slightly ridged on sides in front of eyes, slightly narrower in front and rather deeply grooved behind front margin. Under side and legs metallic green, femora and mesothorax acuducted, the latter with two or three patches of isabella pile; abdomen irregularly punctured, smooth, with eight transverse patches of isabella pile on each side in double columns. Hairs on tibiae rufous; fore edge of front tibiae and tarsi of all the legs metallic green. Habit. Philippine Islands (Coll. Cumming). NB. The figures are of the nature size. This is alluded to in Dr. Schaum's second liste of Cetonidae, and is quoted under the above name." White.

\section{Cetonia bifenestrata Chevrolat.}

Cetonia bifenestrata Cherrolat, Guérin Rev. Zool. IV. 1841. p. 223. - Protaetia befenestrata Burmeister, Handb. 
d. Entom. Bd. III S. 492. - Cet. gemella Newman, The Entomologist 1841. art. XXXIX. p. 171. - Cet. indra Hope, Proceed. entom: Soc. 1841. p. 33; Annal. natur. Hist. VIII. 1841. p. 303; Transact. entom. Soc. III. 1843. p. 281. Cet. bifenestrata Wallace, Transact. entom. Soc. 3. Ser. Vol. IV. 1868. p. 579. - Cet. bifenestrata Gemminger et de Harold, Catal. coleopt. Tom. IV. p. 1322.

C. inter huius generis statura maximas, supra aut brunnea aut fuliginoso-purpurea velutina; clypeo quadrato, margine antico profunde sinuuto, reflexo, dense punctato, opaco, medio non carinato-elevato; thorace plano, corpore angustiore, ante scutellum sinuato, angulis posticis subacutis; scutello subtriangulari; hoc et scapulis immaculatis; elytris planis, apice vix attenuatis, subrotundatis, utroque medio iuxta suturam macula magna subquadrata flaro-aurea, aliisque maculis minoribus, suturalibus aut marginalibus magis minusve ornato; sutura callosa, prominente, postice valde producta, acutissima, carina mediana humiliore; gibbis posterioribus prominentibus; pygidio subtiliter transverse striolato, aut brunneo flavo-bivittato, aut flavo brunneo-vittato; subtus fuliginoso-purpurea sive brunnea, nitidissima, abdominis pectorisque lateribus et punctatis et foveolatis, tomento flavo-aureo magis minusve densius vestitis; processu mesosterni brevi, apice rotundato, vix dilatato; pedibus longis, fortibus, nitidis, purpurescentibus, femoribus tibiisque distanter punctatis, femoribus anterioribus mediisque, tibiis mediis et posterioribus, rufo-fimbriatis, tibiis anterioribus bidentatis.

Longitudo . . . . . . . . Mm. 25-30.

Habitat in insula Luzon. $\sigma$ "오.

Von dieser grossen und schönen Art giebt es hellere, einfach braun gefärbte Individuen, während bei anderen und, wie es mir wahrscheinlich vorkommt, den meisten, die braune Grundfarbe viel dunkler ist und einen Anflug von Purpur besitzt. Sie ist oben gänzlich sammetartig matt, unten aber und an den Beinen, mit Ausnahme der helleren, mit Filz überzogenen Stellen, stark glänzend. Der Clypeus ist viereckig, erhaben gerandet, vorn tief eingeschnitten, mit abgerundeten und aufgeboge- 
nen Ecken neben dem Einschnitte. Er ist flach sammetartig, matt, braun, dicht punktirt, ohne mittlere leistenförmige Erhebung. Der Prothorax ist schmäler wie der Rumpf zwischen den Schultern, ziemlich flach, vor dem Schildchen mässig ausgebuchtet, mit vorspringenden aber abgerundeten Schulterecken. Er ist allein seitlich sparsam punktirt. Bei einigen Exemplaren findet sich neben dem erhabenen Seitenrande des Thorax, von seinen Kopfecken ausgehend, in längerer oder kürzerer Ausdebnung die Spur einer gelblichen, filzigen, inneren Randeinfassung. Die Schultern und das fast dreieckige Schildchen sind matt, braun und ungefleckt. Die Flügeldecken verschmälern sich, von dem Seitenausschnitte an bis zu ihrer Spitze, kaum; ihre äusseren, unteren Winkel sind abgerundet. Sie sind flach und zwischen ibren mittleren Längsrippen und der Naht beträchtlich vertieft. Die letztere ist aufgeschwollen, vorragend, breit und an ihrem Ende sehr scharf und lang zugespitzt. Auf jeder Flügeldecke befindet sich ungefähr in ihrer Mitte, zu Anfang der Vertiefungen, unmittelbar neben der Naht, ein grosser, unregelmässig viereckiger, bald hellerer, bald dunklerer, häufig lebhaft goldgelb gefärbter Filzfleck. Bei einigen Exemplaren liegt in der Mitte zwischen dịesem grossen Flecken und der Spitze, ebenfalls dicht neben der Naht, noch ein viel kleinerer, meistens länglich gestalteter. Ausserdem befinden sich auf jeder Flügeldecke noch zwei grössere oder kleinere Randflecke, der erste zwischen den beiden Nahtflecken, der andere unterhalb des Nahtbuckels gelegen. Das Pygidium ist fein quer gestrichelt und entweder ganz mit gelbem Filze überzogen, so dass nur eine braune mittlere Längsbinde übrig bleibt, oder dasselbe ist braun mit zwei gelben Längsbinden. Wie Burmeister das Pygidium dieser Art beschreibt, nämlich dass dasselbe bei den Weibchen ungefleckt, bei den Männchen aber mit je drei goldfarbenen Flecken an den Seitenecken verziert sei, von denen die beiden inneren sich gewöhnlich zu einem Winkel verbänden, habe ich es bei den von mir untersuchten Exemplaren nicht gefunden. Die Unterseite ist von der 
Farbe des Thorax und der Flügeldecken, bald heller, bald dunkler braun, bald sehr glänzend. Die Bauchringe sind seitlich zerstreut punktirt und daselbst entweder mit einer sehr breiten, zusammenhängenden Decke von gelbem Filze überzogen, oder aber auf jedem Segmente befinden sich jederseits ein vorderer grösserer, ovaler und ein hinterer, kleinerer, mehr runder Filzfleck. Auch die Hinterhüfte ist grösstentheils mit solchem Filze überzogen. Das Sternum ist glänzend braun, der Fortsatz des Mesosternum ist nicht sehr gross, gerundet, seitlich kaum erweitert. Die Pleura, Parapleura, die Mesosternalplatte, die Unterfläche des Schulterstückes und der umgeschlagene Theil des Prothorax sind gleichfalls, bald mehr bald weniger, mit gelbem Filze bedeckt. Die Beine sind lang und kräftig. Die Vorderschienen haben bei dem Männchen dicht vor dem Endzahne eine kleine Spitze; die Schenkel häufig einen gelben Längsstreifen; immer ha. ben sie gelbe Kniepunkte. Die vorderen und mittlern Schenkel so wie die mittleren und hinteren Schienen sind röthlich gewimpert. Schenkel und Schienen sind bei den dunkleren Stücken häufig dunkel purpurfarben, bei den helleren grünlich metallisch glänzend. Die Tarsalglieder sind verhältnissmässig kurz und haben an den Gelenken Haarbüschel.

\section{Cetonia dubia Wallace.}

Cetonia dubia Wallace, Transact. entom. Soc. 3. Ser. Vol. IV. 1868. p. 582. - Cet. dubia Gemminger et de Harold, Catal. coleopt. Tom. IV. p. 1323.

„Plana, depressa, lateribus angulatis supra olivaceocuprea, subtus cupreo-aenea; thorace elytrisque albo-inaculatis; processu sternali non dilatato, incurvato.

Above, coppery-olive; clypeus punctate, the anterior margin recurved and notched; thorax subtriangular, punctate, with two linear marks and several spots whitish; scutellum elongate, triangular, with a white band at the base; elytra flat, subquadrate, the sides angular, with numerous irregular spots and linear markings; pygidium white marked; beneath, bronzy green or coppery, the 
sides more or less covered with a whitish crust; the sternal process straight, not dilated at the end, incurved in the (?) female. Lenght 8-10 lines. Hab. Philippine-Islands (B. M.) - A curious species, much resembling C. Bremii, but at once distinguished by its flatter elytra and simple sternal process. Two specimens in the British Museum differ somewhat in the form of the sternal process which may be a sexual difference, as they are otherwise very much alike. This makes some approach to my genus Sternoplus." Wallace.

Ich kenne diese Art nicht und würde sie für eine Varietät der folgenden halten, erwähnte W all a c e nicht so ausdrücklicb, dass sie durch die eigenthümliche Form ihres Mesosternalfortsatzes sich der bis jetzt einzigen Art einer anderen Gattung, nämlich Sternoplus (Cetonia; Protaetia) Schaumii, White, von Celebes anschliesse.

\section{Cetonia ferruginea Eschscholtz.}

Cetonia ferruginea Eschsch. Gory et Percheron, Monogr. d. Cét. p. 196. pl. 35. fig. 3. - Protaetia ferruginea Burmeister, Handb. d. Entom. Bd. III. p. 491. - Prot. cinnamomea, Burmeister 1. c. p. 491. - Prot. sybaritica Newman, The Entomol. 1841. Art. XXXIX. p. 169. Cet. ferruginea Wallace, Transact. entom. Soc. 3. Ser. Vol. IV. 1868. p. 582. - Cet. ferruginea Gemminger et de Harold, Catal. coleopt. Tom. IV. p. 1323.

C. supra laete ferruginea, opaca, velutina; subtus aenea, nitida; clypeo quadrato, marginato, antice non sinuato, punctato, medio parum elevato, subnitido; fronte velutino, aut immaculato, aut punctis minimis sive duobus, sive quattuor, sive sex flavo-albescentibus ornato; antennis aeneis; thorace scapulis angustiore, subconvexo, saepius viridi biplagiato, aut immaculato aut magis minusve albo-punctato, ante scutellum sinuato, angulis humeralibus subrotundato; scutello subtriangulari, saepius viridi marginato; scapulis viridibus, punctatis, tomento albido postice marginatis; elytris parallelis, planis, apice sub-rotundatis, parum punctatis, sutura parum prominente, fine 
parum acuminata, iuxta suturam saepius viridi-plagiatis, aut, fascia abbreviata transversa apicali excepta, omnino immaculatis, aut punctis lineolisque flavescentibus et suturalibus et marginalibus, magis minusve signatis; pygidio basi quattuor, apice duabus maculis albido-flavis; abdomine lateribus punctatis, in utroque maculae albescentes octo duplici serie ordinatae; coxae posteriores tomento albido vestitae; pectoris latere magis minusve albido-tomentoso; processus mesosterni brevis, apice parum dilatatus; pedes fortes, longi, femoribus anticis mediisque, tibiis mediis et posterioribus flavo-fimbriatis.

Longitudo

Mm. 23-25.

Habitat in insulis Luzon et Bohol. $\delta$ ㅇ․

Diese Art variirt hinsichtlich der Zeichnung sehr und hat daher zu der Aufstellung mehrerer Arten, die später mit Recht wieder eingezogen wurden, Veranlassung gegeben. Hierher gehören Cetonia cinnamomea Burm. und C. sybaritica Newman. Nicht so aber scheint es mir mit C. Bremii Schaum, die von Gemminge $r$ und von Harold gleichfalls mit der ferruginea vereinigt wurde, der Fall zu sein. Ich halte dieselbe für eine selbstständige Art und habe sie deshalb untęr die Synonymen der ferruginea nicht aufgenommen. Weiter unten werde ich auf sie zurückkommen. Cet. ferruginea hat die Grösse und Gestalt der C. marmorata, nur die grössten Exemplare sind etwas länger. Sie ist oben lebhaft braun, etwas in das Röthliche spielend, häufig mit zwei grossen, dunkleren, grünlichen, verschieden gestalteten, meistens dreieckigen Flecken auf dem Thorax neben dessen Mittellinie. Auch zeigen sich solche grünliche Streifen häufig auf den Flügeldecken neben der Naht, und auch ihre Seitenränder haben nicht selten diese Färbung. Ebenso ist auch das Schildchen häufig grün gerandet. Der Clypeus ist viereckig, mit erhabenem Rande, grob punktirt, vorn und seitlich braun metallisch glänzend, in der Mitte etwas erhaben. Vorn ist derselbe nicht eingebuchtet, sondern der erhabene Rand ist daselbst in der Mitte bloss niedriger als mehr seitlich. Die Stirn ist braun, matt, sammetartig wie der Thorax und die Flügel- 
decken, entweder ungefieckt, oder mit zwei, mit vier und, in einzelnen Fällen, selbst mit sechs kleinen weisslich gelben Punkten, die in einer, in zwei oder drei Reiben nebeneinander stehen, geschmückt. Der Thorax ist schmäler als die Schultern und selbst als die Flügeldecken weiter nach hinten; vor dem Schildchen ausgebuchtet, mit rorragenden aber doch abgerundeten Schulterecken. Er ist entweder durchaus ungefleckt oder zeigt einen gelb. lichen Punkt in jedem Kopfwinkel und neben den Seitenrändern, und ausserdem noch entweder bloss zwei neben einanderstehende Punkte in der Mitte des Discus, oder aber seitlich von dieser noch zwei bis vier andere. Das Schildchen ist ungefleckt, die Schulterblätter sind grün, punktirt, an ihrem oberen Rande mit röthlichen Härchen besetzt, hinten in grösserer oder geringerer Ausdehnung gelb gerandet. Die Flügeldecken sind ziemlich flach, verschmälern sich nach der Spitze zu kaum merklich; dic Naht and die mittlere Längsrippe ragen nur wenig hervor und die Vertiefung zwischen beiden ist unbedeutend; erstere hinten nur wenig zugespitzt. Sie sind entweder, mit Ausnahme eines längeren oder kürzeren gelblichen Querstreifens unmittelbar über ihrer Spitze, gänzlich ungefleckt oder zeigen verschiedene gelbliche Punkte und Strichelchen. Bei den am stärksten gezeichneten befindet sich auf jeder Flügeldecke ein Punkt zwischen Scbulter und Schildchen, ein kleiner Querfleck unterhalb ihrer Mitte neben der Naht; unterhalb dieser ein etwas längerer, halbmondförmiger und ausserdem drei bis vier verschieden gestaltete, von denen der zweite der längste ist, neben dem Seitenrande. Diejenigen Exemplare, wo entweder nur die Querlinie an der Flügeldeckenspitze, oder noeh ein Punkt in dem Augenwinkel und an dem Seitenrande des Thorax sich befinden, alles ubrige aber ungefleckt ist, bilden die C. cinnamomea von Burmeister. Das Pygidium ist grünlichbraun, fein quergestrichelt und mit vier grösseren Flecken an seinem Grunde, so wie mit zwei solcher kleincrer an seiner Spitze versehen. Die Unterseite ist broncefarben, stark glänzend. Die Bauchringe sind an ihren Seiten mässig punktirt nnd zeigen an jeder 
Seite zwei Reihen alternirender Querflecken, in jeder Reihe vier, von denen die beiden mittlern der vordersten Reihe nicht selten fehlen. Auch die Hinterhüfte ist hinten mehr oder weniger gelbfilzig. Die Seiten der Brust sind punktirt, gestrichelt und mit feinen röthlichen Härchen besetzt. Auch die Pleura, Parapleura und Mesosternalplatte sind mehr oder weniger gelbgefleckt. Bei allen Exemplaren liegt vor den Hinterhüften-Schenkelgelenken ein gelber Zwillingsfleck. Der Mesosternalfortsatz ist seitlich beträchtlich erweitert. Schenkel, Schienen und Tarsi sind lang und kräftig, braun metallglänzend, die ersteren gestrichelt, die Schienen punktirt, beide in den Vertiefungen mit zerstreuten röthlichen Härchen besetzt. Die Beine haben weissgelbe Kniepunkte, während die Schenkel häufig, aber nicht immer, an der Unterseite längere oder kürzere hintere Randstreifen besitzen. Die Schienen haben drei Randzähne, von denen bei dem Männchen der hinterste nur sehr wenig hervorragt und fast obsolet ist.

10. Cetonia ducalis n. sp. Mohnike. Taf. X. Fig. 1.

C. statura permagna; supra brunnea, opaca; subtus aenea-nitida; clypeo quadrato, parum emarginato, punctato, subnitido, hoc et fronte brunneis, opacis, medio non elevatis; pronoto immaculato, albo-limbato, ante scutellum sinuato, angulis scupularibus subrotundatis; elytris subconvexis, apice vix angustatis, carina mediana suturaque elevatis, hac parum acuminata, utroque infra scapulam albolimbato fasciolisque albis tribus, duabus suturalibus una marginali, ornato; pygidio albo quinque-maculato, rufo fimbriato; abdomine maculis albis tomentosis quadruplici ordine distincto; pectoris lateribus vix albo variatis, flavopilosis; processu mesosterni rotundato, parum dilatato, pedibus longiusculis, fortibus; femoribus omnibus, tibiis mediis ac posticis flavo fimbriatis.

Longitudo

Mm. 28-51.

Habitat in insula Luzon. $-\sigma$ ㅇ․

Diese Art ist die grösste der mir bekannten eigent- 
lichen Cetonien von den Philippinischen Inseln, da sie selbst Cet. bifenestrata in den meisten Fällen an Länge und fast immer an Breite übertrifft. Ihr Clypeus ist viereckig, mit einem niedrigen Rande umgeben, vorn wenig aber doch mehr wie bei Cet. ferruginea eingebuchtet, in der Mitte ohne alle Erhebung, dicht und fein punktirt und nur ganz in der Nähe seines Randes glänzend, da sich der matte branne Sammetüberzug von der Stirn. weit nach vorn erstreckt. Die Fühlhörner sind braun. Der Thorax ist verhältnissmässig nicht so schmal wie bei der vorigen und fast eben so breit wie die Flügeldecken unterhalb ihres Seitenausschnittes, vor dem Schildchen ausgebuchtet, an den Schulterecken ziemlich abgerundet. Neben seinem Rande verläuft, von den Schultern seinen Anfang nehmend, ein weisser, in der Mitte des Vorderrandes unterbrochener Filzstreifen. Die Schultern sind punktirt, braun und mit röthlich gelben Härchen bestanden. Das Schildchen hat die Gestalt eines langschenkligen Dreieckes. Die Flügcldecken sind gewölbter wie bei der vorigen Art, verschmälern sich nach hinten sehr wenig, sind daselbst abgerundet, die Naht, Mittelleiste und die Endbuckel ragen mehr hervor und die Vertiefung zwischen den ersteren ist beträchtlicher wie bei der ferruginea. Auf jeder Flügeldecke befinden sich in ihrer Mitte, neben der Naht, eine kleine weisse Querlinie oder, anstati derselben, ein Paar neben cinander gestellter Punkte und unterhalb derselben, mehr in der Nähe der Spitze, ein feiner, nach unten gerichteter, weisser Halbmond. Auf der Höhe zwischen beiden befindet sich an dem Rande eine weisse Querlinie und nicht selten stehen, wie auf der Abbildung, oberhalb und unterhalb derselben noch zwei weis se Randpunkte. Das Pygidium ist fein quer gestrichelt mit vier oberen und zwei unteren weissen Längslinien. Unten ist dasselbe mit einer dichten gelblichen Haarbürste besetzt. Die Brust ist an den Seiten punktirt und zeigt daselbst vier Reihen von je vier alternirenden weissen Flecken, ähnlich wie bei der vorigen Art. Die Brustseiten zeigen, mit Ausnahme von dem umgeschlagenen Theile des Thorax, kaum hier und da 
Spuren von weissem Filze; sie sind nadelrissig gegrubt und mit röthlichen Härchen besetzt. Der Mesosternalfortsatz ist runder und seitlich weniger erweitert wie bei der ferruginea. Die Beine sind kräftig und ziemlich lang. Die Schenkel sind nadelrissig, die Schienen stark punktirt. Beide tragen zerstreute Härchen. Alle Schenkel, so wie die vorderen und hinteren Schienen, haben einen starken, gelblich-röthlichen Haarsaum. Die Vorderschienen haben drei Randzähne, von denen der hinterste bei dem Männchen nur eben angedeutet ist.

\section{Cetonia papalis n. sp. Mobnike. Taf. X. Fig. 2.}

C. supra aterrima, velutina; subtus nitida, cerasina; elypeo quadrato, marginato, antice vix sinuato, densissime et subtilissime punctato, nitido, medio parum elevato; fronte albo aut bi - aut quadri-punctato; antennis nigrorufescentibus; thorace antice lateribus albo-limbato; angulis scapularibus maculis magnis sanguineis, medio vittis duabus albo-margaritaceis ornato; scapulis postice margaritaceo-margiantis; elytris iuxta scutellum, suturam, marginesque, humero apiceque, maculis lineolisque albo-margaritaceis distinctis, inter svturam ct carinas medianas sanguineo-maculatis, sutura postice valde producta, acuminata; pygidio subtiliter transversim striolato, rubro, basi albo quattucr-maculato; abdominis pectorisque lateribus albo variegatis; aciculatis, punctatis; femoribus rubris; tibiis nigro-rubescentibus; tarsis nigris; processu mesosterni parvo, brevi, apice rotundato, non dilatato.

Longitudo . . . . . . . . . . Mm. 25.

Habitat in insulis Panaon, Bohol, Leyte, Mindanao $\delta$ ㅇ.

Diese, von allen'mir bekannten Cetonien im engeren Sinne, aus der indischen Inselwelt die schönste, ist zugleich eine der grössten, da sie zwischen Cet. bifenestrata und Cet. ferruginea die Mitte hält. Sie ist oben, die näher zu erwähnenden Flecken und Zeichnungen abgerechnet, tiefschwarz und sammetartig; unten glänzend und dunkelkirschroth, mit Ausnahme der mittleren Brusttheile, 
welche schwärzlicher sind. Der Clypeus ist viereckig, umrandet, vorn tiefer ausgebuchtet wie bei den vorigen Arten, in der Mitte etwas erhaben, dicht und sehr fein punktirt, bis zur Stirn hin glänzend. Die letztere ist matt, entweder bloss schwarz oder zeigt zwischen den Insertionsstellen der Fühlhörner zwei oder vier weisse Punkte. Sind vier derselben vorhanden, so stehen sie in zwei Reihen und befindet sich das zweite Paar weiter nach hinten auf dem Scheitel. Der Thorax ist von der Breite der Flügeldecken unterhalb des Seitenabschnittes, vor dem Schildchen ausgebuchtet und besitzt vorspringende, aber doch abgerundete Schulterecken. Der obere Theil der Seitenränder wird nach innen von weissen Randstreifen eingefasst, welche vorn eine Lücke offen lassen, indem sie etwas nach innen von den Augenwinkeln aufhören, dabei aber ein wenig nach hinten gebogen sind. Die ganze Schulterecke, bis dicht an den Schildchenwinkel, nimmt ein grosser, runder, blutrother, ebenfalls sammetartiger, matter Flecken ein. In der Mitte des Thorax befinden sich zwei längere oder kürzere weisse, etwas in das gelbliche spielende, perlmutterartig glänzende Längsstreifen. Häufig finden sich hinter denselben, etwas weiter von einander entfernt, vor den Ecken des Schildchens, noch zwei, aber kürzere und schmälere Längsstreifen, wie auf -der Abbildung. Auch sie haben den eigenthümlichen Perlmutterglanz wie überhaupt alle weissen Flecken und Linien auf der Oberseite dieser schönen Art. Die Schultern sind schwarz, punktirt und haben in der ganzen Breite eine hintere weisse Randeinfassung. Das Schildchen ist länglich, ziemlich gross, unten abgestumpft. Die Flügeldecken sind ziemlich flach, hinten nur sehr wenig verschmälert, an der Spitze geradlinigt. Die mittlere Rippe so wie die Naht ragen nicht sehr hervor und der Raum zwischen beiden ist nur wenig vertieft. In jedem dieser Zwischenräume befindet sich ein grosser, blutrother Längsfleck, der aber nicht bis zu dem Ende der Vertiefung nach hinten reicht. Die Naht ist nach hinten weit vorgezogen und endigt in einer langen aber nicht sehr scharfen Spitze. Auf jeder Flügeldecke zeigen sich 
noch folgende weisse, perlmutterartig glänzende Zeichnungen: Ein kurzer Querstreif neben dem obern Winkel des Schildchens; eine längere Längslinie von der Schulter schief nach innen und unten, so wie eine andere, in entgegengesetzter Richtung, ron der Basis des Schildchens nach unten und aussen verlaufend und mit der vorhergehenden einen spitzen Winkel bildend; zu Anfang der Vertiefung ein grösserer Querflecken neben der Naht, so wie ein zweiter, ähnlicher in geringer Entfernung von deren Spitze. Diese beiden Flecke bilden die obere und untere Begrenzung der erwähnten grossen rothen Längsflecken. Zwischen ihnen so wie unterhalb der letzten, liegen, neben der Naht, noch in dem einen Falle mehr, in dem andern weniger kleinere weisse Flecken und Punkte. Ausserdem liegen auf jeder Flügeldecke noch vier Randflecken, von denen der dritte, dessen Lage der Mitte beider grösserer Nahtflecken entspricht, der grösste ist. Alle weissen Flecken und Striche sind bei den einzelnen Stücken bald stärker, bald schwächer gezeichnet. Das Pygidium ist blutroth, matt, fein quer gestrichelt, mit vier Längsflecken auf seiner Basis. Die Bauchabschnitte zeigen an den Seiten nur eine sehr schwache Sculptur, und je sechs weissliche Längsflecke, von denen vier in der hinteren, zwei aber in der vorderen Reihe. Auch die Hinterhüften sind weiss gefleckt. Auf dem Metosternum befindet sich vor den Trochanteren der Hinterschenkel ein Doppelfleck, und sind ausserdem die Pleura, Parapleura, die Unterseite der Schulterblätter und der umgeschlagene Theil des Thorax mehr oder weniger weissgefleckt. Der Mesosternalfortsatz ist kurz, kegelförmig, seitlich nicht erweitert. Die Beine sind ziemlich lang áber schlanker wie bei den beiden vorigen Arten; viel weniger punktirt und nadelrissig, mit Ausnahme gelblicher Wimpern der vorderen und mittleren Schenkel so wie der mittleren und hinteren Schienen, nicht mit Härchen besetzt. Die Schenkel sind dunkel kirschroth, die Schienen und Füsse schwarz. Die Schienen haben weisse Kniepunkte. Auch die Randzähne der letzteren sind nicht so herverstehend und scharf, wie bei der vorigen, namentlich ist solches 
bei den Männchen der Fall, wo der oberste Zahn des vorderen Paares kaum mehr als angedeutet ist.

12. Cetonia leúcogramma n. sp. Mohnike. Taf. X. Fig. 3.

- C. umbrina, supra opaca, subtus nitida; clypeo subquadrato, antice parum emarginato, punctato, medio elevato, subnitido ; antennis brunneis; thnrace lateribus punctato; ante scutellum sinuato, albo-limbato, medio punctis duobus, supra scutelli basin lanulis duabus albis signato; scutello basi albo-limbato; scapulis postice albo margiratis; elytris subconvexis; carina suturaque parum elevatis, hac non acuminata, utroque prope scutellum, suturam, marginemque lineolis albis transversis ornato; pygidio albo-adsperso; abdomine parum ac distanter punctato, latere utroque maculis albido-tomentosis octo alternantibus, duplici serie positis variegato; pectoris lateribus coxisque posterioribus tomento albido adspersis; processu mesosterni brevi, non dilatato; pedibus brevioribus; tibiis anticis tridentatis.

Longitudo

Habitat in insula Luzon.

Oben rein braun, matt; unten braun, etwas metallisch glänzend. Clypeus nicht ganz viereckig mit etwas abgerundeten Ecken, erhaben umrandet, vorn ein wenig eingebuchtet, grob punktirt, in der Mitte erhaben; Fühlhörner braun; Thorax von der Breite der Flügeldecken, hinter deren Seitenausschnitte, auf jeder Seite nit weissem, von der Schulter bis zu dem Augenwinkel reichenden Randstreifen, auf dem Discus zwei weisse Punkte und unter denselben, vor der Basis des Schildchens, zwei solche, nach aussen gekrümmte Monde; dic Schultern hinten mit weisser Randeinfassung; die Flügeldecken hinten sehr wenig verchmälert, mit wenig hervorragender Mittelrippe und Naht, die letztere ohne hintere Zuspitzung. Auf jeder von ihnen eine weisse Querlinie oben neben der Basis des Schildchens; eine zweite, schräge von oben nach unten und innen verlaufende, neben der Spitze des letzteren, zwei andere, quere, weiter unten ne- 
ben der Naht. Zwischen diesen beiden so wie unterhalb der unteren noch verschiedene weisse Punkte. Ausserdem vier quere Randlinien, von denen die oberste unterhalb des Seitenausschnittes, die unterste oberhalb der Spitze gelegen ist und zwischen der zweiten und dritten noch ein weisser Punkt. Das Pygidium fein quer gestrichelt, an den Seiten mit weissen Atomen bestreut. Die Baúchringe sind nur wenig und zerstreut punktirt, mit vier Reihen von je vier alternirenden, länglichen Seitenflecken. Dic Hinterhüften so wie die Mesosternalplatte, die Pleuren,- Parapleuren und die umgeschlagenen 'Theile des Thorax an einzelnen Stellen mit weisslichem Filze bedeckt. Alle Seitentheile der Brust ausserdem punktirt und nadelrissig. Der Mesosternalfortsatz kurz, vorn abgerundet, seitlich nicht erweitert. Die Beine ziemlich kurz und nicht besonders stark, braun, metallisch glänzend; Schenkel nadelrissig, Schienen punktirt, die letzteren an dem ersten Paare dreigezähnt, keine hellgefärbte Kniepunkte an denselben.

\section{Cetonia plebeja n. sp. Mohnike. Taf. X. Fig. 4.}

C. supra brunnea aliquid rufescens, opaca; subtus aenea, nitida; clypeo subrotundato, marginato, antice sinuato, punctato, medio elevato, subnitido; thorace rotundato, convexo, albido limbato, disco bipunctato, ante scutellum sinuato; hoc triangulari; scapulis postice albo marginatis; elytris parallelis, convexioribus, apice rotundatis, carina mediana suturaque parum elevatis, hac aliquod acuminata, infra scapulas albo-limbatis, punctulis minimis duodecim albescentibus, quarum duobus inter humerum et scutellum, totidem prope margines, quattuer iuxta suturam totidemque in apice sitis, distinctis; pygidio brunneo, densissime ac subtilissime transversim striolato; abdomine lateribus distanter punctatis, maculis alboflavescentibus tomentosis quadruplici serie ornatis; coxis posterioribus pectorisque lateribus tomento albido dense tectis, punctatis, aciculatis, albido-pilosis; processu mesosterni brevi, rotundato; pedibus fortibus, aeneis; femori- 
bus punctatis, striolatis, his et tibiis mediis posterioribusque flavo fimbriatis.

Longitudo

Mim. 18.

Habitat in montibus altioribus insulae Luzon.

Diese Art, von der mir ein Exemplar vorliegt, welches auf Luzon in einer Höhe von $4000^{\prime}$ über der See gefangen wurde, ist oben braun aber etwas heller, nicht ganz so rein und mehr in das Röthliche spielend als die vorige. Der Clypeus ist von verticaler Gestalt, hoch umrandet, vorn ausgebuchtet, in der Mitte erhaben, grob punktirt, etwas glänzend. Die Fühlhörner sind braun. Der Thorax ist rund, gewölbt, mit weissen, von den Augenwinkeln zu den Schultern reichenden schmalen, weissen Randstreifen und auf dem Diseus zwei kleine weisse Punkte zeigend. Das Schildchen ist dreieckig, braun, ungezeichnet. Die Schultern baben eine schmale, weisse, hintere Randeinfassung. Die Flügeldecken sind ziemlieh gewölbt, an der Spitze abgerundet, daselbst kaum verschmälert. Die mittlere Leiste und die Naht ragen wenig hervor. Letztere hat eine kurze Spitze. Auf jeder Flügeldecke befinden sich sechs kleine weissliche Punkte; einer zwischen Schulter und Schildchen, zwei neben der Naht, ein vierter an Seitenrande auf der Höhe zwischen beiden letzterwähnten und zwei nebeneinanderstehende auf der Spitze. Das Pygidium ist braun, ungefleckt, sehr fein horizontal gestrichelt. Der Bauch ist in der Mitte broncefarben glänzend, an den Seiten punktirt und daselbst bis dicht an die Mitte, mit zwei Reihen alternirender Flekken, von denen die äusseren mehr rund, die inneren mehr länglich sind und von denen jede Reihe nur vier enthält, besetzt. Die Hinterhüften, Mesosternalplatten, die Pleuren, Parapleuren so wie der umgeschlagene Theil des Thorax sind nadelrissig, punktirt, dicht mit weissgelblichem Filze bedeckt und zugleich mit einzelnen Härchen bestanden. Der Mesosternalfortsatz ist kurz, rund, seitlich nicht erweitert. Die Schenkel sind nadelrissig und auf ihren Flächen foin behart, die vorderen unten, die mittleren und hinteren hinten kurz gewimpert. Die Schienen haben gelblich weisse Kniepunkte; die der Vorderbeine 
sind breit und haben drei starke Zähne; die mittleren und hinteren sind innen kurz aber dicht gewimpert. Schenkel, Schienen und Tarsi sind broncefarben.

\section{Cetonia lineata n. sp. Mohnike. Taf. X. Fig. 5.}

C. supra viridi brunnea, opaca; subtus nigra, nitida; thorace brevi, quadrato, antice emarginato, punctato, medio elevato; antennis nigro-brunneis; thorace convexo, undique punctato, ante scutellum emarginato, disco albidobipunctato; scapulis scutelloque immaculatis; hoc trigono; elytris valde convexis, parallelis, apice subrotundatis, carina mediana suturaque parum elevatis, undique dense et subtiliter punctato-striatis, maculis duabus marginalibus fasciaque apicali albo-flavescentibus ornatis ; pygidio transversim striolato, nigro; abdomine nigro, nitido, lateribus punctato; sterno punctato, aciculato, pilis flavescentibus vestito, parapleura parteque superiori mesosterni albo-tomentosis; processu mesosterni brevi, valde dilatato; pedibus fortibus, brevibus, nigris, tibiis anticis tridentatis, mediis et posticis interne flavo-fimbriatis.

Longitudo . . . . . . . . . . . Mm. 20.

Habitat in insula Mindanáo.

Eine eigenthümliche Art, die hinsichtlich der Gestalt und Grösse unserer Cet. viridis gleicht, aber oben viel gewölbter ist. Ihre Farbe ist oben ein dunkles mattes Braungrün mit etwas durchschimmerndem Blau, unten ist sie schwarz und glänzend. Der Clypeus ist viereckig, verhältnissmässig kurz mit wenig erhabenem Rande, in der Mitte etwas erhabcn, vorn mässig ausgebuchtet, grob punktirt, ein wenig glänzend. Der Thorax ist stark gewölbt, vor dem Schildchen ausgebuchtet, allenthalben, aber nicht sehr dicht punktirt, auf dem Discus mit zwei sehr feinen gelblichen Punkten versehen. Die Schultern und das ziemlich grosse, dreieckige Schildchen sind ungefleckt. Die Flügeldecken sind stark gewölbt, hinten abgerundet, mit sehr sehwach hervortretender Mittelrippe und hinten nicht zugespitzter Naht. Sie sind mit ausserordentlich dicht neben einander stehenden Reihen sehr feiner eingestochener Punkte besetzt. Auf jeder von ihnen be- 
findet sich, zu Anfange ihres unteren Drittheiles, ein grosser, hinten breiterer, gelblicher Querfleck und unterhalb desselben eine, von dem unteren äusseren Winkel etwas gekrümmt nach der Naht verlaufende, schmale weisse Binde. Sie wird von der der andern Seite nur durch die Naht getrennt. Das Pygidium ist ungefleckt, fein quer nadelrissig. Der Bauch ist an den Seiten zerstreut punktirt, die Brust seitlich nadelrissig, gegrubt und mit einzelnen gelblichen Härchen besetzt; die Mesosternalplatten haben oben und die Pleuren in ihrer ganzen Ausbreitung, einen Ueberzug von grauweissem Filze. Der Mesosternalfortsatz ist kurz, seitlich beträchtlich erweitert. Die Beine sind in allen Theilen kurz aber kräftig; die Schenkel nadelrissig, die Schienen punktirt, die ersteren bei dem vorderen und mittleren Paare, die andern bei dem mittleren und hinteren gelb gewimpert. Die Vorderschienen besitzen drei Randzähne. Auch die Tarsalglieder sind verhältnissmässig kurz.

15. Cetonia Alavo-variegata n. sp. Mohnike. Taf. X. Fig. 6.

C. clypeo brevi, subquadrato, vix emarginato, medio plano, punctato, viridi, squamulis flavescentibus obsito; thorace subrotundo, ante scutellum emarginato, convexo, viridi, opaco, undique punctis squamiforis tecto, flavo-limbato, antice vittis duabus curratis, medio guttis quattuor, postice maculis duabus flavis ornato; scutello viridi, immaculato; scapulis tomento flavo-marginatis, punctatis; elytris viridibus, opacis, convexis, punctatis; punctis piliferis, undique maculis et maioribus et minoribus, irregularibus, punctisque flavotomentosis variegatis, carina mediana suturaque parum elevatis, hac non acuminata; pygidio transversim striolato, excepto medio, tomento flavo dense vestito; abdominis pectorisque lateribus usque ad medium tomento flavo densissime tectis, hoc viridi-aeneo nitente; processu mesosterni brevi, apice subgloboso; pedibus brevibus, fortibus; femoribus tibiisque aciculatis et punctatis, magis minusve flavo-tomentosis; tibiis anticis bidentatis; mediis et posticis flavo-fimbriatis, tarsis nigris. 
Habitat in insula Luzon. $\delta$.

Diese Art hat in der Zeichnung, nicht aber in ihrer Gestalt, einige Aehnlichkeit mit Glycyphana felina Gory et Perch. von Celebcs. Sie ist kurz, verhältnissmässig breit, oben beträchtlich gewölbt. Oben ist sie matt, von lebhafter hellgrüner Farbe; unten, so weit sie daselbst nicht mit Filz bedeckt ist, grün metallisch, stark glänzend. Der Clypeus ist kurz, viereckig, nicht hoch umrandet, in der Mitte flach, vorn nur wenig ausgebuchtet, punktirt, in den Punkten dicht mit gelblichen Schuppen besetzt. Der Thorax ist beträchtlich gewölbt, in der Mitte weniger, an den Seiten dichter punktirt. In ailen Vertiefungen kleine Schuppen. Neben scinen Seitenrändern verläuft, von den Schultern an, ein gelber filziger Randstreifen; wo dieselben in den Augenwinkeln endigen, nehmen zwei sich nach hinten erstreckende breitere, doppelt gekrümmte Längsbinden ihren Anfang. Unterhalb derselben liegen in einer Querlinic vier gelbe Filzflecken und unter diesen zwei andere, grössere neben der Basis des Schildchens. - Das letztere ist unten zugespitzt und ungefleckt. Die Schultern sind stark punktirt und so dicht gelb geschuppt, dass nur die Mitte frei bleibt. Dic Flügeldecken sind gewölbt, an der Spitze abgerundet, mit einer wenig hervortretenden Mittelrippe und nur wenig erhabener, hinten nicht zugespitzter Naht. Sie sind neben dem Schildchen, dem Seitenrande, der Naht und auf der Spitze mit grossen, sehr unregelmässigen, zerrissenen, inselförmigen Flecken von gelbem Filze und zwischen diesen, noch mit kleineren Tröpfchen und Punkten bedeckt. Diese Flecken, wie der grüne Grund zwischen ihnen, zeigen ausserdem bis zur Mitte hin und selbst in dieser, zahlreiche Punkte, aus denen sich kleine Härchen erheben. Das Pygidium ist, einen grünén länglichen Streifen in der Mitte ausgenommen, mit gelbem Filze bedeckt; mit demselben dichten gelben Filzüberzuge sind die Seiien des Bauches und der Brust allenthalben in dem Masse bedeckt, dass nur ein ganz schmaler, von dem Anus zum Mesosternalfortsatze sich erstreckender grüner, metallisch 
glänzender Längsstreifen sichtbar bleibt. Dieser letztere Fortsatz ist kurz und vorn kugelförmig gerundet. Die Beine sind kurz und kräftig, die Schenkel fast ganz, die Schienen etwas weniger mit gelbem Filze bedeckt. Nur hier und da schimmert auf ihnen die dunkle Grundfarbe durch. Die Vorderschienen sind bei den beiden mir vorliegenden Exemplaren, welche ich für Männchen halte, zweigezähnt; die mittleren und hinteren haben am inneren Rande ziemlich lange und dichte, gelbe Wimpern.

\section{Cetonia ambigua Chevrolat.}

Cetonia ambigua Chevrolat, Guérin, Revue zuol. IV. 1841. p.223. - Protaetia ambigua Burmeister, Handb. d. Entom. Bd. III. S. 422. - Cet. subviridis Gemminger et de Harold, Catal. coleopt. Tom. IV. p. 1330.

„Pr. ambigua: viridi-aenea, supra olivacea, opaca; pronoti linea intramarginali, punctis duobus disci, lineolis elytrorum transversis, punctisque flavescentibus; lateribus subtus leucophaeis. Longit. 5“"."

"Auf Luzon, von Cuming. Diese Art hat die Bildung der vorigen (Pr. taciturna Guérin), ist aber etwas kleiner, oben ganz haarlos und unten anders gezeichnet. Der dicht und ziemlich grob bogig punktirte Kopf ist vorn stark aufgebogen und stumpf zweizackig, besonders beim Männchen, aber matt und haarlos. Der Vorderrücken ist matt olivengrün, gleichmässig zerstreut punktirt, gegen die Spitzen hin etwas gröber, hier neben dem Rande mit einer schmalen gelblichen Linie geziert, und auf der Mitte mit zwei kleinen Punkten. Die Schulterblätter sind vorn nadelrissig, schuppig, hinten gelb gesäumt. Das Schildchen ist punktfrei, matt. Die Flügeldecken haben eine olivengrüne matte Färbung, einzelne Bogenstriche in der Vertiefung neben der Naht und eine dichtere aber ähnliche Punktirung aussen neben der schwachen Kante zwischen Schulter und Endbuckel. Diese Gegend glänzt auch ein wenig. Auf jeder Flügeldecke bemerkt man einen gelben Punkt mitten auf dor Schulterhöhe, einen Streif am Seitenrande vor dem Ausschnitt, mehrere kleinere und grössere Randpunkte von da bis 
zum Ende, einen Punkt auf dem Endbuckel, zwei in der Nahtecke, und zwei grössere Querflecke in der Vertiefung, den ersten am Vorderrande, den zweiten innen neben dem Endbuckel, zwischen welchen noch einige kleine Punkte auftreten. Das Nahtende ist stark zugespitzt. Die Afterklappe ist matt braungrün, nadelrissig, mit vier gelben Längsstreifen geziert, die am Grunde zusammenfliessen. Die stark glänzende, grünlich erzfarbene Unterfäche ist an beiden Seiten beinahe ganz gelbgrau, doch zieht sich am Hinterrande des Bauchrings ein glänzender Saum fort, welcher sich am Ende in einen nach vorn gerichteten Haken ausdehnt. Die Schenkel haben gelbgraue Randstreifen und die Schienen einen farbigen Kniepunkt. Der Haarsaum ist an ihnen schwach: die vorderen haben drei scharfe Randzähne, von welchen die zwei unteren einander mehr genähert sind." Burmeister. Ich habe das Exemplar im Museum zu Halle, welches Burmeister vor sich hatte als er diese Beschreibung entwarf, genau untersucht und hierdurch die Ueberzeugung erhalten, dass Cet. ambigua wirklich eine selbstständige, eigenthümliche Art ist, die sehr mit Unrecht von La cor daire - Gen. des Coléopt. Tom. III. p. 536. Note 1- zu Cet. manillarum Chevrol.; von Ge mminger und von Harold aber zu Cet. perviridis Newm., zwei weiter unten zu besprechende Arten, gezogen wurde. Sie gleicht, wie Burmeister bemerkt, nicht allein in der Gestalt, sondern auch in dem Colorite und der Zeichnung am meisten Cet. taciturna Guérin aus den Molukken, und steht dieser ohne Zweifel viel näher als irgend einer anderen der mir bekannten Arten von den Philippinen.

\section{Cetonia querula Newman.}

Cetonia querula Newman, The Entomologist 1841. art. XXXIX. p. 171. - Cet. mandarinea Gemminger et de Harold, Catal. coleopt. Tom. IV. p. 1327.

„Nigro-aenea, nitida, maculis nonnullis lanuginosis incertis albidis; elytra prave striata: striis 5 abbreviatis prope suturam sitis. Corp. long. 5 unc., lat. 3 unc. - Inhabits the Philippine-Islands. A specimen captured by 
Mr. Cumming is in the Cabinet of the Entomological Club. This insect is about the size of the wellknown Europaean species, Cetonia stictica; its colour is very dark, but occasionally relieved, especially on the sides of the prothorax, the legs etc., with a metallic splendour; the elytra have the elevated longitudinal ridge so general among. the Cetoniae, and in depressed space between this and the suture are fife abbreviated striae, a single one and two pairs; the elytra, mureover, are nearly covered with coarse but shallow punctures." - Newman.

Diese Beschreibung stimmt keineswegs mit der Cet. mandarinea Weber in allen Punkten so überein, dass ich, ohne das Originalexemplar gesehen zu haben, mit G em$m$ inger und $v$. Harold dieselbe und die Cet. querula für identisch halten möchte.

\section{Ceionia philippensis Fabricius.}

Cetonia philippensis Fabricius, System. Eleutherat. Tom. II. p. 152 ; eiusd. System. Entom. p. 49. - Cet. philippensis Olivier, Entom. Vol. I. p. 34. pl. 10. fig. 97. Cet. philippensis Herbst, Coleopt. Vol. III. p. 275. - Cet. philippensis Schönherr, Synonym. Insector. Bd. I. Th. 3. S. 136. - Cet. philippensis Gory et Percheron, Monogr. d. Cét. p. 175. pl. 31. fig. 1. - Protactia philippensis Burmeister, Handb. d. Entom. Bd. III. S. 496. - Cet. philippensis Wallace, Transact. entom. Soc. 3. Ser. Vol. IV. 1868. p. 581. - Cet. philippensis Gemminger et de Harold, Catal. coleopt. Tom. IV. p. 581.

C. supra viridis aenea, nitida; subtus aenea sive cuprea; clypeo oblongo, marginato, antice sinuato, angulis reflexis, medio elevato, punctato; thorace linea intra-marginali maculisque disci quattuor, anterioribus duabus maioribus, albis ornato; scapulis postice albo tomentosis; elytris planis, maris sutura carinaque mediana magis quam foeminae prominentibus, illa parum acuminata, lateribus striolatis, basi, iuxta scutellum et suturam nec non prope marginem maculis transversis albo-tomentosis, impressis, ornatis; pygidio transversim striolato, lateribus tomento albo tecto; abdomine maculis tomentosis flavo-albescen- 
tibus sedecim, serie quadruplici positis, ornato; coxa postica tomentosa; pectoris lateribus magis minusve tomento obtecto; processu mesosterni brevi, parum dilatato; pedibus aeneis; maris femoribus partim tomentosis; tibiis anticis in mare uno, in foemina duobus dentibus ante apicem munitis, mediis et posticis margine interno flavo-fimbriatis.

Longitudo

Mm. $20-22$.

Habitat in insula Luzon.

Diese längst bekannte Art ist oben dunkelgrün metallisch glänzend, etwas in das bräunliche spielend, unten an den nicht mit Filz überzogenen Stellen entweder von einem mehr kupferrothen oder mehr broncefarbenen Metallglanze. Der Clypeus ist länger als breit, mässig hoch umrandet, vorn ausgebuchtet und, bei dem Männchen beträchtlicher wie bei dem Weibchen umgebogen; in der Mitte etwas erhaben, ziemlich fein, aber bei dem Männchen weniger punktirt. Auf der Stirn befinden sich mitunter zwei weissliche Filzflecken. Die Fühlhörner sind grün, metallisch glänzend. Der Thorax ist nicht sehr gross, ziemlich flach, in der Mitte fast ganz glatt, an den Seiten bei dem Männchen schwächer, bei dem Weibchen stärker punktirt. Neben dem Rande verläuft von der Schulter bis zum Augenwinkel eine ziemlich breite, vertiefte, weisse Linie. Ausserdem befinden sich in der Mitte des Discus zwei neben einander stehende grössere, und unter diesen, mehr von einander entfernt, zwei kleinere runde weisse Flecken. Die Schulterblätter sind punktirt und hinten weissfilzig. Das Schildchen ist durchaus glatt, ohne Punkte und Flecken, stark glänzend. Die Flügeldecken sind neben dem Schildchen vertieft, glatt, bei dem Weibchen an den Seiten und auch in der Vertiefung, grob aber sehr oberflächlich punktirt; selbst auf dem Discus stehen noch zerstreute Punkte. Bei dem Männchen ist die Punktur noch viel undeutlicher und verwischter. Die Mittelleiste ragt bei dem Männchen stärker, bei dem Weibchen weniger hervor, und ist die Vertiefung bei ersterem viel beträchtlicher. Die Naht ist bei beiden prominirend, zeigt eine tiefe Rinne und ist bei dem Männchen stärker, bei dem Weibchen weniger zugespitzt. Auf jeder 
Flügeldecke befinden sich zwei gelblich weisse Querflecke neben der Naht, der eine zu Anfang der Verticfung, der andere ebenfalls in derselben, neben dem Endbuckel; ferner unterhalb der letzteren vier kleinere mehr runde Flecken, von denen die drei oberen in einer Reibe stehen und nicht selten in einander zu einer Querbinde verfliessen; ausserdem noch fünf bis sechs am Aussenrande, einer neben der Spitze des Schildchens, einer neben dem Grunde desselben, einer zwischen letzterem und der Schulter, so wie endlich unterhalb dieser ein grösserer zwischen der Spitze des Schildchens und dem Randausschnitte. Das Pygidium zeigt zwei grosse dreieckige Randflecken, die unten mehr oder weniger tief eingeschnitten sind und einen schmalen nach oben sich noch mehr verengerenden $Z$ wischenraum haben. Die Bauchringe haben auf jeder Seite, in zwei alternirenden Reihen, acht weissgelbe Querflecken. Die Hinterhüften und Pleuren sind ganz, die Mesosternalplatten an ibrem vorderen und hinteren Rande mit solchem Filze bedeckt, wie auch die Unterseite der Schulterstücke und der umgeschlagene Theil des Thorax. Diese Filzbedeckung ist bei den Männchen noch dichter und lebhafter gelb gefärbt, wie bei den Weibchen. Der Mesosternalfortsatz ist kurz, seitlich etwas erweitert. Die Beine sind metallisch kupfer-oder broncefarben; die Schenkel, besonders der hintere, bei den Männchen häufig ganz mit gelblichem Filze bedeckt, während bei den Weibchen sich derselbe nur stellenweise zeigt. Die Schienen haben helle Kniepunkte, die vorderen bei dem Männchen unterhalb der Endspitze einen Zahn, bei dem Weibchen zwei derselben. Die hinteren und mittleren sind innen gelb gewimpert.

19. Cetonia purpurissata n. sp. Mohnike. Taf. XI. Fig. 1.

C. capite nigro-rubescente, nitido; clypeo profunde emarginato angulis rotundatis, reflexis, parum ac distanter punctato, medio parum elevato; antennis nigris; thorace nigro-rubro, nitido, lateribus valde sed distanter, disco laevi minus punctato, linea intra-marginali medioque aut 
duabus aut quattuor maculis albis ornato; elytris nitidis, cerasino-brunneis, undique obsolete punctatis, iuxta scutelli basin atque apicem, inter hunc et humerum, iuxta suturam marginesque exteriores magis minusve maculis transversis albis impressis variatis; sutura prominente, parum acuminata; pygidio transversim striolato, lateribus tomento albo vestito; abdomine nitido, laetius cerasino, lateribus maculis albis quadruplici ordine picto; pectore nigro, lateribus punctato-striolatis tomento albo partim tectis; processu mesosterni brevi, apice minimo, non dilatato; femoribus omnibus tibiisque mediis et posticis rufo-fimbriatis; tibiis anticis bidentatis.

Longitudo .

Mm. 20.

Habitat in insula Babuynes. $\delta$.

Diese Art unterscheidet sich von der vorigen, abgesehen von der ganz anderen Färbung, schon auf den ersten Blick dadurch, dass sie kürzer und verhältnissmässig viel breiter ist, was besonders auffallend ist, wenn man das schlank gebaute Männchen der philippensis mit dem dieser Art zusammen hält. Auch der Kopf, namentlich der Clypeus, ist anders gebaut. Der letztere ist viel kürzer, eben so breit als lang, vorn auffallend tief ausgebuchtet, mit runden, aufgebogenen Randecken. Seine Seitenränder sind niedrig, die Mitte ist etwas erhaben, allenthalben fein punktirt, seine Farbe ein dunkles Rothschwarz. Der Thorax ist ebenfalls von dieser Färbung, etwas convexer wie bei der philippensis, glatt und glänzend, wiewohl allenthalben, an den Seiten jedoch mehr wie in der Mitte, zerstreut punktirt. Neben dem Seitenrande verläuft ein vertiefter weissfilziger Randstreifen, während sich in seiner Mitte, bei dem einen der mir vorliegenden Exemplare zwei eingedrückte weisse Punkte, bei den andern vier in zwei Reihen stehende Flecken, von denen die oberen die grösseren, zeigen. Das Schildchen ist ohne alle Punktirung, schwarzroth, sehr glatt und glänzend. Die Schulterblätter sind stark und dicht punktirt, hinten mit weissem Filzrande. Die Flügeldecken sind viereckig, breit, flach, mit wenig hervorragenden Mittelrippen und nur mässig erhabener Naht, 
deren Furche nicht so tief ist wie bei der philippensis. Dieselbe endigt in einer kurzen, feinen Spitze. Auch die Vertiefungen neben der Naht sind lange nicht so beträchtich wie bei letztgenannter. Die Flügeldecken sind glänzend, wiewohl allenthalben oberflächlich und obsolet punktirt, von kirschbrauner Farbe. Jede von ihnen zeigt einen Querflecken neben der Basis des Schildchens, einen neben seiner Spitze so wie einen dritten in der Mitte zwischen ihr und der Schulter. Neben der Naht liegen unter einander zwei grössere Flecken und auf der Spitze vier kleinere, von denen die oberen drei in einer Reihe; ausserdem noch am Aussenrande drei bis vier andere, von denen der unterste, dessen Stellung der Mitte zwischen den beiden Nahtflecken entspricht, der grössere ist. Von allen diesen Flecken sind nur der zwischen dem Schildchen und der Schulter, so wie die beiden Querflekken neben der Naht constant, wie das eine der Exemplare, we?che ich vor mir habe, beweist. Das Pygidium ist roth, fein quer gestrichelt, entweder bloss mit vier Flecken auf seinem Grunde oder einem grösseren zu jeder Seite. Die Bauchringe sind bei den Männchen, welche ich allein kenne, eben wie bei der philippensis, in der Mitte tief eingedrückt, sehr zerstreut punktirt, von lebhafter, glänzender, kirschrother Farbe, an jeder Seite mit zwei Reihen von je vier alternirenden weissen Filzflecken verziert. Die Hinterhüfte ist entweder ganz oder nur zum Theil mit Filz bedeckt. Die Brust ist schwarzgrün, seitlich mehr oder weniger weiss gefleckt. Im Allgemeinen ist die Filzbedeckung an der Unterseite dieser Art ungleich schwächer und weniger dicht wie bei der vorigen. Der Mesosternalfortsatz hat eine kleine, rundliche, seitlich nicht erweite Spite Sie Beine sind schlank, Schenkel und Schienen stark punktirt, von schwarzer Farbe, die Schenkel nicht theilweise mit Filz bedeckt wie bei der vorigen; sie alle, so wie die mittleren und hinteren Schienen, sind röthlich gewimpert. Die Vorderschienen haben, bei den mir vorliegenden beiden Männchen, unter der Endspitze nur einen Zahn. 


\section{Cetonia Bremei Schaum.}

Cetonia (Protaetia) Bremei Schaum, Annal. d. 1. Soc. Entom. de France 1844. p.413; ibidem 1849. p. 278. - Cet. Bremei Wallace, Transact. entom. Soc. 5. Ser. Vol. IV. 1868. p. 582. - Cet. ferruginea Lacordaire, Gener. d. Coléopt. Tom. III. p. 536. Not. 1. - Cet. ferruginea Gemminger et de Harold, Catal. coleopt. Tom. IV. p. 1323. „Purpurea-nigra, opaca, thoracis linea marginali vittisque duabus disci abbreviatis albidis, elytris albido-maculatis, femoribus rufis. Long. 19 millim. ( $8^{1 / 2}$ lign.)"

„Caput nigrum, opacum, punctatum, apice emarginatum. Antennae nigrae. Thorax longitudine dimidio latior, basi supra scutellum profunde sinuatus, lateribus retundatis, a medio ad apicem angustatis, postice subsinuatis, purpureo-niger, opacus, linea marginali vittisque duabus disci anterioris sordide albidis; scutellum elongatum, purpureonigrum, opacum. Elytra subparallela, postice rotundata, tarso plano, carina obsoleta laterali, sutura elevata, apice spinosa, purpureo-nigra, opaca, plaga obsoleta in medio prope suturam rufescente, maculis septem sordide albidis, quattuor marginalibus, tertia et quarta maioribus, transversis duabus suturalibus, anteriore humata, septima transversa iuxta scutellum, etiam ad scutelli latera sordidi albida. Pygidium purpureum punctis quatuor albidis. Subtus purpurea-nigra, medio nitida, pectoris abdominisque lateribus sordide albomaculatis. Pedes nigri, femoribus rufis. Sternum planum, apice rotundatum."

"Habitat in insula Manila. Mus. D. de Brême."

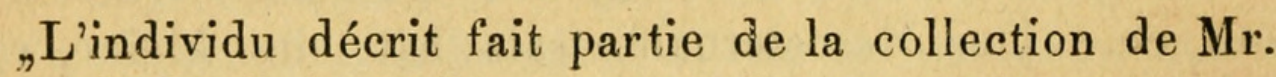
le marquis de Brême. Je me rappelle en avoir vu un second au Musée de Berlin." Schaum.

Ich habe drei Exemplare einer Art vor mir, auf welche diese Beschreibung, abgerechnet einzelne kleine Verschiedenheiten, die wahrscheinlich nur individuelle und daher unwesentliche sein dürften, sehr genau passt. Sie gleichen aber der Cet. ferruginea keinesweges in dem Masse, dass ich sie für eine blosse Varietät derselben 
halten kann, welches die Ansicht von Lacordaire, Gemminger uud von Harold hinsichtlich der von Schaum als Cet. Bremei beschriebenen Art ist.

Die mir vorliegenden Exemplare sind $20 \mathrm{Mm}$. 9 Lin. lang, oben schwarz, etwas in das Braune spielend, so dass man die Farbe „purpureo-nigra" nennen kann. Der Thorax ist wie Schaum denselben beschreibt, nur stehen bei ihm auf dem Discus, anstatt der „beiden abgekürzten weisslichen Längsbinden", bloss zwei solche Punkte, welche bei dem einen Stücke allerdings etwas länglich sind. Dass diese Verschiedenheit keine wesentliche, bedarf aber keiner näheren Erörterung. Die Gestalt und Zeichnung der Flügeldecken meiner Stücke stimmen mit der Beschreibung Schaum's überein; dagegen aber vermisse ich bei ihnen die "plaga obsoleta in medio prope suturam rufescens." Aber auch diese Differenz kann sehr wohl nur eine individuelle sein. Das Pygidium ist bei den mir vorliegenden braun, bei dem einen Stücke mit vier Flecken auf der Basis, bei dem zweiten mit diesen und noch zwei andern auf der Spitze, bei dem dritten mit vier gelblich weissen Längsbinden. Die Unterseite ist ganz wie Schaum sie beschreibt "purpurea-nigra, medio nitida, pectoris abdominisque lateribus sordide albo-maculatis." Die Beine sind bei ihnen kupferfarben, metallisch glänzend. Diese drei Stücke sind ebenfalls von Luzon.

Hiernach halte ich mich für berechtigt, die Cetonia Bremei, da ibre Identicität mit diesen Stücken mir kaum zweifelhaft erscheint, als selbstständige Art und nicht bloss als eine sehr dunkel gefärbte Varietät der ferruginea anzusehen.

\section{Cetonia Guerini Eydoux et Souleyet.}

Protactia Guerini Eydoux et Souleyet, Revue zool. d. 1. Societ. Cuvierienne 1839. p. 265; Voyage autour du monde de la Bonite. Zool. Tom. I. 1841. p. 304. Atl. Insect. pl. 2. pg. 14. - Cetonia Guérini Burmeister, Handb. d. Entom. Bd. III. S. 794. - Gametis Guerinii Burm. l.c. 
Bd. V. S. 556. - Cet. Guerini Wallace, Transact. entom. Soc. 3. Ser. Vol. IV. 1868. p. 581. - Cet. Guerini Gemminger et de Harold, Catal. coleopt. Tom. IV. p. 1326.

C. supra aut olivacea, aut brunnea, aut brunneo-nigriscens, subsericea sive opaca; clypeo quadrato, antice vix emarginato, medio parum elevato, subnitido, dense punctato; hoc et fronte albo-maculatis ; antennis nigris; thorace parum convexo, supra scutellum emarginato, dimidio anteriori attenuato, angulis humeralibus rotundatis, undique dense punctato, linea intra-marginali alba, disco punctis albis duobus ornato; scutello laevi; scapulis postice albomarginatis; elytris planis, quadratis, dense et subtiliter punctatis, iuxta scutelli basin et apicem, inter hoc et humerum, prope suturam marginemque exteriorem albo-maculatis, carinis medianis prominentibus, subnitentibus; sutura modice elevata, apice parum acuminato; pygidio lateribus albo-maculato; abdomine lateribus maculis albis sedecim, quadruplici ordine positis, ornato; pectore tomento albo magis minusve tecto; processu mesosterni brevi, dilatato, pedibus aeneis magis minusve virescentibus.

Longitudo . . . . . . . . Mm. 17-18.

Habitat in insula Luzon. $\delta$ ㅇ.

Mit Recht bemerken Eydoux und Souleyet von dieser Art, dass sie der von Guéri n zuerst beschriebenen Cetonia taciturna von den Molukken sehr nahe stehe. Sie gleicht derselben in der That nicht bloss in der Zeichnung, sondern noch mehr in ihrer verhältnissmässig kurzen und breiten Gestalt. Sie ist oben, mit Ausnahme des glänzenderen Kopfes, matt, bei Stücken, dis etwas abgerieben sind, schwach seidenartig glänzend, von hellerer oder dunklerer, mitunter selbst schwärzlicher Olivenfarbe. Der Clypeus ist viereckig, umrandet, vorn so gut wie nicht ausgebuchtet, in der Mitte sehr wenig erhaben, überall ziemlich grob punktirt. Bei ganz frischen Exemplaren zeigen sich in der Mitte des Clypeus zwei grössere weisse Filzflecken und zwei andere kleinere, oberhalb derselben auf der Stirn. Bei anderen Stücken sind diese Flecken undeutlicher und verwischter. Der Thorax ist wenig gewölbt, verschmälert sich von der Mitte seiner 
Seitenränder nach dem Kopfe zu, hat vor dem Schildchen eine Ausbuchtung und abgerundete Schulterecken. Er ist überall ziemlich weitläuftig punktirt, mit seitlichen weissen Randlinien und zwei ziemlich grossen, weissen Punkten in der Mitte des Diseus versehen. Das Schildchen ist etwas glänzend, ohne Punktirung und Flecken. Die Schulterblätter sind punktirt und haben eine hintere weisse Randeinfassung. Die Flügeldecken sind flach, viereckig, allenthalben und in den Vertiefungen reibenweise punktirt. Die Naht ragt mässig hervor, hat eine Furche und sehr kleine Endspitze. Auf jeder Flügeldecke zeigt sich ein kleiner Querflecken neben der Basis des Schildchens, ein anderer neben dessen Spitze, so wie ein dritter $z$ wisehen diesem und der Schulter. Ausserdem liegen zwei grössere, mehr viereckige neben der Naht; drei bis vier an dem hinteren und ebenso viele länglichere an dem Seitenrande. Alle diese Flecken sind bei frischen und wohlerhaltenen Exemplaren rein weiss, bei älteren mehr schmutzig weiss oder gelblich, wie auf der Abbildung im Atlas zu dem zoologischen Theile der Reisebeschreibung der Bonite. Dieselbe entspricht im Uebrigen durchaus den mir vorliegenden Stücken. Eyd o u x und Soule yet erklären selbst, l. c. p. 305, dass das einzige von ihnen von Nianilla mitgebrachte Exemplar dieser Art "était en mauvais état de conservation, et il est probable que, sur des exemplaires plus frais, les taches que nous indiquons comme jaunâtres devaient être blanches." Das Pygidium ist braun, fein quer gestrichelt und hat zwei weisse Seitenflecken, die einen sehmäleren oder breiteren dunklen Mittelstreifen zwischen sich offen lassen. Der Bauch ist heller oder dunkler braun, glänzend, seitlich schwach punktirt, daselbst mit vier alternirenden Reihen von je vier weissen Flecken. Der Mesosternalfortsatz ist seitlich etwas erweitert. Die Seiten der Brust sind punktirt, nadelrissig und, gleich wie die Hinterhüften, mehr oder weniger mit weissem Filze bedeckt. Die Beine sind erzfarben, glänzend, bei dem einen Stücke mehr bei dem andern weniger grünlich. Die vorderen und mittleren Schenkel, so wie die mittleren und hinteren 
Schienen sind gelblich gewimpert. Die Schenkel haben kürzere oder längere weisse Längsflecken.

\section{Cetonia Kogeri Dupont.}

Protaetia Rogeri Burmeister, Handb. der Entom. Bd. III. S. 796. - Gametis Guerini Burm. 1. c. Bd. V. S. 556. - Cetonia Guerini Wallace, Transaet. entom. Soc. 3. Ser. Vol. IV. 1868. p. 581. - Cet. Guerini Gemminger et de Harold, Catal. Coleopt. p. 1325.

C. praecedenti non valde dissimilis sed multo angustior, supra purpurea, opaca; clypeo quadrato, marginato, antice sinuato, medio elevato, punctato, hoc et fronte albo-maculatis; thorace haud permagno, antice multo angustiore, subconvexo, undique obsolete punctato, intra margines laterales lineis duabus et disco punctis aut maculis duobus albis ornato; scapulis postice albo-marginatis; scutello levi, viridi, immaculato ; elytris subconvexis, elongatis, apice parum attenuatis, sutura carinisque viridibus, undique punctatis, iuxta margines laterales et posteriores, prope suturam scutellumque, nec non inter hoc et humerum albo-maculatis; pygidio purpureo-brunneo, basi ac lateribus tomento albo vestito; abdomine purpurco-nitido, latere utroque maculis albis duplici serie ornato; coxis posticis albo-tomentosis, pectore purpureo-nigrescente, lateribus tomento albo magis minusve tecto; processu mesosterni dilatato, brevi; pedibus viridi-nigrescentibus, nitidis; femoribus albo-maculatis, anticis et mediis, tibiis mediis ac posticis flavo-fimbriatis.

\section{Longitudo}

Habitat in insula Luzon. $\delta$ 9.

Diese Art wurde ron Burmeister, nach einem in der Sammlung von D up ont unter dem Namen Cet. columhina Klug befindlichen Exemplare, zuerst als selbstständige Art beschrieben, später aber von ihm wie von Lacordaire, Gemminger und von Harold u. A. mit der Cet. Guerini vereinigt. Wie es mir scheint, ist solches mit Unrecht geschehen. Ich habe nämlich zwei Stïcke vor mir, welche mit Burmei ster's Beschreibung der Cet. Rogeri sehr übereinstimmen, die aber den 
Stücken im Museum zu Halle, die von ihm selbst als Cet. Guerini bestimmt wurden, durchaus nicht gleichen, um so mehr aber denjenigen, nach welchen ich meine Beschreibung der letzteren entworfen habe. Von dieser aber unterscheidet sich diejenige, welche icb für die ächte und wirkliche Cet. Rogeri halte, schon auf den ersten Blick. Es wird genügen hier allein die Unterschiede zwischen beiden hervorzuheben. Die Rogeri ist viel schlanker gebaut, gewölbter und ihre Flügeldecken sind verhältnissmässig länger, verschmälern sich auch etwas nach ihrer Spitze. Der Clypeus ist vorn viel tiefer ausgebuchtet wie bei der Guerini und die abgerundeten Ecken sind aufgebogen. Die Mitte des Clypeus ist nicht flach wie bei letztgenannter, sondern zeigt seitlich eine vor der Stirn beginende, keilförmige mit zwei Schenkeln nach den Ecken neben dem vorderen Randausschnitte verlaufende Erhöhung. In den vertieften Stellen neben derselben liegen weissfilzige Flecken, ähnlich wie bei der Cet. Guerini. Der Thorax ist bei Cet. Rogeri viel gewölbter, verhältnissmässig kleiner, namentlich schmäler, allenthalben dichter und feiner punktirt. Er, so wie die Flügeldecken haben eine schöne dunkelpurpurrothe Farbe und die letztere, in Folge der durch den seidenartigen Ueberzug, womit sie bedeckt sind, durchschimmernden Punktirung, ein eigenthümliches granulirtes Ansehen. Die weissen Zeichnungen auf Thorax und Flügeldecken sind bei beiden dieselben. Schildehen, Naht und bei dem einen auch die Längsrippen sind grün. Die Vertiefung zwischen den letzteren und der Naht ist nicht so beträchtlich, wie bei der Guerini, auch die Punktirung in derselben nicht so stark. Das Pygidium hat auf der Basis zwei mittlere, runde Längsflecken und auf jeder Seite, neben denselben, einen solchen. Der Bauch ist bei dem einen Stücke ziemlich hell purpurroth, bei dem andern dunkler; bei beiden seitlich mit zwei Reihen von je vier alternirenden Randflecken. Die Unterseite der Brust ist dunkel grünlich schwarz, seitlich bei dem einen Stïcke mehr wie bei dem andern, mit weissem Filze bedeckt. Die Beine sind ziemlich lang und kräftig, von schwarzer Farbe, mit etwas röthlichem 
Anflug. Die Schenkel haben auf der Aussenfläche, neben dem Kniegelenke, kleine weisse Randflecken, die Schienen weisse Kniepunkte, wie bei der Guerini. Die Wimperung derselben ist bei beiden dieselbe. Die Vorderschienen sind dreigezähnt.

\section{Cetonia anovittata Chevrolat.}

Cetonia anovittata Chevrolat in Guérin revue zool. Vol. IV. 1841. p. 223. - Protaetia anovittata Burmeister, Handb. d. Entom. Bd. III. S. 497. - Cet. chloris Newman, The Entomol. 1841. Art. XXXIX. p. 170. - Cet. olivacea Newman 1. c. - Cet. anovittata Lacordaire, Gen. d. Coléopt. Tom. III. p. 536. Not.1. - Cet. anovitlata Wallace, Transact. entomol. Soc. 3. Ser. Vol. IV. 1868. p. 582. - Cet. anovittata Gemminger et de Harold, Catal. coleopt. Tom. IV. p. 1321.

C. supra olivacea, opaca, subtus cuprea, nitida; clypeo quadrato, marginato, antice parum sinuato, medio non valde élevato, punctato, tomento olivaceo vestito, iuxta marginem anticum solum subnitido; antennis olivaceis; thorace subconvexo, intra marginem lateralem et anticum albido lineato, medio aut bi - aut quattuor-punctato, aut vittis duabus tenuibus albis ornato; scapulis postice albo-marginatis; scutello opaco, immaculato; elytris subconvexis, apice parum attenuatis, subrotuntatis, carinis medianis minus prominentibus, sutura magis elevata, parum acuminata, inter scutellum et humerum, prope suturam marginesque et inferiores et laterales, rarius quoque iuxta scutelli basin atque apicem, aut lineolis aut maculis albo-flavescentibus signatis; pygidio viridi, vittis flavo-tomentosis ornato; in utroque abdominis latere maculae flavescentes tumentosae octo, serie duplici positae; pectoris lateribus, coxisque posticis tomento flavescente tectis; processu mesosterni dilatato; pedibus cupreo-micantibus; tibiis anticis in sexu uno et altero tridentatis; mediis ac posticis fiavo-fimbriatis.

Longitudo

Mm. 20.

Habitat in insula Luzon.

Der Clypeus ist mässig hoch umrandet, viereckig, 
vorn etwas ausgebuchtet, in der Mitte nur wenig erhaben, punktirt, bloss in der Nähe des Vorderrandes glänzend, da der braune matte Ueberzug sich sehr weit nach vorn erstreckt. Die Fühlhörner sind braun. Der Thorax ist heller oder dunkler olivenbraun, matt, etwas gewölbt, mit vorspringenden aber abgerundeten Schulterecken, vor dem Schildchen ausgebuchtet. Neben seinem seitlichen und meistens auch seinem vorderen Rande verläuft eine feine weisse Linie, die auf jeder Seite aber erst oberhalb der Schulter ihren Anfang nimmt. Er ist allenthalben punktirt und in der Mitte des Discus mit zwei, häufig mit vier, alsdann in zwei Reihen unter einander stehenden Punkten verziert. In letzterem Falle befinden sich mitunter zwischen den beiden Punkteǹ einer jeden Reihe noch einige weisse Atome, wodurch die Andeutung von zwei sehr feinen Längsbinden entsteht. Das Schildchen ist matt und ungefleckt; die stark punktirten Schultern haben eine hintere weissliche Randeinfassung. Die Flügeldecken sind etwas gewölbt, an der Spitze ein wenig verschmälert und abgerundet. Die Naht ist gefurcht, ragt ziemlich hervor und hat eine kleine Spitze. Die mittleren Längsleisten sind weniger erhaben, und der Raum zwischen ihnen und der Naht ist nicht sehr vertieft. Die Farbe der Flügeldecken ist, wie die des Thorax, ein helleres oder dunkleres Olivenbraun. Auf jeder von ihnen befinden sich zwischen Schulter und Schildchen ein kleinerer oder grösserer, nicht selten kaum sichtbarer, punktförmiger Flecken; zwei Längsstriche oder Längsflecken in der Vertiefung; ein rundlicher neben der Nahtspitze und drei Querflecken an dem äusseren Rande. Zwischen diesen grösseren liegen häufig noch einzelne kleinere. - Sie alle varïren bei den einzelnen Exemplaren sehr hinsichtlich ihrer Grösse und Gestalt. Bei einigen sind die auf der oberen Hälfte der Flügeldecke ausserordentlich fein, wie nur eben angedeutet, die unteren aber mondförmige, mehr oder weniger gekrümmte Linien; bei anderen dagegen beträchtlich breite Querflecken. Bei einigen befinden sich auch noch an der Spitze des Schildchens zwei ganz kleine weissliche Flecken, die bei ande- 
ren, selbst sonst stark gefleckten, fehlen. Das Pygidium ist olivenfarbig, fein quer gestrichelt, mit zwei seitlichen und ebenso viel mittleren, breiteren oder schmäleren gelblichen, filzigen Längsbinden. Bauch und Brust sind kupferfarben, stark glänzend; der erstere hat an jeder Seite zwei alternirende Reihen von je vier gelben Filzflecken. Mit solchen sind auch die Hinterhüften, die Pleuren, die Mesosternalplatten und der umgeschlagene Theil des Brustschildes bedeckt. Die Brustseiten sind dabei nadelrissig und in den Gruben mit Härchen besetzt. Vor den Trochanteren der Hinterschenkel befindet sich ein grösserer gelbfilziger Doppelfleck. Die Beine sind kupferfarben, lang und kräftig, die Schenkel mit gelben Randflecken, vorn und in der Mitte gewimpert. Die Schienen zeigen gelbe Kniepunkte; vorn bei beiden Geschlechtern drei Randzähne, in der Mitte und hinten einen weissen gelblichen Haarsaum.

\section{Cetonia Satrapa n. sp. Mohnike. Taf. XI. Fig. 2.}

C. supra fusco-viridis, opaca; subtus aenea, nitidissima; clypeo quadrato, altius marginato, antice sinuato, angulis reflexis, iuxta marginem tomento flavescente dense tecto, medio plano, subtiliter punctato; fronte viridi; antennis viridibus; thorace subconvexo, dense et subtiliter punctato, linea intra-marginali, antice non interrupta, vittis duabus medianis totidemque maculis inter has et lineam intra marginalem huic saepius coniunctis, flavis, ornato; scapulis postice flavo-marginatis, punctatis; elytris subconvexis, subparallelis; sutura prominente, postice producta, acuminata; iuxta scutellum, inter hoc et bumerum, prope suturam, apice margineque laterali maculis numerosis, forma magnitudineque variis, flavis, tomentosis variegatis; pygidio tomento flavo tecto, viridi tri-vittato; abdomine in utroque latere maculis flavis octo, duplici serie ordinatis, alternantibus, anticis maioribus, medium versus acuminatis, signato; coxis posticis flavo-tomentosis; pectoris lateribus magis minusve tomento tectis; processu mesosterni apice rotundato, non dilatato, parvo; pedibus aeneis; femoribus tomento flavo-marginatis, anticis et me- 
diis flavo-fimbriatis, tibiis anticis maris ac foeminae bidentatis, mediis et posticis flavo-fimbriatis.

Longitudo . . . . . . . . . . Mm. 20.

Habitat in insula Camiguin de Mindanao. $\delta$ ㅇ․

Diese Art unterscheidet sich von der Cet. anovittata sehr wesentlich, wiewohl sie in der Gestalt einige Aehnlichkeit mit derselben zeigt. Sie ist oben lebhaft, bald heller, bald dunkler braungrün, durchaus ohne Glanz und mit einem so dichten filzigen Ueberzuge versehen, dass die Sculptur des Thorax und der Flügeldecken sich nur unter einer starken Loupe urkennen lässt. Der Clypeus ist viereckig, höher umrandet vorn tiefer ausgebuchtet und mehr aufgebogen, wie bei der anovittata. Seine Mitte ist ganz flach, fein punktirt. Eigenthümlich sind bei ihr zwei breite, weissgelbliche, schillernde Streifen, die zwischen den Augen ihren Anfang nehmend, sich von dem Rande bis zu den aufgebogenen Winkeln neben der vorderen Ausbuchtung erstrecken und nur einen schmalen Raum zwischen sich unbedeckt lassen. Die Stỉn ist grün, matt, ungefleckt; die Fühlhörner sind dunkelgrün. Der Thorax ist etwas gewölbt, allenthalben fein nnd dicht punktirt, seitlich von einem breiten, oberhalb der Schultern anfangenden, hinter dem Kopfe ununterbrochenen, vertieften gelben Randstreifen eingefasst. Auf der Mitte des Thorax liegen zwei Längsbinden, die gleichfalls vertieft, bald länger bald kürzer, meistens aber ziemlich breit und von unregelmässiger Gestalt sind; unterhalb derselben zwei Flecken und zwischen diesen und der Randlinie zwei andere. Nicht selten sind dieselben in einander verschmolzen, wie auf der Abbildung. Das Schildchen ist grösser wie das der anovittata, wie bei dieser ungefleckt. Die Schulterblätter haben einen gelben Randsaum. Die Flügeldecken verschmälern sich etwas nach der Spitze zu und sind auch mehr gewölbt und verhältnissmässig kürzer wie bei der anovittata; die Naht ragt beträchtlich hervor und endigt hinten in einer längeren Spitze wie bei letztgenannter. Die Mittelrippen sind nur niedrig. Die Flügeldecken sind neben dem Sehildchen, zwischen diesem und der Schulter, neben der 
Naht und an den Seitenrändern so wie auf ihrer Spitze mit zahlreichen grösseren und kleineren gelben Filzflekken, in deren Gestalt, Grösse und Anzahl eine grosse individuelle Verschiedenheit besteht, bedeckt. Das Pygidium zeigt, in einer dichten gelben Filzdecke, drei schmale grüne, nicht ganz nach oben reichende Längsbinden. Der Unterleib ist sehr glänzend, an den Seiten zerstreut punktirt, und daselbst mit zwei Reihen von je vier, nach der Mitte hin scharf' zugespitzten gelben Längsflecken verziert, von denen die der hinteren Reihe sich mit der Spitze an den unteren, die der vorderen aber mit derselben an den oberen Rand der betreffenden Bauchringe anlegen. Die Hinterhüften sind ganz mit gelbem Filze überzogen, wie auch die Pleuren, die Unterseite der Schultern und der umgeschlagene Theil des Thorax. Die Mesosternalplatten sind punktirt, nadelrissig, mit feinen gelben Härchen besetzt und am vorderen und hinteren Rande mit Filz bedeckt. Der Mesosternalfortsatz ist kurz und endigt in einem runden, seitlich" nicht efweiterten Knopfe, der viel kleiner ist wie bei der anovittata. Die Beine sind erzfarben, glänzend, Schenkel und Schienen nadelrissig und punktirt. Die erstern haben gelbe Randstreifen, die bei einzelnen Stücken fast den ganzen Schenkel einnehmen, und sind an dem vorderen und mittleren Paare gelblich gewimpert, eben wie die mittleren und hinteren Schienen. Die letzteren haben gelbe Kniepunkte und bei beiden Geschlechtern am Vorderrande nur einen Zahn oberhalb der Endspitze.

\section{Cetonia chlorotica Burmeister.}

Protaetia chlorotica Burmeister, Handb. d. Entom. Bd. III. S. 500. - Cetonia subviridis Newman, The Entomol. 1841. Art. XXXIX. p. 170. - Cet. germana Newman, 1. c. - Cet. Manillarum Lacordaire Gen. d. coléopt. Tom. III. p. 536. Not. 1. - Cet. Manillarum Wallace, Transact. entom. Soc. 3. Ser. Vol. IV. 1868. p. 584. Cet. subviridis Gemminger et de Harold, Catal. Coleopt. Tom. IV. p. 1330.

C. supra aut viridis aut viridi-brunnea, opaca; sub- 
tus viridi-aenea nitidissima; clypeo quadrato, marginato, antice sinuato, subtiliter ac dense punctato, medio plano; antennis brunneis; thorace triangulari, subconvexo, linea tenui intramarginali punctisque duobus disci minimis, albo-flavescentibus distincto; scapulis punctatis, postice albo-marginatis; scutello brevi, immaculato; elytris parallelis, subconvexis, apice rotundatis, sutura prominenti, acuminata; inter scutellum et humerum, iuxta suturum, apice margineque laterali punctatis et lineolis albo-flavescentibus ornatis; pygidio tomento flavo dense tecto; abdominis lateribus maculis sedecim flavo-tomentosis, quadruplici serie, variatis; pectore, sterno excepto, densissime tomento flavo obducto, processu mesosterni brevi, dilatato, pedibus viridi-aeneis, nitidis.

Longitudo

Mm. 17.

Habitat in insula Luzon. of $f$.

Diese Art, von welcher ich das von Burme ister bestimmte Original-Exemplar vor mir habe, gleicht auf den ersten Blick in hohem Grade jener, die van mir Uebers. d. Cet. d. Sunda-Inseln und Molukken S. $76-$ als Protaetia Ternatana beschrieben wurde, wiewohl sie in der Form des Clypeus und des Brustschildes, so wie auch noch in einigen andern Punkten, sich wesentlich von ihr unterscheidet. Der Clypeus ist quadratisch, seitlich niedriger als vorn umrandet, daselbst nicht unbeträchtlich ausgebuchtet, mit abgerundeten, aufgebogenen Ecken, in der Mitte wenig erhaben, punktirt, matt; die Stirne etwas gewölbter und gleichfalls matt, zwischen den Fühihörnern feiner punktirt. Die letzteren sind braungrün. Der Thorax ist fast dreieckig, ziemlich gewölbt, an den Seiten zerstreut und gröber, nach der Mitte zu, feiner punktirt, matt, mit seitlicher, feiner gelblicher Randlinie, die aber erst oberhalb der Schulter beginnt, und zwei kleinen, gelblichen Punkten in der Mitte des Discus. Die etwas dunkleren, stark punktirten Schulterblätter haben eine hintere gelbliche Randeinfassung. Das Schildchen ist ziemlich kurz, matt, unpunktirt, ungefleckt. Die Flügeldecken sind nicht ganz unbeträchtlich gewölbt, parallel, hinten gerundet, mit hervorragender, hinten stark zugespitzter 
Naht. Die Vertiefung zu beiden Seiten derselben ist sehr gering. Neben der Naht zeigen sich verschiedene concentrische, bogenförmige, nach aussen concave, stumpfe, erhabene Linien. Die Flügeldecken sind allenthalben, am stärksten aber an den Seiten, ziemlich grob punktirt. Auf jeder von ihnen befindet sich ein kleiner gelblicher Punkt zwischen Schildchen und Schulter, zwei kleine neben einander stehende, mitunter mit einander verbundene und so eine kleine Querbinde bildende, in ihrer Mitte neben der Naht; in der Mitte zwischen diesen und der Spitze, ebenfalls ein Paar Punkte oder eine kleine Querbinde, nicht selten von halbmondförmiger Gestalt; ausserdem einige Punkte an der Spitze, so wie einige Strichelchen und Punkte am Seitenrande. Hinsichtlich dieser Zeichnung besteht grosse individuelle Verschiedenheit. Häufig fehlen einige der genannten, oder aber es ist statt des einzelnen Punktes eine Gruppe von Punkten vorhanden und es sind dieselben bald stärker bald schwächer.

Die ganze Oberseite hat eine helleré oder dunklere, mitunter in das Olivenbraune übergehende, grüne Färbung, ist matt, an abgeriebenen Stellen aber hell metallisch grün schimmernd.

Das Pygidium ist fein quer gestrichelt und dergestalt mit gelbem Filze bedeckt, dass allein in der Mitte kleinere oder grössere grüne Stellen durchschimmern. Die Unterseite ist in der Mitte sehr glatt und glänzend, hell metallisch grün, oder mehr kupferfarben. Die Brustseiten sind bis zum Sternum mit einer ununterbrochenen dichten, gelben Filzdecke überzogen; am Bauche finden sich jederseits zwei Reihen von je vier Randflecken, von denen die in der inneren Reihe vorn und hinten zugespitzt sind. Der Mesosternalfortsatz ist seitlich nur wenig erweitert. Die Beine sind schlank, grün metallisch glänzend, die Schenkel mit gelben Randflecken und gewimpert. Die Schienen haben gelbe Kniepunkte; die mittleren und hinteren sind gelb gewimpert, die vorderen haben auch bei den Männchen drei Randzähne. 


\section{Cetonia Manillarum Chevrolat.}

Cetonia Manillarum Chevrolat in Guérin Revue zool. Tom. IV. 1841. p. 213. - Protaeiia Manillarum Burmeister, Handb. d. Entom. Bd. III. S. 497.

C. supra obscura aenea, aliquid viridescens, subnitida ; subtus obscure-fusca, nitida; clypeo quadrato, marginato, antice vix sinuato, angulis rotundatis, medio elevatiore, undique punctato; antennis brunneis; thorace subconvexo, linea intra-marginali alba, disco punctis duobus albis ornato, dense punctato; scutello subtriangulari, immaculato, non punctato; scapulis punctatis, postice albomarginatis; elytris subparallelis, subconvexis, densissime subtiliter punctato-striatis, sutura non acuminata, hac et carinis medianis prominentibus, iuxta scutelli basin et apicem, inter hunc et humerum, prope suturam, apice et margine laterali, albo-maculatis; pygidio striolato, basi et apice albo-maculato; abdomine maculis albis sedecim, quadruplici serie positis, non alternantibus, distincto; pectoris lateribus magis minusve albo-maculatis; processu mesosterni parum dilatato; pedibus fortibus, fusco-nigris, nitidis; tibiis anticis maris et feminae tridentatis.

Longitudo . . . . . . . . . Mm. 17-18.

Habitat in insula Luzon. $\sigma$ \%

Die von Burmeister 1. c. als Cetonia Manillarum Chevrol. beschriebene Art wird von S c ha um - Annal. d. 1. Soc. Entom. de France. 1849. p. 279. - mit der von Chevrolat selbst, unter diesem Namen in Guérin's zoologisoher Revue Vol. IV. 1841. p. 223 bekannt gemachten, für nicht identisch gehalten, sondern zu Cet. anovittata Chevrol. gezogen. Ihm stimmen auch Gemmi nge $r$ und von Harold in ihrem Cataloge Tom. IV. p. 1321 bei. Nach genauer Vergleichung aber der von Burmeister selbst als Cet. Manillarum bestimmten Stïcke im Museum zu Halle und anderer mir vorliegender, denselben vollkommen gleichender, mit der in Guérin's Revue mitgetheilten Beschreibung der Cet. Manilla. rum, finde ich, dass diese Beschreibung weniger mit der anovittata, als mit den mir vorliegenden Exemplaren der 
B u r m eis t er'schen Cet. Manillarum übereinstimmt. Die letztere ist jedenfalls eine eigenthümliche, unter den vielen verwandten Arten von den Philippinen, welche ich in einer beträ̉chtlichen Anzahl von Exemplaren vor mir habe, sich als selbstständig darstellende Art.

Sie hat einen ziemlich schlanken und gestreckten Körperbau, ist dabei aber gewölbter als die Cet. anovittata; oben dunkel erzbraun, matt, bei einigen Stücken jedoch etwas glänzender, mit einem leichten metallischen Anfluge. Der Clypeus ist viereckig, mässig hoch gerandet, vorn sehr wenig ausgebuchtet, mit abgerundeten Ecken, in der Mitte breit erhaben, allenthalben dicht, aber ziemlich grob punktirt. Braune Fühlhörner. Der Thorax ist gewölbt, mit etwas vorspringenden Winkeln in der Mitte seiner Seitenränder, vor denselben aber keineswegs sehr verschmälert, allenthalben fein und dicht punktirt, mit ziemlich breiten, schon neben der Basis der Flügeldecken beginnenden, hinter dem Kopfe nicht zusammenhängenden weissen Randstreifen und zwei grösseren weissen Punkten in der Mitte des Discus. Das Schildchen ist ohne Punktirung und nicht gefleckt, etwas glänzend. Die stark punktirten Schulterblätter haben eine weisse hintere Randeinfassung. Die Flügeldecken sind fast parallel, hinten etwas gerundet, mit stark hervortretender Naht und eben solchen mittleren Leisten. Der Raum zwischen letztern und der Naht ist stark vertieft; diese etwas glänzend, nicht sehr gefurcht, am Ende ohne Spitze. Die Flügeldecken sind sehr dicht, aber fein punktirt; hauptsächlich in der Vertiefung bilden diese Punkte deutlichere Längsreihen. Auf jeder von ihnen liegen ein grösserer weisser Filzfleck neben der Basis des Schildchens, ein kleinerer, mehr linienförmiger, neben dessen Spitze und ein dritter zwischen letzterer und der Schulter. Letztere hat, von der scapula an, eine weisse Randeinfassung, die unterhalb des Seitenausschnittes in einen grösseren Querfleek übergeht. Auf diesen folgen, fast in gleichen Abständen von einander, längs dem äusseren und unteren Rande bis zur Nahtspitze, noch fünf andere, grössere Querflecken. Der dritte von ihnen ist der 
grösste. Seine Lage entspricht der Mitte von zwei grössern neben der Naht liegenden Flecken. Im Allgemeinen ist die Zeichnung bei dieser Art mehr constant und individuell nicht so verschieden, wie bei der anovittata und andern. Das Pygidium ist Orange-farbig gestrichelt und mit vier weissen Flecken auf seiner Basis, so wie zweien auf seiner Spitze, gezeichnet. Der Bauch hat auf jeder Seite die bekannten zwei Reihen von je vier weissen Randflecken, die aber nicht alterniren und kleiner sind wie bei der anovittata und andern verwandten Arten. Auch die Brustseiten sind viel weniger mit Filz überzogen und zeigen nur einzelne weisse Flecken. Sie sind punktirt und nadelrissig. Der Mesosternalfortsatz endigt knopfförmig und ist seitlich wenig erweitert. Die Beine sind schwarzbraun, glänzend, nicht sehr lang aber kräftig. Die vorderen und mittleren sind gelb gewimpert, die hinteren haben einen weissen Randflecken neben dem Kniegelenke. Die vorderen Schienen sind bei beiden Geschlechtern dreigezähnt, die mittleren und hinteren fein gelb gewimpert und alle mit weissen Kniepunkten versehen. Die Tarsi sind kurz.

\section{Cetonia venerabilis n. sp. Mohnike. Taf. XI. Fig. 3.}

C. supra laete viridis, sericea; subtus cuprea, nitida; clypeo quadrato, marginato, antice profundius sinuato, angulis rotundatis, nitido, medio elevato, saepius tomento viridi tecto, punctato; antennis brunneis; thorace subconvexo, flavo-marginato, disco saepius bipunctato; scapulis grosse punctatis, aut viridibus aut cupreis, saepius postice flavo marginatis; scutello immaculato, non punctato; elytris subconvexis, parum convergentibus, iuxta suturam, apice, margineque laterali, maculis flavo-tomentosis magis minusve ornatis; pygidio basi et lateribus flavo-tomentosis; abdomine lateribus quadruplici ordine flavo-maculato; pectore tomento flavo magis minusve vestito; processu mesosterni dilatato; pedibus robustis, viridicupreo-micantibus, tibiis anticis in utroque sexu tridentatis. 
Longitudo

Habitat in insula Luzon. $\delta$.

Ich habe die drei mir vorliegenden Exemplare dieser Art sowohl mit allen von New man im "Entomologisten" gegebenen Beschreibungen Philippinischer Cetoniden, als auch mit zahlreichen Varietäten der Cet. ferruginea, anovittata, chlorotica Burm. und anderer, sehr sorgfältig verglichen. Hieraus ergab sich als Resultat, dass ich diese Art für eine selbstständige, bis jetzt noch nicht beschriebene halten muss. Sie ist oben allenthalben lebhaft blattgrün gefärbt, matt, sammtartig; unten stark metallisch, je nacbdem man sie gegen das Licht hält, mehr grün oder mehr kupferroth glänzend. Der Clypeus ist quadratisch, mässig hoch umrandet, in der Mitte breit, polsterartig erhaben, punktirt, bis zu dem Vorderrande matt, mit grünem Ueberzuge. Der Vorderrand allein ist, mehr oder weniger stark, glänzend, sehr beträchtlich ausgebuchtet, mit stumpfen, etwas aufgebogenen Ecken. Fühlhörner braun. Thorax ziemlich gewölbt, mit gleichmässig gebogenen, in der Mitte nicht eckigen Seitenrändern und abgerundeten Schulterecken. Neben dem Rande verläuft ein gelber Streifen, der sich mitunter mit dem der andern Seite hinter dem Kopfe vereinigt. Seine Mitte ist entweder leer oder es zeigen sich auf ihr zwei grössere oder kleinere, mitunter kaum sichtbare gelbe Punkte. Das Schildchen ist ungefleckt; die entweder grünen oder kupferbraunen, stark punktirten Schulterblätter haben einen hinteren gelben Rand. Derselbe fehlt aber dem einen, übrigens durchaus frischen Stücke der mir vorliegenden. Die Flügeldecken sind ziemlich convex, verschmälern sich nach der Spitze zu ein wenig und haben eine sehr beträchtliche Vertiefung neben der Naht, da diese und die mittlere Längsrippe stark hervorragen. Erstere hat nur eine sehr kurze Spitze. Alle drei mir vorliegenden Exemplare sind verschieden gezeichnet. Bei dem am stärksten gezeichneten finden sich auf jeder Flügeldecke ein gelber, rundlicher Flecken zwischen Schulter und Naht, zwei grössere, viereckige neben letz terer und ein kleinerer neben ihrer Spitze, ausserdem 
vier grössere, von denen der dritte am längsten ist, am Seitenrande. Bei dem zweiten. Stücke befinden sich nur der untere Nahtflecken, der kleinere neben ihrer Spitze, so wie die vier Randflecken. Das dritte Stück endlich hat nur den oberen, aber zu einem Punkte verkümmerten Nahtflecken, einen Púnkt unter dem Endbuckel, so wie einen etwas grösseren Randflecken unterhalb des Nahtpunktes. Diese Flecken sind bei allen gelbfilzig. Die Flügeldecken sind überall, aber sehr fein und ziemlich weitläuftig punktirt. Das Pygidium ist entweder an den Seiten ganz mit gelbem Filze überzogen, so dass nur ein mittlerer grüner Längsstreifen übrig bleibt, oder es hat vier Flecken auf dem Grunde und zwei auf der Spitze; oder aber die unteren sind mit den mittleren auf dem Grunde verbunden. Der Bauch ist an den Seiten und an seiner Spitze zerstreut punktirt und hat die bekannten vier Reihen von je vier, alternirenden Randflecken. Die Brustseiten sind bei dem einen Stücke fast ganz, bei den andern nur hier und da mit gelbem Filze überzogen. Sie sind nadelrissig und auch mit einzelnen röthlichen Härchen besetzt. Vor den Trochanteren der Hinterschenkel liegt ein gelber Doppelfleck und auch die Hinterhüften sind entweder ganz oder theilweise gelbfilzig. Der Mesosternalfortsatz ist ziemlich breit und seitlich erweitert. Die Beine sind mässig lang aber sehr kräftig. Die Schenkel haben längere oder kürzere gelbe Randstreifen, die Schienen solche Kniepunkte. Die letzteren sind an dem ersten Paare bei dem Weibchen vorn breit, bei dem Männchen schmäler, bei beiden dreigezähnt. Die mittleren und hinteren haben wie die vorderen und mittleren Schenkel einen gelben Haarsaum. Auch die Tarsi sind kurz aber stark gebaut.

28. Cetonia Boholica n. sp: Mohnike. Taf. XI. Fig. 4.

C. supra viridis, opaca; subtus obscure aenea, nitida; clypeo vix marginato, feminae quadrato, maris longiore, antice profunde sinuato, medio plano, punctato, viridi; antennis brunneis; clypeo subconvexo, angulis anticis saepius flavo-aureo maculato; scutello immaculato; scapulis 
punctatis, obscure viridibus, rarius postice aut flavo-punctato aut flavo-marginato, elytris feminae quadratis, planioribus, maris subconvexis, parum convergentibus; in utroque, inter suturam carinasque medianas valde prominentes, profunde depressis, singulo infra medium, iuxta suturam, maculis duabus magnis hamatis, margine vero maculis aut tribus aut quattuor, quarum inferiores duo maiores, flavo-aureis ornato; sutura feminae inermi, maris acutissime acuminata; pygidio viridi, lateribus magis minusve flavo-tomentosis; feminae abdomine lateribus quadrüplici serie macularum tomentosarum distincto, maris vero tomento flavo-aureo dense restito; pectoris lateribus maris undique dense, feminae partim solum et distanter tomentosis; processu mesosterni subgloboso, dilatato; pedibus fortibus, femoribus anticis et mediis, tibiis mediis et posticis dense flavo-fimbriatis, feminae tibiis anticis tridentatis maris vero bidentatis.

Longitudo

Mm. 20-23.

Habitat in insula Bohol. $\sigma$ \%

Bei dieser Art, von der ich sechs Exemplare vor mir habe, findet sich ein mehrfacher Geschlechtsunterschied. Bei dem Männchen ist der Clypeus etwas länger und schmäler, in der Mitte ganz flach, bei dem Weibchen dagegen mehr angeschwollen, überhaupt breiter und mehr viereckig; bei beiden nur sehr niedrig umrandet, vorn aber tief ausgebuchtet, allenthalben fein und dicht punktirt. Die Fühlhörner sind braun. Der Thorax ist mässig gewölbt, mit gleichmässig bogigen Seitenrändern, sehr fein und kaum sichtbar punktirt, mitunter mit zwei kleinen goldgelben Flecken, als Andeutung einer Randlinie, in den Augenwinkeln. Das Schildchen ist ziemlich gross, grün, ohne Punktirung und Flecken. Die Flügeldecken sind bei dem Weibchen viereckig und flacher, bei dem Männchen mehr gewölbt und hinten etwas verschmälert. Die mittleren Leisten und die Naht ragen beträchtlich hervor, und der Raum zwischen beiden ist stark vertieft. Die Naht ist gefurcht und bei dem Männchen mit einer starken und scharfen, bei dem Weibchen mit keiner Endspitze versehen. Auf jeder Flügeldecke liegen in der 
Vertiefung, dicht neben der Naht, zwei grosse Flecke; der obere von runder oder viereckiger Gestalt, der untere mehr von der Gestalt eines langschenkligen Dreieckes, mit der Spitze nach unten und aussen gerichtet. Der Mitte beider entsprechend, ibnen gegenüber, befindet sich ein breiter und langer, sich oben verschmälernder Randfleck, während ein zweiter, gekrümmter unter demEndbuckel liegt, und mit seiner Spitze hart an den untersten Nahtflecken stösst. Dieser zweite Randfleck fehlt nicht selten. Ausserdem befinden sich, unterhalb des Seitenausschnittes, noch mitunter zwei bis drei kleinere Flecken. Alle diese Flecken sind von schöner, goldgelber Farbe, wo sie ausgeblichen sind, mehr weisslich. Das Pygidium ist fein punktirt; und entweder ganz mit gelbem Filze überzogen, so dass nur ein unterer, dreieckiger Ausschnitt grün bleibt, oder aber es befinden sich in der Mitte desselben, von dem Grunde ausgehend, zwei dreieckige Flecken, und neben ihnen, auf jeder Seite, ein kleinerer, runder. Der Bauch ist bei den Männchen dergestalt mit feinem, seidenartigen Filze von hochgelber Farbe bedeckt, dass nur ein schmaler mittlerer Streifen, die untere Hälfte des vorletzten Segmentes und das ganze letzte, eine lebhaft glänzende, dunkle Erzfarbe zeigen. Auch die-Brustseiten sind bei dem Männchen dicht und ununterbrochen mit solchem Filze überzogen. Bei dem Weibchen finden sich dagegen am Bauche nur die bekannten vier Reihen alternirender Randflecken; ein Doppelfleck vor den Trochanteren der Hinterschenkel, aber auf den Pleuren, $\mathrm{Pa}$ rapleuren, den Unterseiten der Schulterstücke so wie dem umgeschlagenen Theile des Thorax, nur hier und da filzige Flecken. Der Mesosternalfortsatz ist halbkugelig seitlich erweitert. Die Beine sind kräftig; die Schenkel des Männchens häufiger, die des Weibchens seltener mit gelben Randstreifen, die Schienen immer mit gelben Kniepunkten. Die vorderen und mittleren Schenkel, die mittleren und hinteren Schienen haben einen gelben Haarsaum, die Vorderschienen bei dem Männchen zwei, bei dem Weibchen drei Randzähne. 
29. Cetonia compacta n. sp. Mohnike. Taf. XI. Fig. 5.

C. supra laete viridi-brunnea, opaca; subtus brunnea, nitida; clypeo quadrato, marginato, antice emarginato, angulis rotundatis, medio elevato, undique punctato; antennis brunneis; thorace lateribus arcuato, angulis scapularibus rotundato, convexo, ante scutellum parum sinuato, usque ad medium punctis minimis piliferis tecto, linea intra-marginali et punctis medianis aut duobus aut quattuor flavis, tomentosis distincto; scutello triangulari, immaculato, non punctato; scapulis punctatis, pilis flavis dense vestitis, postice tomento flavo marginatis; elytris valde convexis, convergentibus, striato-punctatis, apice rotundatis, sutura minime acuminatis, hac et carinis medianis parum elevatis, iuxta scutelli apicem, prope suturam, apice margineque laterali, maculis flavis, tomentosis, ornatis; pygidio punctato, omnino paene tomento flavo obtecto; abdomine punctato, quadruplici serie flavo-maculato; pectoris lateribus aciculatis, pilosis, tomento flavo vestitis; processu mesosterni apice rotundato, parum dilatato; pedibus fortibus, brevibus, obscure brunneis, femoribus pilosis, his et tibiis medianis posticisque flavo-fimbriatis, tibiis anticis tridentatis; tarsis brevibus.

Longitudo

Mm. 18.

Habitat in insula Camiguin prope Mindanao. $\delta$ \%

Eine am nächsten der Cet. flavo-variegata stehende, sich durch ihren kúrzen, gedrungenen Körperbau so wie ihre sehr beträchtliche Convexität auszeichnende Art. Sie ist oben hellbraungrün mit vorherrschendem Grün und matt, unten dagegen dunkelbraun und glänzender. Der Clypeus ist ziemlich klein, quadratisch, stumpf gerandet, vorn ausgebuchtet mit abgerundeten Ecken, in der Mitte schwielig erhaben, allenthalben punktirt. Die Fühlhörner sind braun. Der Thorax hat gleichmässig gebogene Seitenränder, abgerundete Schulterecken, ist stark convex, vor dem Schildchen wenig ausgebuchtet, bis zur Mitte hin fein, aber nicht dicht punktirt und in den Vertiefungen mit ganz kurzen Härchen besetzt. Er bat einen 
seitlichen, an den Schultern beginnenden, hinter dem Kopfe unterbrochenen, gelben, filzigen Randstreifen und auf dem Discus zwei oder vier, in letzterem Falle in zwei Reihen gestellte gelbe Punkte. Die Schultern sind stark punktirt, dicht haarig und zugleich mit einem breiten hinteren Randsaume. Das Schildchen ist ohne Punktirung und Flecken. Die Flügeldecken sind stark convex, etwas convergirend, an der Spitze abgerundet. Sie sind bis zum Discus hin reihenweise punktirt. In der Vertiefung, die sehr unbeträchtlich ist, bilden diese Punktreihen mit ihrer Concavität nach aussen gerichtete Bogen. Die mittleren Längsrippen, so wie die Naht, ragen wenig hervor; letztere hat eine sehr geringe Furche und eine ganz kleine Endspitze. Auf jeder Flügeldecke befinden sich folgende Flecken: Ein ganz kleiner oberhalb der Spitze des Schildchens, unmittelbar neben der Nabt; zwei ziemlich grosse in der Vertiefung gleichfalls neben letzterer, so wie zwei andere neben ihrer Spitze; ausserdem noch ein Flecken oder Punkt auf der Mitte des Grundes zwischen Śchildchen, und Schulter so wie endlich drei bis vier grössere und verschiedene kleinere neben dem Seitenrande. Das Pygidium ist nadelrissig, mit Härchen besetzt, und so dicht mit gelbem Filze bedeckt, dass nur in seiner Mitte die dunkle Grundfarbe mehr oder weniger durchschimmert. Der Bauch ist allenthalben punktirt, nicht sehr glänzend, auf den letzten Segmenten mit röthlichen Härchen besetzt, und zeigt seitlich die so häufig vorkommenden vier Reihen von je vier alternirenden Randflecken. Die Brustseiten sind nadelrissig, röthlich behaart und allenthalben, aber nicht sehr dicht gelbfilzig. Der Mesosternalfortsatz ist abgerundet, seitlich etwas erweitert. Die Beine sind kurz und kräftig; die Schenkel nadelrissig, behaart, mit gelben Randstreifen, und, wie auch die mittleren und hinteren Schienen, röthlich gelb gewimpert. Die letzteren haben gelbe Kniepunkte. Vorn sind sie dreigezähnt. Auch die Tarsi sind kurz aber kräftig. 
30. Cetonia tenuicollis n. sp. Mohnike. Taf. XI. Fig. 6.

C. supra obscure olivacea, opaca ; subtus nigra, nitida; clypeo parvo, subquadrato, antice sinuato, medio subelevato, dense punctato; antennis obscure fuscis; thorace parvo, subrotundo, elytris angustiore, plano, punctato, linea intra-marginali abbreviata, discoque punctis octo albis ornato; scapulis punctatis, piliferis, postice albomarginatis; elytris planis, convergentibus, undique dense punctatis, lineolis, maculis, punctisque albis permultis variegatis; carinis suturaque parum prominentibus; hac non acuminata; pygidio punctato, subpiloso, albo-variegato; abdomine albo maculato; pectoris lateribus aciculatis, pilosis, maculis nonnullis albidis variatis; processu mesosterni aliquid elongato, non dilatato; pedibus fortibus non longis; femoribus punctatis, subpilosis, flavo-fimbriatis; tibiis mediis et posticis fimbriatis, anticis tridentatis.

Longitudo . . . . . . . . . . Mm. 20.

Habitat in insula Camiguin de Mindanao ?.

Der Clypeus ist in der Mitte nur sehr wenig erhaben, klein, nicht ganz quadratisch, sondern mit etwas gebogenen Seitenrändern, vorn nur mässig ausgebuchtet, mit sturnpfen Ecken, allenthalben punktirt; Fühlhörner dunkelbraun. Thorax klein, hinten schmäler als die Flügeldecken unterhalb des Seitenausschnittes, mit gleichmässig gebogenen Seitenrändern, auffallend flach, allenthalben punktirt, mit weissem, nur bis zum untersten Drittheil des Randes reichenden Streifen neben demselben, in der Mitte mit acht gelblichen Punkten, von denen je drei in einer Längslinie, und je einer neben denselben liegen. Das Schildchen dreieckig, klein, ungeflcckt; die Schultern punktirt mit hinterem weissen Randstreifen. Die Flügeldecken flach, etwas convergirend, hinten gerandet, mit sehr wenig erhabenen Mittelleisten und Naht; die letztere nicht zugespitzt. Sie sind allenthalben, aber nicht reihenweise, wie bei der vorigen, punktirt und mit zahlreichen grösseren und kleineren, gelblichweissen Punkten, Flecken und Linien zerstreut 
bedeckt. Ihre Grundfarbe ist, wie die des Thorax und Kopfes, ein dunkles, mattes, schwärzliches Braun. Das Pygidium ist braun, matt und nadelrissig, oben mit einem, in der Mitte getrennten gelblichweissen Filzstreifen, von dem sich zwei weniger dichte Fortszäte nach der Spitze hinziehen. Hin und wieder zeigen sich auf dem Pygidium einzelne Härchen. Die Unterseite ist schwarz, der Bauch glänzend, zerstreut punktirt, mit zwei Reihen schma"ler, nicht alternirender Randflecke, von je vier an jeder Seite. Die Brustseiten sind nadelrissig, zerstreut mit röthlichen Härchen besetzt, und zeigen nur an einzelnen wenigen Stellen weisse Filzflecken. Der Mesosternalfortsatz ist etwas verlängert, nicht seitlich erweitert. Die Beine sind ziemlich kurz aber kräftig, die Schenkel nadelrissig, mit Härchen besetzt und, wie auch die mittleren und hinteren Schienen, gewimpert. Die letzteren haben weisse Kniepunkte und sind an dem vordersten Paare dreigezähnt.

31. Cetonia moerens n. sp. Mohnike. Taf. XI. Fig. 7.

C. supra brunneo-nigra, opaca, subtus aut nigra aut obscure brunnea, nitida; clypeo quadrato, marginato, antice sinuato, punctato; antennis nigris; thorace convexo, ante scutellum profunde sinuato, punctato, linea intra-marginali punctisque disci sex aut octo albis distincto; scapulis postice albo-marginatis; scutello longo, angusto, acuminato; elytris convexis, convergentibus, prope scutellum depressis, undique grosse punctatis, sutura carinisque prominentibus, gibbis posticis callosis, sutura maris acuminata, feminae inermi; pygidio nigro, punctato, tomento albo magis minusve tecto, haud rare albo quadrivittato; abdominis pectorisque lateribus albo-maculatis; processu mesosterni maris brevi, rotundato; feminae longiori, acutiori; pedibus fortibus, longiusculis; tibiis anticis maris bidentatis, feminae vero tridentatis.

Longitudo .

Mm. 20.

Habitat in insula Mindanao. $\delta \%$.

Diese Art unterscheidet sich von der vorigen durch 
einen ganz anderen Körperbau und stimmt in dieser Beziehung mehr mit der oben beschriebenen Cet. Satrapa überein, kann aber nicht als Varietät dieser letzteren angesehen werden. Sie ist oben braunschwarz, matt, aber nicht so dicht wie die meisten andern Arten, mit dem eigenthümlichen, filzigen Ueberzuge bedeckt, so dass der Thorax und die höheren Stellen der Flügeldecken, einen gewissen, wenn auch nur sehr geringen Grad ron Glanz besitzen. Unten ist das Männchen dunkelbraun, das Weibchen schwarz, beide glänzend. Der Clypeus ist quadratisch, umrandet, vorn ausgebuchtet, in der Mitte etwas erhaben, grob und dicht punktirt. Füblhörner schwarz. Thorax viel gewölbter, grösser und von anderer Gestalt wie bei der vorigen; die Seitenränder bilden an ihrem vorderen Dritttheile einen stumpfen Winkel. Er ist an den Seiten dichter, in der Mitte zerstreuter, grob punktirt; vor dem Schildchen tief ausgebuchtet; hat seitlich und, bei dem Männchen, auch eine vordere weisse Randeinfassung und in der Mitte, bei dem Weibchen sechs, bei dem Männchen aber acht, ähnlich wie bei der vorigen Art gestellte, vertiefte weisse Flecken. Das Schildchen ist länger, schmäler und spitzer wie bei letzterer. Die Schulterblätter sind glänzend schwarz, punktirt und mit einem hinteren, breiten, weissen Randstreifen. Die Flügeldecken sind ziemlich gewölbt, an der Spitze etwas convergirend, allenthalben, besonders aber bei dem Weibchen, wo die Sculptur überhaupt viel stärker als bei dem Männchen ist, dicht aber grob punktirt. Die Naht und Mittelrippen, so wie die hinteren Buckel ragen stark hervor. Die letzteren sind, besonders bei dem Weibchen, stark schwielig aufgetrieben und ohne alle Punktur. Die Naht hat bei dem Männchen eine ziemlich starke und kräftige Spitze, bei dem Weibchen keine. Auf jeder Flügeldecke liegt oben in der Schildchenecke ein ziemlich grosser, weisser Filzfleck, ein anderer, ebenfalls grösserer, neben der Spitze des Schildchens, ein dritter, kleinerer, zwischen diesem und der Schulter; zwei grosse, meistens hakenförmige, der obere nach innen, der untere nach aussen gekrümmt, neben der Naht, in der Vertiefung; zwei 
oder drei an dem hinteren, und vier, von denen der dritte, dessen Lage der Mitte der beiden grossen Nahtflecken entspricht, der grösste ist, an dem Seitenrande. Alle diese Flecken sind vertieft. Das Pygidium ist schwarz, punktirt, bei dem Männchen mit vier weissen Längsbinden, bei dem Weibchen etwas haarig, mit zwei grossen dreieckigen, nur einen schmalen Zwischenraum offen lassenden weissen Flecken, in deren jedem sich oben eine runde schwarze Stelle befindet. Der Bauch ist an den Seiten zerstreut punktirt und trägt die so häufig vorkommenden vier Reihen von je vier alternir enden Randflecken. Die Hinterhüften sind bei dem Männchen ganz weiss. Die Brustseiten sind stark nadelrissig und hier und da mit röthlichen Härchen besetzt. Vor den Trochanteren der Hinterbeine liegt ein weisser Doppelfleck und ist die Mesosternalplatte auch oben weiss gefleckt. Auch die Pleuren, die Unterseite der Schulter und der umgeschlagene Theil des Thorax sind mit solchem Filze bedeckt. Der Mesosternalfortsatz ist bei dem Weibchen etwas mehr nach vorn verlängert und nicht ganz so stumpf und abgerundet wie bei dem Männchen. Die Beine sind dunkelbraun, bei dem Weibchen etwas schwärzlich, kräftig und ziemlich lang; die Schenkel nadelrissig, vorn und in der Mitte nicht sehr stark röthlich gewimpert, mit weissen Randflecken; die Schienen haben weisse Kniepunkte, sind hinten so wie in der Mitte schwach und kurz gewimpert und haben vorn bei dem Weibchen drei, bei dem Männchen nur zw ei Randzähne.

Diese Art steht, wie schon oben bemerkt wurde, der Cet. Satrapa am nächsten, ist aber keine Varietät derselben.

32. Cetonia incerta n. sp. Mohnike. Taf. IX. Fig. 8.

C. pracedentibus multo minor, supra obscure viridis, aenea, subnitida; subtus nigra, subnitida; clypeo parvo, quadrato, minime marginato, antice non sinuato, medio non elevato, dense punctato; thorace subconvexo, angulis humeralibus rotundato, ante scutellum vix sinuato, grosse 
punctato, vitta mediana elevatiori, fossisque quattuor erosis distincto; scapulis permagnis, punctatis; scutello minus punctato; elytris convexis, convergentibus, gibbis posticis valde prominentibus, inter hos et suturam depressis, sutura minus elevata non acuminata; pygidio transversim striolato; abdomine pectoreque lateribus magis ac densius, medio minus punctatis; processu mesosterni brevi, subacuto; femoribus grosse punctatis; tibiis anticis omnino indentatis, mediis et posticis unidentatis, rufo-fimbriatis.

Longitudo

Habitat in insula Mindanao. $\delta$.

Das einzige Exemplar, welches mir von dieser interessanten Art vorliegt, ist leider so schlecht erhalten, dass sich fast nur noch die Gestalt beschreiben lässt. Die Farbe ist oben, mit Ausnahme der später zu besprechenden helleren Stellen auf den Flügeldecken, ein dunkles, schmutziges, beinahe schwärzliches, Grün mit mattem Metallglanze, unten ein mattes, schmutziges, nur in der Mitte etwas glänzenderes Schwarz. Da das vorliegende Stück ganz abgerieben erscheint, so ist diese Färbung jedenfalls nicht die ursprüngliche. Der Clypeus ist nnr niedrig umrandet, vorn nicht ausgebuchtet, in der Mitte etwas erbaben, allenthalben punktirt. Die Fühlhörner sind schwärzlich. Der Thorax ist gewölbt, hinten gerundet, vor dem Schildchen kaum etwas ausgebuchtet, allenthalben grob, und ziemlich weitläuftig punktirt. In seiner Mitte verläuft ein erhabener, etwas glänzender Streifen von dem Kopfe bis zum Schildchen, neben welchem auf jeder Seite drei vertiefte, in frischem Zustande wahrscheinlich mit weissem Filze bedeckte Stellen liegen. Die Schultern sind gross, stark punktirt. Die Flügeldecken sind convex, verschmälern sich nach hinten beträchtlich und zeigen besonders stark hervorragende Hinterbuckel. Die Naht ist mässig erhaben und nicht zugespitzt. Die Flügeldecken sind allenthalben punktirt und zeigen zwischen den Schultern und dem Scutellum, neben der Naht, so wie am Seitenrande, vertiefte Stellen, in denen sich noch die Spuren eines früheren, weissen Filzüberzuges erkennen lassen. Das Pygidium ist stark 
punktirt, in seinem gegenwärtigen Zustande ohne Flecken. Unten ist das vorliegende Exemplar ganz schwarz, die Stellen, wo früher hellere Flecken waren, lassen sich nicht mehr erkennen. Die Seiten des Bauches und der Brust sind stark punktirt. Der Mesosternalfortsatz ist kurz, etwas spitzig. Die Beine sind kräftig und ziemlich lang, die Schenkel grob punktirt. Die mittleren und hinteren Schienen haben einen röthlichen, spärlichen Haarsaum und einen Randzahn, die vorderen dagegen sind gänzlich ungezähnt.

\section{Sectio VI. Cremastochilidae.}

\section{Genus I. Callynomes Westwood.}

\section{Callynomes niveo-sparsa Westwood.}

C. atra, supra velutina, opaca, subtus nitida; clypeo lato, brevi, arcuato, antice marginato, aliquid reflexo, dense punctato; fronte atomis albidis parum sparso; antennis fusco-nigris nitidis; thorace parvo, elytris multo angustiore, plano, subrotundo, angulis anticis protractis, acuminatis, scabrose-punctato maculis, partim obsoletis, albidis octo, triplici serie positis ornato; scapulis grosse punctatis, nitidis, postice tenuissime albo-marginatis; scutello triangulari; acutissimo, lateribus albo; elytris infra humeros attenuatis, dein parallelis, planis, iuxta suturam depressis, punctatis, medio marginibusque lunulis maculisque niveis signatis; pygidio triangulari, perpendiculari, apice reflexo; abdomine punctato, atomis albis adsperso, segmenti ultimi lateribus productis, acuminatis; pectore punctato et, lateribus et medio, albo-variegatis; trochanteribus albis ; femoribus tibiisque punctatis; illis albo-maculatis, his margine externo unidentatis, tarsis longis, gracilibus, nigris, nitidis.

Longitudo

Habitat in insula Mindanao. $\$$.

Oben tief schwarz, sammetartig matt, unten etwas glänzend, mehr schwarzgrau. Der Clypeus ist kurz, 
breit, seitlich convex, vorn umrandet, halbbogenformig ausgebuchtet, dicht punktirt. Die Stirn ist flach, die Fühlhörner sind glänzend schwarzbraun. Der Thorax würde fast rund sein, ragten nicht die Schulterecken etwas, die Augenecken dagegen stärker spitzig hervor; er ist flach, grob punktirt und zeigt acht mehr oder weniger deutliche, halbmondformige weisse Fleckchen, von denen vier in einer Reihe in der Mitte und je zwei oberhalb und unterhalb derselben liegen. Das Schildchen ist klein, dreieckig, mit sehr scharfer und feiner unterer Spitze, seine Mittc ist schwarz, seine Seiten sind weiss. Die Schultern sind stark punktirt, glänzend, und haben, von vorn angesehen, einen sehr feinen, schneeweissen hinteren Rand. Die Flügeldecken sind allenthalben, vornämlich zwischen den seitlich stark hervortretenden Schultern viel breiter als der Thorax; flach, unterhalb des Schildchens, neben der Naht, selbst beträchtlich vertieft, an den Spitzen abgerundet und von den stark nach binten hervortretender Analbuckeln an, senkrecht auf das Pygidium niedersteigend. Sie sind allenthalben dicht und grob aber nicht tief, narbenförmig punktirt und haben auf jeder Seite, neben der Naht, eine eingerissene Längslinie. Auf jeder Flügeldecke liegt eine, über dem zweiten Bauchringe beginnende, von dem Rande sich schräg nach oben bis zur Naht erstreckende und daselbst mit der der andern Seite zusammenstossende, aus feinen schneeweissen, lose aneinander gereihten Linien, Flecken und Atomen gebildete Querbinde. Unterhalb derselben liegt eine kürzere neben der Naht, und eine dritte zwischen den Hinterbuckeln. Alle drei sind durch feine weisse Atome längs der Naht mit einan der zusammenhängend. Auch auf den Schultern und neben der Spitze des Schildchens liegen einige solcher Atome. Das Pygidium ist ziemlich grob punktirt, dreieckig, senkrecht nach unten gerichtet, seine Spitze etwas nach hinten gebogen. Die Bauchringe sind punktirt, in der Mitte weniger, an den Seiten stärker und dichter weiss gesprenkelt, und haben eine sehr feine, untere, weisse Randeinfassung. Der letzte, von den Flügeldecken nur zum Theil bedeck te Abschnitt, bildet, seit- 
lich von deren Ende, zwei scharfe, nach hinten hervorragende Spitzen. Die Brustseiten und selbst das Sternum sind punktirt und fein gestrichelt, dabei glęichfalls, obwohl in der Mitte weniger dicht, mit weissen Flecken bestreut. Die Beine sind ziemlich lang und schlank; Schenkel und Schienen punktirt, die ersteren mit weissen Trochanteren und unteren weissen Randstreifen. Die Schienen sind sämmtlich mit einem Randzahn, die Tarsi lang, schlank, glänzend schwarz.

\section{Nachträgliche Bemerkuug.}

Nachträglich sehe ich mich veranlasst, mit Beziehung auf das Weibchen der Phaedimus-Art, welches ich zu Anfang der vorstehenden Abhandlung beschrieben, auch auf Taf. VI. Fig. 1 abgebildet habe und hinsichtlich dessen ich die Möglichkeit äusserte, dass dasselbe vielleicht das Weibchen von $\mathrm{Ph}$. Jagori Gerstaecker sein könne, aus einem Briefe von Herrn G. S e m pe $r$ in Altona, vom 3. Jan. d. Jahrs, das folgende mitzutheilen:

"Sie führen mit einem? das dunkle $\&$ des Phaedimus als $\mathrm{Ph}$. Jagori auf. Ich glaube aber, dass es nur eine Varietät von $\mathrm{Ph}$. Cumingi ist. Ich erhielt von $\mathrm{Cu}$ mingi nur 4 Stück von 1860 und 1861 von Luzon und ausserdem circa 80 Stück von Mai 1859 von. Lugban auf Luzon. Unter diesen 80 waren etwa $8-10$ \& von der braunen Färbung. $\mathrm{Ph}$. Jagori ist aller Wahrscheinlichkeit nach von der südlichen Hälfte Luzon's (Camarines), wo mein Bruder gar nicht gewesen ist und nach der Erinnerung, die ich von dem Exemplar im Berliner Museum habe, auch verschieden von meinem braunen ㅇ․"

Es ist möglich, dass Herr Semper Recht hat und dass das von mir beschriebene und abgebildete Weibchen, nichts als eine Varietät von $\mathrm{Ph}$. Cumingi ist. Ich selbst würde dieses nicht länger bezweifeln, wenn zwischen jenem Weibchen und dem von letztgenannter Art keine anderen Unterschiede als bloss in der Färbung beständen. Diese Unterschiede habe ich oben näher angeführt; sie sind 
nicht sehr bedeutend, aber, wie ich glaube, doch genügend um dieses rothgefärbte Weibchen und das bekannte grün und golden gefärbte von $\mathrm{Pb}$. Cumingi, nicht für identisch zu halten. $\mathrm{Ob}$ dasselbe $\mathrm{zu} \mathrm{Ph}$. Jagori gehört, ist eine andere Frage, die vorläufig nicht beantwortet werden kann. Ich habe deshalb auch nur die leise Vermuthung, dass solehes vielleicht der Fall sein könnte, ausgesprochen.

Auch hinsichlich der Philippinischen Cremastochiliden-Art, welche ich unter dem Namen „Callynomes niveo-sparsa“ Westwood beschrieben habe, muss ich noch einige Worte sagen. Unter dem einzigen Exemplare derselben in der mir von Herrn G. S em per zugeschickten Cetoniden-Sammlung, befand sich eine Etiquette mit folgender Bemcrkung: "Callynomes niveo-sparsa Westw. Thes. Ent. pl. a. fig. 1." In Betreff dieser Etiquette theilt Herr S em per mir das folgende mit: „Im Juli 1869 war Prof. W estwood bei mir und nahm 5 Hymenopteren und 1 Coleoptere mit, um sie zu beschreiben. Anfang Mai 1870 erhielt ich dieselben zurück mit einem kurzen Brief, worin W estwood erst den Ueberbringer, Eduard Saunders, bei mir introducirt und darauf schreibt: ${ }_{n} \mathrm{He}$ is the bearer of a small box containing the few rare insects You were so good as to lend my, which I have drawn and described, and for the use of which I return You my best thanks."“ _ _ Der eine Käfer ist der den Sie mitgehabt haben und ich weiss weiter nichts über denselben zu sagen. Da die Etiquette lautet „»Thes. Ent. pl. a. fig. 1 " " und oben - unter den Hymenopteren - pl. b und pl. c citirt sind, so sollte ich doch meinen, dass diese Tafeln wirklich publicirt sein sollten. Die Publication konnte also nicht vor August 1869 stattgefunden haben. Der Charakter der kleinen Schrift auf den Etiquetten stimmt mit dem des Briefes von Westwood, so dass ich mit Bestimmtheit annehme, dass die Etiquetten von W est wood selbst geschrieben sind."

Es ist mir aber nicht möglich gewesen, sowohl längs buchhändlerischem als auf anderem Wege etwas Näheres über den von Westwood, wie Herr S e mper für gewiss 
hält, eigenhändig citirten, von demselben herausgegebenen "Thesaurus Entomologicus" zu vernehmen. Auch Herr Dr. E. A. Dohrn in Stettin und Herr L. von Heiden in Frankfurt a. M., beide im Besitz von so sehr reichbaltigen entomologischen Bibliotheken, waren nicht im Stande mich hinsichtlich des genannten Werkes zu unterrichten. Ich muss also dafür halten, dass dasselbe bis jetzt noch nicht erschienen ist. Professor Westwood, an den ich mich schliesslich selbst wandte, hat mich mit keiner Antwort beehrt.

\section{Erklärung der Abbildungen.}

\section{Taf. VI.}

Fig. 1. Phaedimus Jagori Gerstaeker. $\&$ (?).

- 2. Coryphocera simillima Mohn. $\delta$.

» 2a. Kopftheile von Coryphocera simillima. $\delta$.

\2b. Kopftheile von Coryphocera Mac Leayi. $\delta$.

- 3. Coryphocera paupera Mohn. $\delta$.

\4. Clinteria formosa Mohn. ㅇ.

\5. Agestrata Semperi Mohn. $\delta$.

D 6. Macronota vidua Wallace. + .

\section{Taf. VII.}

Fig. 1. Macronota propinqua Mohn. $\&$.

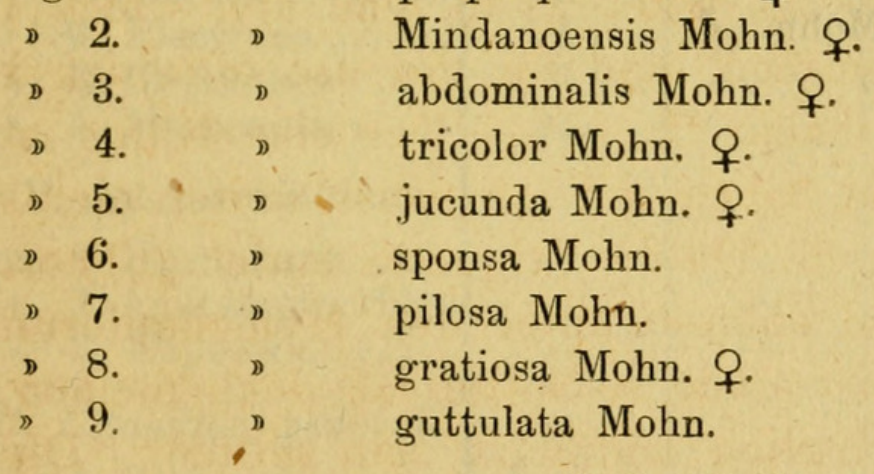

Taf. VIII.

Fig. 1. Macronota lugubris Mohn. $\delta$.

-2. \ Mohn. ㅇ.

D 3. Glycyphana rubromarginata Mohn. \&.

D 4. D aethiessida White. ㅇ.

D 5. \ pulcherrima Mohn.

D6. " rubroscutellaris Mohn.

7 . $>$ robusta Mohn.

- 8. Astraea francolina Burmeister.

\9. " margaritacea Mohn. 


\section{Taf. IX.}

Fig. 1. Astraea biguttulata Mohn.

\2. „ tigrina Mohn.

„3. Euglypta megaspilota Wallace.

\4. . attenuata Mohn.

$₫ 5$. \ biplagiata Mohn. .

\6. Cetonia multoguttulata Mohn. \&.

- 7. caeruleo-signata Mohn. $\sigma$.

\section{Taf. X.}

Fig. 1. Cetonia ducalis Mohn.

"2. " papalis Mohn.

$3 . \quad$ leucogramma Mohn. $q$.

\4. „ plebeja Mohn. ㅇ.

$\gg 5$. \ lineata Mohn. ㅇ.

D6. "flavomarginata Mohn. $\delta$

\section{Taf. XI.}

Fig. 1. Cetonia purpurissata Mohn. $\sigma^{7}$.

$\checkmark 2$. $>$ Satrapa Mohn. $\delta$.

๑3. venerabilis Mohn. $\delta$.

D 4. D Boholica Mohn. $q$.

D 5. D compacta Mohn. \&.

\6. 6 tenuicollis Mohn. ㅇ.

\7. moerens Mohn.

๑ 8. $₫$ incerta Mohn. $\delta$. 
Tabellarische Uebersicht der in den verschiedenen Regionen des Indischen Archipels vorkommenden Cetoniden-Gattungen nebst Angabe der Anzahl von Arten, durch welche sie daselbst vertreten werden.

\begin{tabular}{|c|c|c|c|c|c|}
\hline $\begin{array}{l}\text { Systematische } \\
\text { Uebersicht. }\end{array}$ & 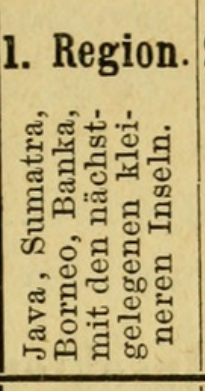 & $\begin{array}{l}\text { Timor, } \\
\text { Flores. }\end{array}$ & 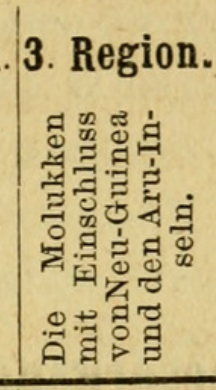 & 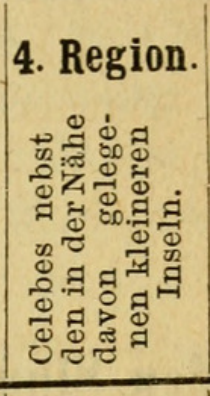 & $\begin{array}{l}\text { 5. Region. } \\
\begin{array}{l}\text { Die Philip- } \\
\text { pinen u. Su- } \\
\text { lu-Inseln. }\end{array} \\
\end{array}$ \\
\hline I. Goliathidae genuini. & & & & & \\
\hline $\begin{aligned} & \text { Gen. } \text { 1. Mycteristes } \\
& \text {. } \text { 2. Phaedimus } \\
& \text { क } \text { 3. Prigenia ........ } \\
&\end{aligned}$ & $\frac{1}{1}$ & $\overline{\overline{ }}$ & $\bar{z}$ & ㅍ & $\overline{2}(3 ?)$ \\
\hline $\begin{array}{l}\text { II. Coryphoceridae. } \\
\text { Gen. 1. Diceros ......... } \\
\text { ग 2. 'Coryphocera .... }\end{array}$ & $\begin{array}{l}6 \\
5\end{array}$ & 2 & - & $\overline{1}$ & $\begin{array}{l}1 \\
3\end{array}$ \\
\hline $\begin{array}{l}\text { III. Gymnetidae. } \\
\text { Gen. 1. Clinteria........ } \\
\text { o 2. Agestrata...... } \\
\text { ग } 3 . \text { Lomaptera..... }\end{array}$ & $\begin{array}{r}11 \\
3 \\
3\end{array}$ & $\frac{2}{1}$ & $\overline{\overline{18}}$ & $\frac{1}{-}$ & $\begin{array}{l}1 \\
2 \\
1\end{array}$ \\
\hline 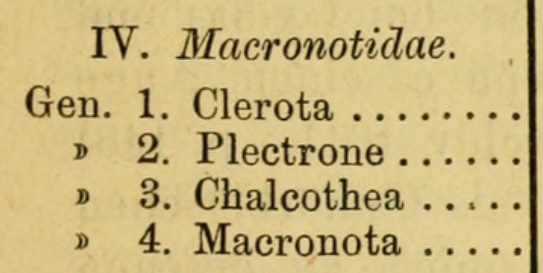 & $\begin{array}{r}1 \\
1 \\
3 \\
25\end{array}$ & $\bar{z}$ & $\overline{\bar{z}}$ & $\overline{\bar{z}}$ & $\overline{1}$ \\
\hline $\begin{array}{l}\text { V. Schizorrhinidae. } \\
\text { Gen. 1. Hemipharis .... } \\
\text { 2. Anacamptorrhina } \\
\text { " } 3 . \text { Eupoecila ....... }\end{array}$ & $\bar{z}$ & $=$ & $\begin{array}{l}1 \\
2 \\
3\end{array}$ & $\bar{z}$ & $\bar{z}$ \\
\hline 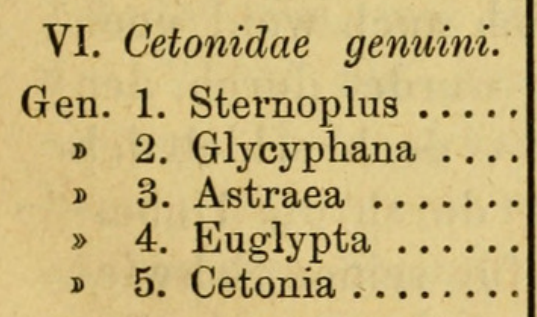 & $\frac{26}{16}$ & $\frac{\overline{1}}{\overline{3}}$ & $\frac{13}{4}$ & $\frac{1}{5}$ & $\begin{array}{r}\overline{7} \\
4 \\
4 \\
32\end{array}$ \\
\hline 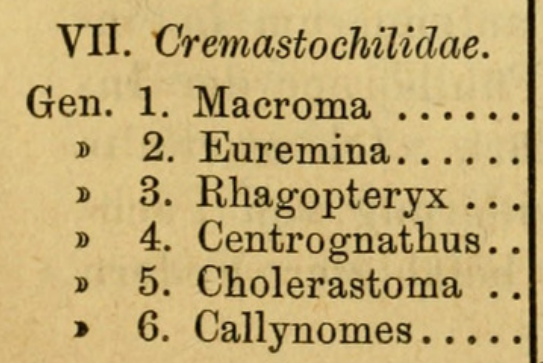 & $\begin{array}{l}4 \\
1 \\
1 \\
1 \\
1 \\
-\end{array}$ & $\begin{array}{l}\bar{z} \\
\bar{z}\end{array}$ & $\begin{array}{l}\overline{-} \\
\bar{z} \\
\bar{z}\end{array}$ & $\begin{array}{l}\bar{z} \\
\bar{z} \\
\bar{z}\end{array}$ & $\begin{array}{l}\bar{z} \\
\bar{z} \\
\overline{1}\end{array}$ \\
\hline & 110 & 9 & 43 & 18 & 74 \\
\hline
\end{tabular}




\section{$2 \mathrm{BHL}$ Biodiversity Heritage Library}

Mohnike, O. 1873. "Die Cetoniden der Philippinischen Inseln." Archiv für Naturgeschichte 39, 109-247. https://doi.org/10.5962/bhl.part.12371.

View This Item Online: https://www.biodiversitylibrary.org/item/30120

DOI: https://doi.org/10.5962/bhl.part.12371

Permalink: https://www.biodiversitylibrary.org/partpdf/12371

\section{Holding Institution}

MBLWHOI Library

Sponsored by

MBLWHOI Library

\section{Copyright \& Reuse}

Copyright Status: NOT_IN_COPYRIGHT

This document was created from content at the Biodiversity Heritage Library, the world's largest open access digital library for biodiversity literature and archives. Visit BHL at https://www.biodiversitylibrary.org. 